\title{
THE EFFECTIVENESS OF A HOPE INTERVENTION \\ IN COPING WITH COLD PRESSOR PAIN
}

\author{
By \\ Carla J. Berg \\ 2007 \\ M.S., University of Kansas, 2003 \\ Submitted to the Department of Psychology and the \\ Faculty of the Graduate School of the University of Kansas \\ In partial fulfillment of the requirements for the degree of \\ Doctor of Philosophy
}

Nancy A. Hamilton, Ph.D.

Chairperson

Committee Members

$\begin{array}{r}\hline \text { Doug Denney, Ph.D. } \\ \hline \text { Raymond L. Higgins, Ph.D. } \\ \hline \text { Stephen S. Ilardi, Ph.D. } \\ \hline \text { Todd Little, Ph.D. } \\ \hline \text { Shane J. Lopez, Ph.D. } \\ \hline \text { Robert K. Twillman, Ph.D. }\end{array}$

Date defended: 
The Dissertation Committee for Carla J. Berg certifies that this is the approved version of the following dissertation:

THE EFFECTIVENESS OF A HOPE INTERVENTION

IN COPING WITH COLD PRESSOR PAIN

\begin{tabular}{r}
\hline Nancy A. Hamilton, Ph.D. \\
Committee Chair
\end{tabular}

Doug Denney, Ph.D.

Raymond L. Higgins, Ph.D.

Stephen S. Ilardi, Ph.D.

Todd Little, Ph.D.

Shane J. Lopez, Ph.D.

Robert K. Twillman, Ph.D.

Date approved: 


\author{
ABSTRACT \\ THE EFFECTIVENESS OF A HOPE INTERVENTION \\ IN COPING WITH COLD PRESSOR PAIN \\ Carla J. Berg \\ Department of Psychology \\ Doctor of Philosophy
}

The Gate Control Model posits that cognitions and affect play a critical role in the experience of pain. Thus, research has been aimed at illuminating psychological factors that impact pain experience and targeting psychological processes that may alleviate suffering associated with pain. Hope is one individual difference construct that has been found to be related to better pain coping, specifically longer pain tolerance, higher pain thresholds, and less reported pain severity (Snyder, Berg et al., 2005). Given these relationships, the present study sought to capitalize on the propensities of high-hope people by designing and testing the effectiveness of a hopebased intervention aimed at enhancing pain coping skills. This study used an experimental pain induction method, namely the cold pressor task, and a college-aged sample. A two (Condition: Hope Intervention vs. Control) x two (Gender: Male vs. Female) factorial design was used to evaluate this multi-component intervention, involving a guided imagery segment, dialogue, skills enhancement, and a practice worksheet. Results indicated that the intervention was successful in significantly increasing hope from pre- to post-intervention, particularly among females. 
Furthermore, those in the intervention condition demonstrated greater pain tolerance. Yet, those in the intervention condition also reported greater pain severity and more sensory and affective characteristics of the pain. However, further examination of this data suggest that this relationship should be interpreted with caution, as both the hope intervention group and control group showed increased error in pain severity ratings at the extreme ends of the pain tolerance distribution. Nonetheless, we can speculate about some possible reasons that this may have occurred. For example, this intervention may have involved processes related to mindfulness. Implications for practice and future research are discussed. 


\section{ACKNOWLEDGMENTS}

The road to the completion of this dissertation has been an especially difficult one. From the time of its proposal to its defense, I (along with the community at the University of Kansas) have lost a brilliant mentor and a truly admirable role model, C. R. Snyder. There are no words to express my gratitude for having him as my mentor and advisor for the past five years, nor are there words to express my deep sorrow for having lost him. I will reflect on his many outstanding qualities for years to come as I strive to emulate him in my growth as a researcher, mentor, colleague, and friend.

I would like to thank Nancy Hamilton for graciously offering her time and effort as my dissertation chair only five short months before my defense. This dissertation required many hours of her editing and patience, and I am truly grateful to have the opportunity to work with her. I also would like to thank the rest of my committee for their patience and generosity of time, as well as their support throughout the past five years. In addition, I have had the pleasure of working with a great team of research assistants that went above and beyond to make data collection a smooth process.

Last, I would like to thank my family back home and the warm family that I have developed here at KU for their support, friendship, and guidance. I have accomplished much more in my time at KU than a Ph.D. I have achieved a life that is much different than I could have anticipated five years ago, and I attribute a great deal of my personal and professional growth to my KU family. 


\section{Table of Contents}

Chapter 1: Introduction and Literature Review..........................10

Pain Perception...............................................11

Psychological Factors and Interventions Related to Pain.............17

Theory of Hope............................................28

Summary and Hypotheses.....................................36

Chapter 2: Methods.................................................. 37

Design.................................................... 38

Research Participants.........................................39

Pain Tolerance Apparatus.....................................40

Measures.......................................................42

Interventions .............................................49

Procedure..................................................52

Statistical Analyses..............................................55

Chapter 3: Results..............................................57

Chapter 4: Discussion and Conclusions...............................68

References........................................................... 80

Tables........................................................ 125

Figures.......................................................... 132

Appendix A: Email Recruitment Message..............................139

Appendix B: Revised Trait Hope Scale.............................. 140

Appendix C: Positive and Negative Affect Schedule....................141 
Appendix D: Self-Presentation Scale................................142

Appendix E: The Pain Catastrophization Scale...........................143

Appendix F: Short-Form McGill Pain Questionnaire.....................144

Appendix G: Post-Task Questionnaire............................... 145

Appendix H: Answer Sheet......................................... 147

Appendix I: Informed Statement of Consent..........................149

Appendix J: Experimental Medical History Questionnaire.................150

Appendix K: Introduction Script................................... 151

Appendix L: Hope Intervention Instruction Set...................... 152

Appendix M: Worksheet for Performing the Cold Pressor Task.............154

Appendix N: Control Condition Instructions...........................156

Appendix O: Written Confirmation re Pain..............................157

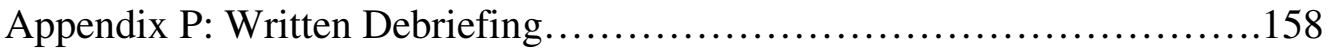

Appendix Q: Power Analysis.........................................159

Appendix R: Correlations Among Demographics and Baseline

Psychological Measures...........................................160

Appendix S: Correlations Among Post-Intervention Measures and Pain

Variables................................................161

Appendix T: Correlations Among Demographics, Psychological

Measures, and Pain Variables..................................162 
List of Tables

Table 1: Characteristics of Study Participants..........................125

Table 2: Mean Scores on Baseline Psychological Measures..................126

Table 3: Mean Scores on Post-Intervention Psychological Measures

and Pain Dependent Variables..............................127

Table 4: Correlations of Hope Scale Scores to Demographic and

Psychological Variables.......................................128

Table 5: Correlations of Pain Threshold, Tolerance, and Severity to

Demographic and Psychological Variables......................129

Table 6: Adjusted Mean HSR Scores from Baseline to Post-Intervention...130

Table 7: Adjusted Means on Pain Dependent Variables Among

Conditions and Gender.............................................131 


\section{List of Figures}

Figure 1: Diagram illustrating the ascending system and descending

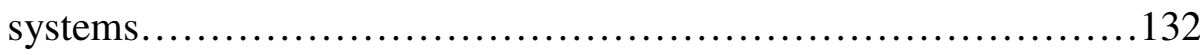

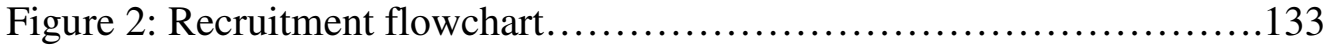

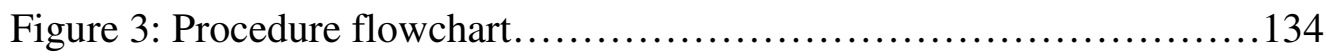

Figure 4: Line graph illustrating the interaction effect of gender $\mathrm{x}$ condition on change in hope...................................135

Figure 5: Bar graph illustrating pain tolerance among condition $\mathrm{x}$

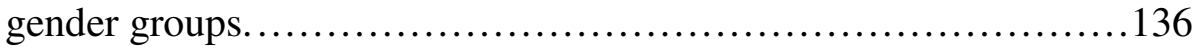

Figure 6: Line graph illustrating the interaction effect of gender $\mathrm{x}$ experimenter 2 gender on pain tolerance........................137

Figure 7: Line graph illustrating the interaction effect of gender $\mathrm{x}$ experimenter 2 gender on pain severity ratings...................138 


\section{Chapter 1: Introduction and Literature Review}

Pain is a major public health problem. Between $11 \%$ and $55 \%$ of the U.S. population suffer from chronic pain. Pain is among the most disabling and costly afflictions in North America (Eisenberg, Kessler, Foster, Norlock, Calkins, \& Delbanco,1993), Europe, and Australia as well as many other countries (IASP, 2003). Indeed, pain disables more people than cancer or heart disease (Bonica, 1987) and is estimated to cost $\$ 40$ million annually (see Brownlee \& Schrof, 1997), more than both of these conditions combined. Procedures such as pharmacotherapy and surgical interventions have been used to treat pain. However, these procedures have not always been effective in controlling pain. It should be noted, however, that although many people suffer from chronic pain, many adjust well and remain engaged with life despite the pain (Affleck \& Tennon, 1991). Accordingly, instead of focusing on painrelated deficits, research has begun to focus on individual difference factors that relate to positive adjustment to pain, especially in those situations where pain cannot be relieved by medical procedures and pharmaceutical drugs or in the case of chronic pain (Turk \& Rudy, 1992). One important psychological predictor of coping with pain is hope.

The proposed study investigates a newly developed brief intervention based on hope theory that aims to enhance the ability to cope with acute experimental pain. As a preamble to explaining the purposes of the present study, I will discuss theories and mechanisms of pain perception, giving specific attention to psychological factors (e.g., cognitions, affect, motivation) that are known to affect pain processing. Next, I 
will focus on behavioral interventions targeting these factors that have been developed for pain management. Finally, I will discuss the conceptualization of hope, the psychological factors tapped by the hope construct, and the role of hope in coping, health, and pain perception in particular.

\section{Pain Perception}

Pain can be categorized in different ways. One is by identifying the originating site of the pain. Of main interest to the present study is peripheral nociceptive pain. Peripheral pain originates in muscles, tendons, or the peripheral nerves themselves. Nociceptive pain is pain in which the nerves transmit information to the central nervous system about tissue trauma. Furthermore, pain usually is categorized as being acute or chronic. Acute pain often is associated with tissue damage, inflammation, or a disease process and is associated with fear and anxiety. It is time limited and typically acts as a warning to trigger a person to seek relief (Caudill, 2002). Conversely, chronic pain lasts for a longer period of time and is often accompanied by a disease process or injury (Turk \& Melzack, 1992) and is associated with several biological, psychological, and sociological consequences (Caudill, 2002).

The present study is concerned with acute peripheral nociceptive pain, and it investigates pain threshold, pain tolerance, and pain severity ratings. More specifically, pain threshold has been described as, "the point during the administration of a painful stimulus at which it is responded to by the person as 'painful'," whereas pain tolerance is defined as, "the point at which a person is no longer able to tolerate a 
painful stimulus, or the maximum amount of pain a person can tolerate" (Phillips \& Gatchel, 2000, p. 187). Pain severity is the reported intensity of the pain sensation. Modern theories of pain can trace roots back to the $17^{\text {th }}$ century and the writings of Renee Descartes, who argued that pain involved a straight-through sensory projection system in which there was a one-to-one correspondence between physical events and the psychological experiences of pain. Descartes' biomedical model of pain had a long-standing impact on the conceptualization of pain (Melzack \& Casey, 1965). Until the 1950's, little consideration was given to the psychological aspects of pain, including cognitions and affect. As the lack of support for Descartes' theory was noted and growing evidence was generated regarding the psychological aspects of pain, a more comprehensive theory of pain was needed (Melzack \& Casey, 1965).

Gate Control Model (GCM). According to Melzack and Wall's (1965) GCM, pain is a multidimensional phenomenon wherein the sensory-physical components of the painful experience are integrated with motivational-affective and cognitiveevaluative components. In simple terms, they proposed that sensory messages travel from the peripherally stimulated nerves to the spinal cord, where they are reprocessed and sent through "open gates" to the thalamus, which is the main brain center for tactile information. When this signal reaches the brain, the sensory information is processed in the context of the individual's (1) thoughts, expectancies, and attentional state (i.e., cognitions); and (2) current mood and level of motivation, all of which may be related to their prior pain experiences. Thereafter, this composite information 
influences the perception and experience of the pain and guides the individual's responses. The brain can react to pain by "closing the gate" (i.e., through cognitive and/or affective processes that decrease the pain experience) or by "opening the gate" (i.e., through cognitive and/or affective processes that intensify pain).

The Ascending System. On a simple phenomenological level, the ascending system is responsible for relaying information about painful stimuli to the CNS (see Figure 1). The ascending system involves nociception, which refers to the conversion of stimuli into nerve impulses via nociceptors (i.e., pain receptors). To describe the neurobiological process associated with the ascending system, the output of pain impulses is transmitted to the thalamus by two major ascending systems in the anterolateral quadrant of the spinal cord, although several others have been identified. Specifically, it is thought that mast cells release histamine in response to painful stimuli, which stimulates a range of neurochemicals to be released from the nociceptor ending (McHugh \& McHugh, 2000). These neurochemicals enhance the stimulation of nociceptors, eventually causing the nociceptor terminals to depolarize, which results in an action potential that is transmitted toward the spinal cord (McHugh \& McHugh, 2000; refer to Figure 1). The two types of nerve fibers that carry the majority of pain messages are the A-delta (i.e., faster conducting fibers associated with sharp, quick pains) and the $\mathrm{C}$ fibers (i.e., slower conducting fibers related to aching pains; Caudill, 2002).

The GCM (Melzack \& Wall, 1965) suggested that the balance between impulses from the large, fast conductors and those from small, slow conductors are 
interpreted at the spinal cord level and transmitted to the brain (Melzack and Wall, 1965, 1982, 1989). Activity in the large afferents may inhibit activity in the smaller fibers in the dorsal horns of the spinal cord where they synapse. Impulses sent to the brain depend on the relative activity of these large and small fibers in the posterior roots of the spinal cord. Basically, a predominance of small fiber activity causes presynaptic facilitation, thus "opening the gate" and causing pain, whereas a prevalence of large fiber activity causes a "closing of the gate" and a prevention of pain. However, the functioning of the central nervous system and the descending system responsible for interpreting these signals is complex.

Central Control and the Descending Systems. Phenomenologically, the CNS and the descending system work together to interpret and respond to painful stimuli. It is at this point that psychological factors can modify the pain experience. In order to explain the role of psychological factors in this process, it is important to describe the neurobiological processes involved. The higher centers of the frontal cortex appear to be responsible for the interplay between cognitive and motivationalaffective activities. Before the cortex activates discriminative or motivational systems, sensory input is localized, identified in terms of physical properties, evaluated in terms of past experiences, and modified primarily by the frontal cortex (Melzack, 1986).

Connections among centers in the brainstem like the reticular formation, the hypothalamus, and the limbic system account for strong unpleasant emotions and motivations reported by those in pain. The reticular formation is involved in the 
avoidant drive linked with pain (Melzack, 1986). Stimulation of the nucleus gigantocellularis and central grey matter produces avoidant behavior, while stimulation of the medial and intralaminar nuclei of the thalamus produces fear-like responses (Melzack, 1986). Escape from and avoidance of pain are learned behaviors, and these brain centers function to match new, incoming information with memories of past experiences (Wall \& Melzack, 1983). The cortex, in turn, sends impulses to the spinal cord, which serve to inhibit the firing of transmission cells (T-cells) through descending systems in the white matter (Melzack \& Wall, 1982). Many structures in the brain project into the dorsal horns of the spinal cord and inhibit the dorsal horn cells from firing. The GCM proposes that descending fibers from the PAG, the reticular formation, and the nuclei raphes magnus (NRM) inhibit the transmission from afferent fibers to the T-cells, being mediated by inhibitory neurons in the SG (Hagbarth \& Kerr, 1954; Reynolds, 1969).

The neurons in the PAG and throughout other areas of the CNS responsible for pain regulation have numerous enkephalin receptors, which bind with morphine and morphine-like endogenous opioid substances called endorphins and enkephalins. The larger and more stable endorphin molecule is formed, in part, by enkephalin, which may act as a local transmitter to the endorphins" more general "master role" (Terenius, 1981). Stress severity and duration are important triggering factors in determining whether the brain's analgesic systems (i.e., opioid or non-opioid systems) are activated. In general, the opioid system responds to shorter and less severe stress, while non-opioid systems are involved in more severe stress of greater 
duration (Frenk et al., 1986). However, the role of endorphins in acute clinical pain is not evident.

Despite our knowledge about the gating process, questions still remain regarding the exact site at which gating occurs. Moreover, the complex relationship between the ascending and descending systems is not clearly understood. Wall (1989) highlights that there is no fixed relationship between afferent activity and the sensory or behavioral outcome. However, pain responses are neither random nor exclusively the result of mental processes. Wall (1989) has shown that the afferent messages arriving in the spinal cord can be processed at one of three different speeds, which depends on the context of other information coming in from the periphery and the integration of descending messages from the brain. Information can be either processed rapidly with the gating mechanism or assimilated more slowly over minutes or hours. Moreover, it is important to note that pain may function adaptively or maladaptively as a result of its complex perceptual nature. This process may be adaptive in some cases but maladaptive in others. For example, from an evolutionary perspective, being able to focus attention on escape and protection from an enemy rather than on painful stimuli (despite the need to be alarmed about injury) is adaptive in these urgent, threatening situations. In some cases, the quick perception of pain or an intense pain may alert us of damage or pathology that must be immediately attended to. However, experiencing intense pain when there is relatively little injury or damage or when the condition is chronic may be maladaptive. 
Drawing upon the GCM framework and integrating the most recent psychological, physiological, and anatomical research, Price (1988) developed a theory regarding how the descending controls operate. He proposed that while the sensory-discriminative, arousal, and some motor responses associated with pain appear to be activated in parallel, the influence of affective states may depend on sequential cognitive processing. While nociceptive inputs are likely to be associated with an aversive response, Price (1988) emphasized the emotional aspects of the responses to nociceptive inputs, claiming that they are varied, as in the case of anger, frustration, and anxiety, depending on how one assigns meaning and cognitive appraisal to these sensations. He highlighted the interplay between cognitive appraisals, emotional experiences, attitudes, memories, and personality. Moreover, he asserted that pain-related affect is processed at the very last stage, which is supported by evidence from hypnosis research. Thus, it is important to note the impact of cognitions and affect and the interplay between these factors on the experience of pain.

\section{Psychological Factors and Interventions Related to Pain}

Consistent with the GCM, many psychological factors, particularly cognitions (i.e., thoughts, knowledge, meaning, expectancy, and attention) and affect (i.e., positive affect, negative affect, motivation), have been found to be related to pain. In addition, experimental protocols and interventions that have manipulated cognitions and affect have been effective in altering pain experience (for summaries, see 
Fernandez \& Turk, 1989; Suls \& Fletcher, 1985; for individual studies, see Cioffi \& Holloway, 1993; Rokke \& Lall, 1992; Wegner, Schneider, Carter, \& White, 1987).

\section{$\underline{\text { Cognitions }}$}

Expectancy. One form of cognitions found to impact the experience of pain is expectancy. Outcome expectancies are expectancies that a specific behavior will produce particular outcomes or anticipations of automatic reactions to particular cues. Expectancies have been shown to produce changes in pain, anxiety, depression, alertness, tension, sexual arousal, asthma, and warts (reviewed in Kirsch, 1990, 1999). Expectancy has been found to play a major role in psychotherapy outcomes (Friedman, 1963; Goldstein, 1960; Kirsh, 1999; Nau, Cputo, \& Borkovec, 1974), such as cognitive therapy for depression, accounting for no less than $40 \%$ of the variance (Ilardi \& Craighead, 1994). Expectancy also has accounted for a majority of the effectiveness of medications, such as nausea medications (Wolf, 1950), asthma medications (Luparello, 1970), and antidepressants, accounting for the majority of the outcome (Blashki, Mowbray, \& Davies, 1971; Greenberg \& Fisher, 1989; Joffe, Sokolov, \& Streiner, 1996; Kirsch \& Sapirstein, 1999; Walach \& Maidhof, 1999). Surgery outcomes also are largely contingent on expectancy. In fact, one review (Roberts et al., 1993) found that $70 \%$ or more of the patients showed at least good improvement from the use of five surgical treatments that are now shown to be nonefficacious. In addition, the underlying mechanisms of hypnosis and expectancies are quite similar (see Kirsch \& Lynn, 1995). 
Pain expectancies are beliefs regarding the severity of pain and also may include beliefs about one's pain threshold and anticipated ability to tolerate pain. According to Leventhal and Everhart (1979) and Pennebaker (1982), the expectation of pain activates pain memories or schemas that selectively filter and amplify incoming information until the perception is sufficiently congruent with the pain schema. One study found that the same stimulus (a vibration) could be perceived as painful, pleasant, or neutral, depending on what information people were given to establish expectancy (Anderson \& Pennebaker, 1980). This means that expectancy, or schema-driven processes (top-down processes), overrule stimulus-driven processes (bottom-up processes). Moreover, ratings of treatment credibility and expectancy predicted post-treatment success of cognitive behavioral treatment (Kole-Snijders et al., 1999), massage, and acupuncture (Kaluokalani et al., 2001) among low back pain patients.

Self-efficacy expectancies are beliefs that one is capable of successfully performing the requisite behaviors on which given outcomes depend. According to Bandura $(1982,1997)$, a person assesses his or her capacity to perform the actions necessary for achievement of a goal, such as alleviating one's own pain. Self-efficacy expectancies have been shown to predict pain tolerance (Bandura et al., 1987; Keefe, Lefebvre, Maixner, Salley, \& Caldwell, 1997; Litt, 1988; Vallis \& Bucher, 1986; Williams \& Kinney, 1991).

Pain expectancy and self-efficacy expectancy may impact one another. For example, patients facing painful stimuli who do not believe that they can control their 
pain (i.e., have lower self-efficacy expectancies) may have lower treatment expectancy, and thus may assume that the pain will be greater (i.e., have higher pain expectancies). Moreover, if patients expect the pain to be daunting (i.e., have higher pain expectancies), they may not feel they have the requisite motivation to perform the necessary tasks to cope with the pain (i.e., have lower self-efficacy expectancies).

Patients' beliefs about pain and treatment success often mismatch with the rationale and effectiveness of the treatment (Rossy, Buckelew, Dorr et al., 1999). Beliefs, attitudes, and expectancies about pain are shown to differ among pain sufferers and hold strong associations with pain and pain disability (Linton, 2000), especially in cases where the specific anatomical origin and symptoms of the pain are ambiguous, such as with chronic musculoskeletal pain (Jensen, Turner, Romano, \& Lawler, 1994). People who are prone to catastrophizing overpredict pain (Crombez et al., 2002), are less open to new information to change pain behavior (Goubert et al., 2002), and have negative expectancies about their ability to perform physical tasks (Schmidt, 1985). Pain might have a strong informative value regarding one's efficacy judgments of executing physical tasks, which in turn, influences motivation to perform tasks (Bandura, Adams, \& Beyer, 1977; de Gier, Peters, \& Vlaeyen, 2003). Moreover, expectancies may change over time in response to treatment, such that pretreatment expectancy may be high when entering treatment (Martin et al., 1977, Frank, 1982; Wienberger \& Eig, 1999) but may change after the patient has actually experienced treatment (Hardy et al., 1995) for many reasons (e.g., length of treatment, 
the relationship with the therapist, the kind of language used to the patient, and the initial amount of information provided to the patient; Horvath, 1990).

Coping. In addition to the role expectancies play in the experience of pain, cognitions about pain are often classified in the context of "coping" with pain. Lazarus and Folkman (1984) defined coping as "constantly changing cognitive and behavioral efforts to manage specific external and/or internal demands tat are appraised as taxing or exceeding the resources of the person" (p. 141). They described two forms of cognitive and behavioral efforts to cope: (1) problem-focused coping, consisting of direct efforts to alter the demands on the person; and (2) emotion-focused coping, representing efforts to regulate emotions associated with the stressful encounter. Examples of problem-focused coping include defining the problem, generating and weighing alternative solutions, and following a plan of action. Emotion-focused coping includes a variety of strategies such as avoidance, seeking emotional support, and positive reappraisal. Although the distinction between emotion-focused coping and problem-focused coping has evolved over time (Lazarus \& Folkman, 1984), coping in general is described in terms of how pain is conceptualized by the individual.

Meaning. Overlapping with transactional coping theory, the parallelprocessing theory, proposed by Leventhal (1993), integrates two forms of information processed under painful conditions: a sensory schema and a distress schema. Activation of the distress schema, or focusing on the unpleasantness of the experience may intensify pain, whereas activation of the sensory schema that identifies and 
evaluates sensory experiences may reduce pain. Catastrophizing, or negative thinking focused on potential deleterious outcomes, represents the distress schema of Leventhal's parallel processing model. Higher levels of catastrophization have been related to lower tolerances to laboratory-induced cold pressor pain (Geisser, Robinson, \& Pickern, 1992), higher ratings of pain during painful diagnostic procedures (Buckelew, Conway, \& Shutty, 1992), and higher ratings of pain and increased use of analgesics following breast surgeries (Jacobsen \& Butler, 1996). Regardless of whether catastrophizing is best classified as a cognitive coping strategy or as a type of appraisal (Jensen, Turner, Romano, \& Karoly, 1991; Keefe, Salley, \& Lefebvre, 1992), this pattern of negative thinking provides valuable information about the meaning of painful sensations. Because catastrophizing is associated reliably with higher levels of pain and emotional distress, particularly depression (Sullivan, Thorn, \& Haythornthwaite, 2000), sensory focusing and distraction strategies may be differentially effective in reducing this maladaptive cognitive-affective component of the pain experience.

Attention. Related to the conceptualizations of coping styles and the schemas related to pain, Cioffi (1991) proposed a cognitive-perceptual model of physical sensations such as pain, which provides a framework for investigating the direction and content of the attention during painful challenges (Cioffi, 1991). He suggested that sensory focusing may reduce distress by distracting the individual from interpreting the meaning of the sensations, by providing valuable self-regulatory information about the sensations, and by increasing perceptions of control (Cioffi, 
1991). It may be the case that sensory focusing or distraction strategies are expected to reduce pain by altering the meaning assigned to these somatic experiences (Cioffi, 1991).

Ignoring sensations via distraction to an external stimulus (avoidant coping) works well for milder and shorter pain stimuli, whereas focused attention (nonavoidant coping) has been found to be more effective for persistent or intense pain (Baron, Logan, \& Hoppe, 1993; McCaul \& Malott, 1984; Suls \& Fletcher, 1985). Moreover, sensation-focused attention has been found to be more effective than avoidant coping (Ahles, Blanchard, \& Leventhal, 1983; Dar \& Leventhal, 1993; Suls \& Fletcher, 1985) and emotion-focused coping (Leventhal, Brown, Shacham, \& Engquist, 1979), resulting in less reported distress. Self-Control Training, one CBT intervention found to be efficacious in treating pain, emphasizes important selfmanagement aspects related to attention and cognition, including perceived control, freedom of choice, and personal competence (Beiderman \& Schefft, 1994).

The premise of mindfulness provides a different perspective on the role of attention and meaning. Mindfulness is a concept that has been defined as enhanced attention to and open awareness of current experience (Deikman, 1982; Martin, 1997). It builds on this idea that attention to sensory, cognitive, and affective experiences may be important in disengaging individuals from automatic thoughts, habits, and unhealthy behavior patterns and allowing them to respond to experiences more intentionally (Ryan \& Deci, 2000). For example, pain sufferers may become aware of self-debilitating statements such as "this pain is killing me." Mindfulness 
involves disengaging from creating additional thoughts, positive or negative, and encourages the nonjudgmental observation and experiencing of thoughts and feelings, which results in identifying these thoughts and feelings more objectively. Thus, experiencing pain mindfully may enable one to eliminate psychological distress associated with physical pain. Mindfulness-based interventions have been found to be effective in reducing pain intensity with chronic pain patients (Kabat-Zinn et al., $1985,1987)$ and in reducing stress levels and mood decline among cancer patients (Brown \& Ryan, 2003; Speca et al., 2000).

Because cognitions clearly play a role in the perception of pain, researchers have devised interventions focused on developing effective cognitions. Cognitivebehavioral therapy (CBT), a key component of pain management programs, enhances a person's ability to cope effectively with pain and its consequences using a variety of cognitive and behavioral methods (Turk, Meichenbaum, \& Genest, 1983). The cognitive-behavioral model endorses the view that affective, behavioral, cognitive, social, and sensory-physical dimensions are important to conceptualize and treat patients with chronic pain. However, the dimension most emphasized is the role of patient beliefs about and meanings attributed to various aspects of the pain experience (Novy, Nelson, Francis, et al., 1995). Treatment focuses on providing patients with techniques to gain a sense of control over the effects of pain as well as modifying the affective, behavioral, cognitive, and sensory-physical dimensions of the experience. Given the numerous potential factors upon which treatment may focus, cognitive treatments have used various theoretical perspectives to guide the specific factors 
targeted and interventions used among pain patients. Cognitive therapies have been found to be superior to waiting list on pain experience, mood, cognitive coping and appraisal, and social role functioning (Morley, Eccleston, \& Williams, 1999) and has been shown to be cost-effective (Cipher et al., 2001; Morley, Eccleston, \& Williams, 1999).

Relaxation Techniques. Attention and other cognitions also can be altered by using relaxational strategies, which have been found to be effective for helping people cope with a wide range of medical conditions including burns (e.g., Patterson, Everett, Bursn, \& Marvin, 1992; Patterson \& Ptacek, 1997), cancer (e.g., Liossi \& Hatira, 1999; Syrjala, Cummings, \& Donaldson, 1992), fibromyalgia (e.g., Haanen et al., 1991), headaches (e.g., Zittman, van Dyck, Spinhoven, Linssen, \& Corrie, 1992), and various forms of chronic pain and surgery (e.g., Lambert, 1996; Malone \& Strube, 1988; Mauer, Burnett, Oulette, Ironson, \& Dandes, 1999). Interventions such as diaphragmatic breathing, guided imagery, progressive muscle relaxation, and autogenics have been efficacious in treating pain.

Guided imagery is one cognitive relaxation intervention used to alleviate responses to noxious stimuli. It can be defined as using one's imagination to create healing mental images that involve the senses (Mobily, Herr, \& Kelley, 1993; Owens \& Ehrenreich, 1991) or a method for helping patients create sensory-rich images in their minds to promote relaxation, concentration, and body awareness (Mannix, Chandurkar, Rybicki, Tusek, \& Solomon, 1999). The use of imagery has been recommended as an adjunctive or complementary therapy to traditional analgesic 
regimens to maximize pain relief (Agency for Health Care Policy and Research, 1994). Research has provided support for the effectiveness of guided imagery (e.g., Daake \& Gueldner, 1989; Geden, Beck, Hauge, \& Pohlman, 1983; Moran, 1989; Spinhoven \& Linssen, 1991). Research has found that the effectiveness of imagery is related to the ability to generate and become involved in sensory or imaginative experiences (Kwekkeboom, Huseby-Moore, \& Ward, 1998).

\section{$\underline{\text { Affect }}$}

Affect has been posited to contain two separate, orthogonal dimensionspositive affect and negative affect (Watson \& Clark, 1988). Positive affect (PA) reflects the extent to which a person feels enthusiastic, active, and alert. PA is a state of high energy, full concentration, and pleasurable engagement, whereas low PA is characterized by sadness and lethargy. Negative affect (NA) is a general dimension of subjective distress and unpleasant engagement that subsumes a variety of aversive mood states, including anger, contempt disgust, guilt fear, and nervousness. Thus, low NA is a state of calmness and serenity (Watson \& Clark, 1988).

Painful events result in an increase of NA (Affleck, Tennen, Urrows, \& Higgins, 1991; Zautra, Burleson et al., 1995), including tension, nervousness, and irritability. Related to this point, high rates of depression have been observed among the chronic pain population (Dickens, McGowan, Clark-Carter, \& Creed, 2002). PA has been associated with less pain among patients with cancer (Guadognoli \& Mor, 1989), fibromyalgia (Potter, Zautra, \& Reich, 2000), sickle-cell disease (Gil et al., 2003, 2004), and rheumatoid arthritis (Potter et al., 2000), as well as in hospital 
inpatients (Kvaal \& Patodia, 2000) and healthy populations (Casten et al., 1997). It may be the case that PA may provide a potential physiological mechanism for analgesia through the release of endogenous opioids (Pressman \& Cohen, 2005). Although it is difficult to discern the direction of the affect-pain relationship, it has been found that inducing PA results in less reported pain sensitivity and more pain tolerance (e.g., Adams \& McGuire, 1986; Gil et al., 2004; Meagher, Arnau, \& Rhudy, 2001) and that inducing NA decreases one's pain tolerance level (Gil et al., 2003, 2004).

Motivation. Despite the effectiveness of cognitive treatments for pain management, some patients do not improve or improve and then relapse (Turk, 1990; Turk \& Rudy, 1991). A possible explanation is lack of sustained motivation on the part of patients. DiClemente and Prochaska (1982) developed the Transtheoretical Model, which describes the process of specific stages and challenges that patients experience as they change maladaptive behaviors into adaptive behaviors. To describe the stages of this model and the associated clinicians' stage-specific tasks, physical inactivity can be considered as an example of a possible maladaptive behavior for patients with chronic pain. As patients progress through the stages of change, they gain a heightened awareness of the need for change and assume a greater responsibility and accountability for managing their pain. Given the challenges involved in maintaining motivation, treatments such as motivational interviewing (MI) and motivational enhancement therapy (MET) are aimed at eliciting patient's reasons, motivations, and potential solutions for change (Jensen, 
1996; Miller \& Rollnick, 2002; Snow et al., 1993). By enhancing a patient's

motivation, these treatments also enhance the effectiveness of other treatments (e.g., CBT, relaxational treatments, etc.).

A common reason for maintaining motivation to cope effectively is social desirability or positive self-presentation. Deshields, Tait, Gfeller, \& Chibnall (1995) found that patients with chronic pain who were higher in social desirability reported less psychological distress but greater pain, suggesting that the socially desirable way of responding is to acknowledge physical pain but not psychological distress. Roth, Snyder, and Pace (1986) conceptualized this tendency to positively present oneself as a way to prevent unacceptable impulses from reaching consciousness and being associated with the self, which has been shown to be adaptive (Snyder, 1989; Snyder \& Higgins, 1988; Taylor \& Brown, 1988). In positively representing the self, people tend to engage in two main self-presentational activities: attributing positive characteristics to themselves and denying negative characteristics. These activities have been found to be somewhat unrelated (Roth, Snyder, \& Pace, 1986).

Given the plethora of psychological interventions for pain management, it is important to note that there is a necessity for future research, specifically in understanding how interventions work to improve pain coping, in understanding what interventions work for whom (Vlaeyen \& Morley, 2005), and in developing brief interventions that may be effective for many people.

\section{Theory of Hope}


Hope has been found to be related to better coping with pain (Snyder, 1998; Snyder, Berg et al., 2005). A series of studies involving cold pressor pain indicated that higher hope people recognized the pain after a longer average time interval, tolerated the pain longer, and reported less severe pain (Snyder, Berg et al., 2005). Furthermore, another study found that people who were not instructed to focus on explicit or implicit goals tolerated the pain from a cold pressor experimental task for significantly longer than those who were not given goal-focused instruction (Stevenson, Kanfer, \& Higgins, 1984).

According to Snyder and his colleagues, hope is the perception of having both the pathways for one's goals and the motivation (agency) to use those routes (Snyder, 1994a, 1994b, 2002; Snyder, Harris et al., 1991; Snyder, McDermott, Cook, \& Rapoff, 1997; Snyder, Sympson et al., 1996). The anchor in what has come to be called hope theory is the notion of goals, which are significant short- or long-term targets of mental action sequences (Snyder, 1996). Pathways thoughts reflect the person's perceived ability to generate multiple plausible routes to goals and to choose new routes when an obstacle blocks previous goals. Agency thoughts reflect the belief that one can initiate and sustain movement along pathways to goals and the ability to maintain motivation. Together, the pathways and agency thoughts iterate and drive engagement and disengagement throughout the goal-pursuit sequence (Snyder, 2000).

It is important to note that there is an ebb and flow to hopeful thinking (Snyder, 1996) and that hope is dynamic. Individual differences in life experiences 
and individual personality characteristics play roles in changing our levels of hope. People have enduring or trait-like levels of hope that transcend specific situations, but there is a state hope level that is specific to a particular time and place.

To depict high- and low-hope people, high-hope individuals clearly conceptualize their goals, often see one major pathway but also numerous alternative pathways and goals, are prepared for setbacks, and bounce back from losses more quickly (Snyder, 1996). On the other hand, low-hope individuals usually have more vague and ambiguous goals, have difficulty generating primary routes to their goals, have fewer alternatives goals, and experience more distress after losses (Snyder, 1996). Moreover, by establishing differing goals in each life arena, high- as compared to low-hope people have advantages in switching goals if previous ones are unobtainable (Snyder, 1996).

In terms of pain, a premise of hope theory is that people constantly engage in goal pursuit thinking and that anything that blocks either pathways or agency thinking necessitates coping activities (Snyder, 1998). When pain is not present, people are free to focus on goals related to daily living and achievement. When pain is present, attention may be focused on the "no pain" goal to the exclusion of other long-term goals. The effective pathways thinking of high-hope people may allow them to find alternative goals of alleviating most of the pain or finding activities that do not irritate the problem may be necessary. Another component of effective pathways thinking is the forming of substeps that will allow one to feel more empowered to lessen the perceived pain, as well as to preserve one's agency thinking. The affirming self-talk 
related to agency thinking of high-hope individuals (e.g., "I can do it", "I'll succeed") also may rejuvenate a person who is in the throes of pain. In the case of acute pain (i.e., pain with a short duration), hope is resilient and returns to its initial level when the pain is alleviated. When pain is chronic (i.e., lasting for long periods of time), however, hope can be undermined because of the long-term effects of such pain on pathways or agency thinking. Overall, hope has implications for cognitive and affective process that may impact the pain experience.

Cognitions. Hope has been found to be related to more effective cognitive appraisals. High hopers perceive stressors as a normal part of life (Snyder, 1994), and they see challenges as goals to be conquered rather than potential failures "waiting to happen" (Snyder, Harris et al., 1991). Moreover, research has found that high- as compared to low-hope persons are more likely to find benefits in their ongoing coping with stressors (Affleck \& Tennen, 1996; Tennen \& Affleck, 1999). Also, high- more than low-hope people are more likely to perceive that their lives have meaning (Feldman \& Snyder, 2001). In addition, higher hope has been related to better psychological adjustment (Kwon, 2002). For example, one study found that, on the days in which individuals experienced higher hope, they also experienced more positive and less negative thoughts (Snyder, Sympson et al., 1996). Thus, it is not surprising that higher hope has been related to lower suicidal ideation among college students (Range \& Penton, 1994).

Hope seems to drive the cognitive self-talk associated with self-regulation. Likewise, high hopers are drawn to positive self-referential thinking (Snyder, 
LaPointe, Crowson, \& Early, 1998). In contrast to low hopers, the high-hope students do not derogate their abilities when they "fail;" instead, they make more adaptive attributions (e.g., they may say "I did not try hard enough" or "I did not identify the correct studying [or test-taking] strategies."). Such strategies and effort attributions may explain why hope does not relate significantly to intelligence (Snyder, McDermott, Cook, \& Rapoff, 2002), whereas it does relate consistently to academic achievement. Higher hope also has been related to greater reported creativity (Onwuegbuzie, 1999), as well as to greater problem-solving abilities and superior academic achievements (Chang, 1998; Lopez, Bouwkamp, Edwards, \& Teramoto Pedrotti, 2000; McDermott \& Snyder, 1999, 2000; Snyder, Hoza et al., 1997). In addition, higher hope has been linked to less distraction related to self-deprecating thoughts (e.g., "I can’t do this!”) when coping with difficult stressors (Onwuegbuzie \& Snyder, 2000; Snyder et al., 2002). On the other hand, low-hope students have been shown to demonstrate greater self-doubt, and accordingly, their negative ruminations interfere with their attending to the appropriate cues in studying and taking exams (Michael, 2000; Snyder, 1999).

Affect. Research has supported a relationship between affect and hope. One study found that higher daily hope correlated positively with ongoing positive affect and negatively with ongoing negative affect (Snyder, Sympson et al., 1996). Highmore than low-hope people also have reported being inspired, energized, and challenged by their life goals (Snyder, Harris et al., 1991), as well as feeling worthy, satisfied, and less troubled by depression (Chang, 1998; Kwon, 2000; Snyder, Hoza et 
al., 1997; Snyder, Sympson et al., 1996). To illustrate these points, low-hope students, in comparison to high-hopers, typically experience high anxiety, especially in competitive test-taking situations (see Onwuegbuzie, 1998; Onwuegbuzie \& Snyder, 2000; Snyder, Sympson et al., 1996). Moreover, high-hope students report greater satisfactions with their academic endeavors than do their low-hope counterparts (Chang, 1998).

In addition to the relationship between hope and affect, hope has been found to be related to motivation in numerous domains (e.g., sustained involvement in sport, lower college dropout rates, lower drug-treatment dropout rates; Brown, Curry, Hagstrom, \& Sandstedt, 1999; Seaton \& Snyder, 2001; Snyder, Shorey et al., 2002). This relationship is not surprising, however, given that the agency component of hope is inherently a motivational factor.

Hope and Health. Research to date has uncovered beneficial relationships between level of hope and coping with illnesses or other health-related problems. For example, research shows that higher hope correlates with better adjustment in terms of coping with severe arthritis (Laird, 1992), breast cancer (Stanton et al., 2000), fibromyalgia (Affleck \& Tennen, 1996; Tennen \& Affleck, 1999), blindness (Jackson, Taylore, Palmatier, Elliot, \& Elliot, 1998), and injuries from a car accident (Elliot \& Kurylo, 2000). In addition, higher levels of hope during spinal cord injury recovery has related to better coping and less depression (Elliot, Witty, Herrick, \& Hoffman, 1991). Moreover, high-hope adolescent burn survivors had better social interactions and elevated self-worth (Barnum, Snyder, Rapoff, Mani, \& Thompson, 
1998). It also has been linked to other adaptive psychological processes such as benefit-finding that lead to increased emotional well-being in patients with medical conditions (Tennen, Affleck, \& Mendola, 1991). Hope also predicts other positive coping strategies such as emotional expression. In this latter point, Stanton and her colleagues (2000) found that high-hope breast cancer patients who engaged in emotionally expressive coping had fewer medical appointments and reported less overall distress than did their low-hope counterparts.

Hope also has been related to treatment adherence among juvenile asthma patients (Moon, Snyder, \& Rapoff, 2001) and adolescent burn survivors (Barnum, Snyder, Rapoff, Mani, \& Thompson, 1998) and has been found to play a role in prevention of cancer (Irving, Snyder, \& Crowson, 1998) and HIV (Floyd \& McDermott, 1998). In addition, high- as compared to low-hope individuals have reported engaging in more physical exercise (Harney, 1990).

Interventions to Increase Hope. Snyder and his colleagues (e.g., Snyder, Cheavens et al., 1999; Snyder, Ilardi, Cheavens et al., 2000; Snyder, Ilardi, Michael, \& Cheavens, 2000; Snyder, McDermott, Cook, \& Rapoff, 2002; Snyder, Parenteau, Shorey, Kahle, \& Berg, 2002; Snyder \& Taylor, 2000) have hypothesized that hope plays a major role in psychotherapy. At the start of therapy before the specific treatment strategies have been initiated, the major source of change centers on the client's expectancy that therapy offers a route to improvement (i.e., increased pathways thinking). Additionally, the client gets a motivational rush (i.e., agency) in that she or he expects initial improvements. Therefore, it is believed that increases in 
pathways and agency should be related to improved subjective well-being in the first part of therapy before any formal interventions per se have been initiated. Once a working relationship has been established, clients are taught specific skills (e.g., cognitive restructuring, social skills training, free association) so as to achieve additional positive changes. These processes involve the pathways components of hope, and as such, changes in pathways thinking are likely to be associated with positive change in these latter portions of therapy (see Snyder, Michael, \& Cheavens, 1999).

Not surprisingly, hope theory has been used as a framework for developing successful individual treatments (Lopez, Floyd, Ulven, \& Snyder, 2000), and it has been used in working with couples (Worthington et al., 1997) and groups (Klausner et al., 1998; Klausner, Snyder, \& Cheavens, 2000). It also has been used in pretreatment education for people prior to the starting of their treatments at a community mental health center (Irving et al., in press). Moreover, interventions based on hope theory have been found to increase hope among elementary through high school students (Lopez, Bouwkamp et al., 2000) as well as among student athletes, who also reported increased confidence in their athletic abilities, superior academic achievements, and elevated self-esteem (Curry et al., 1999; see positive follow-ups reported by Curry \& Snyder, 2000; as well as Curry \& Maniar, 2003, 2004).

Although research has shown that hope affects cognition, affect, and motivation, it is unclear which of these mechanisms is most important in pain management. It may be the case that different hope-related processes are critical at 
different times, under different circumstances, and with different types of pain. The present study aimed to develop interventions to increase hope in order to increase pain tolerance, as well as delay pain onset (i.e., increase pain threshold) and decrease the perceived severity of the pain. Specifically, interventions were aimed at increasing goal-directed thinking, pathways thinking, and agency thinking.

\section{Summary}

The Gate Control Model posits that cognitions and affect play a critical role in the experience of pain. Theoretically, hope is a pattern of thinking in which one is able to set challenging yet realistic goals, plan accordingly to achieve these goals and overcome obstacles, and maintain motivation and self-confidence during the pursuit of goals. Research has shown that hope is related to better coping and adjustment in many areas, one of which is pain management. Given that hope-related thinking has demonstrated this relationship, it appears that hope may be one individual differences construct that may be useful in understanding and impacting the processes involved in the GCM.

\section{Hypotheses}

The study proposed here builds upon a previous series of studies conducted by Snyder, Berg et al. (2005) concerning the relationship between hope and physical pain tolerance on the cold pressor task. This previous research indicates that highrelative to low-hope people report later onsets of pain and endure the physical pain longer. Borrowing from the propensities of high-hope people, the present study sought to teach the principles of hopeful thinking (i.e., goals, pathways, and agency) 
in order to ascertain whether development of these skills improve the coping of lowto moderate-hope people on the cold pressor task. The specific aims of the present study are to investigate the impact of an intervention aimed at enhancing hopeful thinking so as to increase tolerance of the pain for longer time periods, to delay the onset of recognized pain, and to decrease the overall severity of pain ratings. The specific hypotheses of the present study were as follows:

1. Participants who receive the intervention to enhance the hopeful thinking will show a greater increase in hope and will tolerate the pain longer, report a higher pain threshold (i.e., later onset of pain), and report less severe pain in comparison to the participants in the control condition.

2. Individual differences variables such as affect (i.e., emotion), pain catastrophization (i.e., cognition), and social desirability (i.e., motivation) will act as moderators of the aforementioned relationships of hope intervention to change in hope and to the pain dependent variables.

3. Pain expectancy, self-efficacy expectancy (i.e., cognition), and the use of pain coping strategies will be related to pain threshold, pain tolerance, and pain severity ratings. Likewise, pain expectancy, self-efficacy expectancy, and the use of pain coping strategies may mediate the relationships between the intervention and pain tolerance, threshold, and severity.

Chapter 2: Methods 


\section{Design}

Given the documented gender differences in pain coping such that men typically tolerate pain longer and report less severe pain than women (e.g., Fillingim \& Maixner, 1995; Riley, Rboinson, Wise, Myers, \& Fillingim, 1998; Weisse, Foster, \& Fisher, 2005; Snyder, Berg et al., 2005), the design was a 2 (Experimental group: Hope vs. Control) x 2 (Gender: Male vs. Female) factorial design. A power analysis revealed that, in order to have sufficient power to find large effect sizes with an alpha of .05 and 4 groups, a total of 84 participants -21 participants in each of the 4 groups-would be needed. Full results of the power analysis are presented in Appendix Q. Research using the CPT to investigate relationships of opioid pretreatments to pain tolerance (Compton, Athanasos, \& Elashoff, 2003), gender to pain report and cardiovascular reactivity (Myers, 2000), and gender to pain tolerance and threshold (Riley, Robinson, Wise, Myers, \& Fillingim, 1998) have found large effects sizes. Other research investigating the effects of giving accurate or false feedback regarding self-efficacy levels (Litt, 1988) and the effects of a cognitive coping intervention, monetary reinforcement, and the combination of cognitive coping intervention and monetary reinforcement (Baker \& Kirsch, 1991) on pain tolerance using the CPT also found large effect sizes. Thus, it was decided that striving for $N$ to achieve power that would indicate large effect sizes would be sufficient.

The independent variables were gender and the condition to which the participant was assigned (i.e., intervention or control). The following dependent 
variables were assessed: (1) time length of pain tolerance; (2) pain threshold (i.e., time latency to pain onset); (3) overall pain severity ratings; and (4) Short-form McGill Pain Questionnaire (SMPQ) scores. Covariates were selected to reduce possible pretest differences between groups. Positive and Negative Affect Schedule (PANAS) scores, Self-Presentation Scale (SPS) scores, and Pain Catastrophizing Scale (PCS) scores were assessed as possible covariates and moderators. Importance ratings, pain expectancy ratings, and self-efficacy expectancy ratings were evaluated as potential covariates, mediators, and moderators of the relationship between condition assignment and the pain dependent variables. A Post Task Questionnaire (PTQ) was administered to investigate the use of pain coping strategies as a possible mediator between group assignment and the pain dependent variables.

\section{Research Participants}

Students participated as one means of fulfilling the requirements for their introductory psychology classes (PSYC 104) at the University of Kansas, Lawrence. In a mass screening session at the beginning of the Fall, 2005 and Spring, 2006 semesters, introductory psychology students were given the Trait Hope ScaleRevised (HSR; Shorey \& Snyder, 2004). After scoring the HSR, the questionnaires were arranged from the highest to the lowest scores. Moving upward from the bottom of the distribution of the HSR scores for both males and females, students were identified as having low to moderate levels of hope. The mean HSR scores determined the cut-off score for recruitment. The researcher emailed the students who are low in hope and informed them of the nature of the CPT (see script in Appendix 
A). Low- to moderate-hope persons were recruited to ensure that a ceiling effect would not hinder the results of the study; moreover, the applied implications are increased by using persons who are low in hope and as such are relatively ineffective in their coping efforts.

A total of 1630 students completed mass testing. Of the 810 students we attempted to contact, 212 signed up for the study. A total of 174 students consented to participate in the study; the remaining 38 did not attend their testing session. Two students were excluded from the study because of a diagnosis of Raynaud's disease (i.e., one of the exclusion criteria included in the Medical History Questionnaire). The final sample included 172 participants—114 women and 58 men—composing the four groups (Hope-Males $N=27$; Hope-Females $N=62$; Control-Males $N=31$; Control-Females $N=52$; see Figure 2).

\section{Pain Tolerance Apparatus}

The current study focuses on acute experimental pain. To assess acute pain threshold, tolerance, and severity, the cold pressor task (CPT) was chosen because of its extensive use in previous research (dating back as far as 60 years ago; Wolf \& Hardy, 1943) and its validity as an experimental pain induction method (Allen, Blascovich, \& Mendes, 2002; Chambers, Craig, \& Bennett, 2002; Jackson, Iezzi, Fritch, \& Gunderson, 2002; James \& Hardardottir, 2002; Keogh \& Chaloner, 2002; Keogh \& Herdenfeldt, 2002; Keogh \& Mansoor, 2001; Tsao, Glover, Bursch, Ifekwunigwe, \& Zeltzer, 2002; Willoughby, Hailey, Mulkana, \& Rowe, 2002). In a common version of the CPT, a participant submerges his or her nondominant hand 
(up to the wrist) in 0 degree Celsius water. In the present study, the CPT consisted of a bin of water (45.72 $\mathrm{cm}$ long, $20.32 \mathrm{~cm}$ high, $\& 25.40 \mathrm{~cm}$ wide) with a hard rubber screen placed midway. A pump continuously circulated the water within the bin, which was filled on one side of the screen with water and the other with ice to maintain the desired cold temperature. Ice was added as needed to keep the desired temperature. Participants were asked to keep their hands submerged for as long as they could tolerate. The physiological effects of the CPT have been documented extensively in adults (Lovallo, 1975; Lovallo \& Zeiner, 1975; Peckerman, Hurwitz, Saab, Llabre, McCabe, \& Schneiderman, 1994). The pain resulting from exposure to cold temperatures is reportedly carried by small, unmyelinated C fibers (Walsh, Schoenfeld, Ramamurthy, \& Hoffman, 1989). Initially, the perception of pain from the CPT takes the form of a painless feeling of coldness. Over time, the coldness sensation increases and eventually gives way to pain. This reflects the dependent variable of pain threshold. Thereafter, the pain increases. When the pain no longer can be tolerated, the participant removes his or her hand from the bin of water. This latter process taps the dependent variable measure of pain tolerance (i.e., the length of time that the research participant's hand is submerged in the cold water). At a temperature of 0 degrees Celsius, pain intensity is directly proportional to the amount of time the subject is able to tolerate the pain (Wolf \& Hardy, 1941). Laboratory methods of inducing pain in adult human subjects have recently been reviewed and compared (Arendt-Neilsen \& Lautenbacher, 2004; Handwerker \& Kobal, 1993), and 
a large scale normative study of the CPT with adults has been reported (Walsh, Schoenfeld, Ramamurthy, \& Hoffman, 1989).

\section{Measures}

Participants completed the Trait Hope Scale-Revised (HSR), the Positive and Negative Affect Schedule (PANAS), the Self-Presentation Scale (SPS), the Pain Catastrophizing Scale (PCS), the Short-form McGill Pain Questionnaire (SMPQ), the Post-Task Questionnaire (PTQ), and an answer sheet including demographic questions assessing year in college, age, race, and total annual household income, as previous research has documented the relationships of age (Tsao et al., 2004; Cheng, Foster, \& Hester, 2003) and ethnicity (e.g., Campbell, Hughes, Girdler, Maixner, \& Sherwood, 2003; Edwards, Doleys, Fillingim, \& Lowery, 2001; Edwards, Fillingim, \& Keefe, 2001; Edwards \& Fillingim, 1999; Sheffield, Biles, Orom, Maixner, \& Sheps, 2000; Weisse, Foster, \& Fisher, 2005; Woodrow, Friedman, Siegelaub, \& Collen, 1972; Zatzick \& Dimsdale, 1990) to pain tolerance and other pain variables. The measures included in this study can be viewed in Appendixes B through $\mathrm{H}$, respectively.

Trait Hope Scale-Revised. The Revised Trait Hope Scale (HSR; Appendix B) is an eighteen-item self-report measure, which uses six-items each to assess the three hope components of goals, pathways, and agency. Response options on the 8-point Likert-type rating scale range from $1=$ definitely false, to $8=$ definitely true. Half of the items are reverse scored. In assessing the validity of the revised scale, Shorey \& Snyder (2004) found that each of the three hope components is positively related 
(correlations from .54 to .68) yet empirically distinct. As such, the subscales can be used individually or they can be combined as a unified hope measure. Reliabilities for the subscales ranged from .64 to .81 while overall scale reliabilities ranged from .86 to .88 . The revised scale relative to the original (Snyder et al., 1991) is a stronger predictor of various criterion variables including self-efficacy, psychological distress, and well-being. Revised Hope Scale scores were not related to performance goals, hypercompetitive attitudes, or pessimism. Evidence of the unique predictive ability of the new Goals Subscale was provided by findings that this subscale predicted unique variances in goal-related constructs of mastery goals, and goal commitment and stability when controlling for pathways and agency.

Beyond the aforementioned improvements, the new scale was constructed to be amenable for use with structural equation modeling. Six items per subscale facilitate pairing items into three a-priori identified domain representative parcels (average of two item scores) per subscale. Parceling items in this way has eliminated the problem with correlated residuals encountered by Babyak, Snyder, and Yoshinobu (1993), and has resulted in perfect local model identification (the number of estimated parameters is equal to the number of observations in the model). Confirmatory factor analysis using LISREL-8.5 has demonstrated the excellent fit of the overall hope model in which three domain representative parcels load onto each of the three interrelated hope factors $\left(\square^{2} 154.83, \mathrm{df}=72, p<.01, \mathrm{RMSEA}=.059(90 \% \mathrm{CI}=\right.$ $.045 ; .072)$, NNFI $=.98, \mathrm{CFI}=.99)$. Generalizability of the model was established with multigroup factor analysis. Across three samples, the Revised Hope Scale 
evidenced strong metric invariance (equality of variances, covariances, factor loadings, and latent means) (Shorey \& Snyder, 2004).

This model, in which the covariances among the three hope factors are estimated, is equivalent to having all scale items load onto one higher-order hope factor. Thus, the model described attests to using the HSR to: (1) assess individual relationships of the goals, pathways, and agency subscales with various outcomes or criterion variables; (2) provide a unitary measure which can be identified in structural models by three facet representative parcels (the means of goals, pathways, and agency subscales); or, (3) create a sum or mean scale score for use in traditional analytic techniques. The alpha for the HSR in the current study was 0.86 . The alphas for the Goals, Pathways, and Agency subscales were 0.77, 0.76, and 0.75, respectively.

Positive and Negative Affect Schedule. The Positive and Negative Affect Schedule-State Form (PANAS-S; Appendix C; Watson \& Clark, 1988) is a 20-item self-report scale that is designed to measure a two-factor model of mood. The first factor of this model is positive affect (PA), which is characterized by high levels of energy, excitement, and pleasure; the second factor is negative affect (NA), or the subjective distress characterized by unhappiness and lethargy. In theory, the two dimensions are posited to be independent of one another; in practice, however, low to moderate negative correlations between PA and NA are commonly are reported. The state form of the PANAS is being used in order to get the most immediate assessment of the participant's level of positive and negative affect. Participants respond to the 
items using the following scale: $1=$ Very slightly or not at all, $2=A$ little, $3=$ Moderately, $4=$ Quite $a$ bit , and $5=$ Extremely. The internal reliabilities for the PANAS are acceptably high, ranging from .86 to .90 for PA and from .84 to .87 for NA. The PANAS also demonstrates variable test-retest reliability over an eight-week interval. With an eight-week retest interval, the PA manifests temporal reliability coefficients of .47 to .68 , and the NA manifests temporal reliability coefficients of .39 to .71 . These temporal stability coefficients of the general ratings are high enough to suggest that they may in fact be used as trait measures of affect. That is, even momentary moods are, to a certain extent, reflections of one's general affective level (Costa \& McCrae, 1980; Watson \& Clark, 1984). Furthermore, the PANAS has been shown to have convergent and discriminant validity. This scale was included in order to examine positive and negative affect as possible covariates or moderators in the relationships between condition assignment and pain threshold, tolerance, and severity ratings. The alphas for the PA and NA subscales in the current study were 0.88 and 0.82 , respectively.

The Self-Presentation Scale. The Self-Presentation Scale—Short Form (SPS; Appendix D; Roth, Snyder, \& Pace, 1986) is a 20-item scale designed to assess the propensity to attribute positive characteristics to the self (i.e., the attributive subscale; SPS-Attributive) and to deny the applicability of negative characteristics (i.e., the repudiative subscale; SPS-Repudiative). Findings suggested that these tendencies are somewhat unrelated. Respondents answer the items by indicating True or False. The SPS has been shown to demonstrate internal consistency (coefficient alpha $=.60, .60$, 
and .67 for the overall SPS, the positive attribution scale, and the negative repudiative scale, respectively). The SPS has also been shown to have convergent validity such that it correlated with measures of self-consciousness, depression, and self-esteem. The results of the validity study also demonstrated that the attribution and repudiative subscales are somewhat independent. Reliable negative correlations were found between depression and the attribution and repudiative subscales. The repudiative subscale was negatively correlated with measures of self-consciousness, whereas no relationship was found between the attribution subscale and the self-consciousness measures. Only the tendency to attribute positive characteristics to self was related to self-reported self-esteem. A reliable correlation was found between the repudiative and attribution subscales $(r=.19, p<.01)$, suggesting that the two subscales are slightly related but assess primarily independent processes. This scale was included in order to examine self-presentation as a possible covariate or moderator in the relationships between condition assignment and pain threshold, tolerance, and severity ratings. The alpha for the SPS in the current study was 0.32 , and alphas for the SPS-Attributive and SPS-Repudiative were 0.54 and 0.44 , respectively. The Pain Catastrophizing Scale. The Pain Catastrophizing Scale (PCS; Appendix E; Sullivan, Bishop, \& Pivik, 1995) consists of 13 items describing different thoughts and feelings that one might have when experiencing pain. The PCS instructs participants to reflect on past painful experiences, and to indicate on a 5point scale $(0=$ Not at all to $4=$ All the time $)$ the degree to which they experienced each of 13 thoughts or feelings during their pains. The PCS yields a total score and 
three subscale scores assessing rumination (PCS-Rumination), magnification (PCSMagnification), and helplessness (PCS-Helplessness). The PCS has been shown to manifest acceptable internal consistency alphas (total PCS $=.87$; rumination subscale $=.87$; magnification subscale $=.60$; and helplessness subscale $=.79 ;$ Sullivan et al., 1995). It also has been shown to manifest test-retest reliability over a latency period of six weeks $(r=.75)$. In a study using the CPT, catastrophizers reported a higher frequency of catastrophizing thoughts. Catastrophizers and noncatastrophizers, however, did not differ significantly in the frequency of coping thoughts or neutral thoughts. The PCS also has demonstrated convergent validity; it has related to measures of depression, anxiety, negative affect, and fear of pain. This scale was included in order to examine pain catastrophization as a possible covariate or moderator in the relationships between condition assignment and pain threshold, tolerance, and severity ratings. The alpha for the PCS in the current study was 0.90 , and the alphas for the PCS-Rumination, PCS-Magnification, and PCS-Helplessness were and $0.90,0.61$, and 0.84 respectively.

The Short-Form McGill Pain Questionnaire. The Short-Form McGill Pain Questionnaire (SMPQ; Appendix F; Melzack, 1987) is designed to assess the experience of pain. It consists of 15 descriptors (11 sensory and four affective) that are rated on a four-point intensity scale of $0=$ None to $3=$ Severe. This scale can produce sensory (SMPQ-Sensory), affective (SMPQ-Affective), and total descriptor pain (SMPQ) scores. The short form has correlated highly with the original McGill Pain Questionnaire (Melzack, 1975). Scores are determined based on the number of 
descriptors endorsed, the intensity reported for each descriptor, and the overall intensity rating of the pain experience. The data indicates that the McGill Pain Questionnaire provides quantitative information that can be treated statistically, and it also is sufficiently sensitive to detect differences among different pain relief methods (Melzack, 1975). This scale was included as a dependent variable to test the effects of the intervention on the experience of pain. The alpha for the SMPQ was 0.82, and alphas for the SMPQ-Sensory and SMPQ-Affective were 0.76 and 0.73 , respectively. Post-Task Questionnaire. The Post-Task Questionnaire (PTQ; see Appendix G) was developed by Snyder, Berg, and colleagues (2005) to assess pain management strategies. The questionnaire asked the participants: (1) how cold they thought the water was; (2) their rating of the overall pain experienced during the CPT using the VAS; (3) how important doing well on the CPT was for them on a scale of 0 to 10 ; (4) how hard they tried on the CPT on a scale of 0 to 10 ; and (5) how much they used the information presented prior to the CPT on a scale of 0 to 10 . These questions were asked in order to examine the effects of the intervention and to check the manipulation. Next, the questionnaire asked participants to "briefly list any strategy that you used to deal with pain in the experiment." Then, they were asked to "go back and beside each, rate how helpful you found that strategy to be" using a scale of $1=$ not helpful to $9=$ the most helpful. This was done in order to assess strategies used by participants and to assess the effectiveness of these strategies in coping with cold pressor pain (i.e., the relationships between these strategies and pain onset, tolerance, and ratings). This scale was included in order to examine the use/helpfulness of 
strategies as a possible mediator in the relationships between condition assignment and pain threshold, tolerance, and severity ratings. The alpha for the PTQ was 0.88 .

In addition to these instruments, the experimenters completed an experimenter sheet that recorded the pain threshold and length of pain tolerance, as well as water temperature, hand size, and the experimenters involved in the testing of the participant in order to investigate these factors as possible covariates or moderators in the potential relationships of gender and condition to the pain dependent variables. First, variations in CPT temperature as little as 2 degrees Celsius have affected experimental outcomes (Mitchell et al., 2004). Second, hand size has been found to be positively related to pain tolerance and latency to onset of pain (Snyder, Berg et al., 2005). One reason for this may be the surface area to volume ratio differences, such that hands that have a shorter distance around the hand have a greater ratio. The greater this ratio, the more likely it is that the participant will experience pain more quickly as a result of the hand being cooled more quickly. Third, experimenter characteristics have been found to have an affect on CPT performance. One such characteristic is gender (Levine \& De Simone, 1991). In one study (Kallai, Barke, \& Vosse, 2004), subjects tolerated pain longer when they were tested by an experimenter of the opposite sex and reported higher pain intensities when they were tested by female experimenters.

\section{Interventions}

Hope Intervention. The hope intervention group received instruction designed to enhance the three components of hope (Appendix L). The intervention involved 
four main parts: (1) guided imagery; (2) debriefing and dialogue about the guided imagery exercise; (3) strategies instructions; and (4) a worksheet. The worksheet included a list of strategies to enhance the motivation, pathways thinking, and effective goal-setting, as well as a list of activities to enhance the three components (Appendix M).

Part A: Guided imagery. The guided imagery portion of the intervention was designed to enhance hopeful thinking. Specifically, the experimenter asked the participants to think of times when they really wanted to achieve something and felt as though they had the motivation and strategies necessary to achieve their goal. They were asked to focus on the emotions and cognitions they used as they pursued those goals. The imagery concluded by asking the participants to reflect on how remembering this situation may help them to achieve future goals (see Appendix L).

Part B: Dialogue. The experimenter asked the participant: (1) "What situation did you think of?" (2) "Why was this goal so important to you?" (3) "How did you maintain your motivation when things got difficult?" (4) "How did you decide how you were going to go about getting to your goal?" (5) "How did achieving your goal make you feel?" (6) "How did these experiences help you to prepare for the future?" and (7) "What did you learn from this experience that will help you on the task?" (see Appendix L). The experimenter responded to participant answers with basic reflections, either reflecting content, emotion, or meaning.

Part C: Strategies instruction. The experimenter provided the participant with a worksheet including a list of strategies to enhance goal-directed thinking, pathways 
thinking, and agency. Examples of such strategies included: (1) "Set goals that will be difficult but not impossible"; (2) “Think about the steps involved in reaching your goal"; and (3) "Think about similar challenging situations where you overcame difficulties to reach a goal" (see Appendix L and M).

Part D: Worksheet. The worksheet instructed the participants to: (1) write about a situation where they felt they set a difficult but achievable goal and felt as though they had sufficient strategies and motivation to reach the goal; (2) write a list of positive self-talk statements (e.g., "you are doing a good job") to use during the cold pressor task; (3) write a list of strategies for overcoming anticipated obstacles during the cold pressor task; and (4) estimate the time they can tolerate the cold pressor task and list what information they will use to adjust their goal (see Appendix M).

These instructions were piloted to investigate robustness and the clarity of the instructions and worksheet in Summer, 2005. Results from the pilot study found that the intervention was effective in enhancing hope. Statistical analysis revealed that the average change in hope scores from pre- to post-intervention was a 2.88 increase $(\mathrm{N}=$ $16 ; \mathrm{SD}=5.54)$. Given the small sample size, a t-value of $-2.08(\mathrm{p}=.055)$ provides support for its effect in increasing hope. Furthermore, the average duration of the intervention was 15 minutes and 56 seconds.

Control Condition. Participants in the control condition received instruction to read a book regarding decorating and organizing the home for 15 minutes. This was 
to control for the time lag between survey completion and the CPT and to control for the activity in which the control group participants were engaged.

\section{Procedure}

Upon arrival to the laboratory, participants were randomly assigned to the hope intervention condition or control condition by flipping a virtual coin (see Figure 3). After entering the laboratory, the research participants were given a verbal overview of the study, and thereafter were asked to sign a consent form (see Appendix I). This overview was intended to inform the research participants of our interest in exploring factors that may relate to pain tolerance. Participants then filled out the Medical History Questionnaire inquiring about arthritis, circulatory problems, trauma to the nondominant hand, peripheral neuropathy, diabetes, or any other major medical problems (Appendix J). If the participant checked any of these medical conditions, they were excluded from participating in this study. The intent of this precaution was to prevent the running of the CPT on persons with serious medical problems.

The experimenter gave participants a brief introduction about the study to aid them in understanding the purpose and importance of their participation in the experiment (Appendix K). This was done in order to facilitate them adopting the goal

of doing well on the CPT as a personal goal, thus ameliorating some of the concern of the artificiality of the CPT.

Participants then completed the PANAS, the SPS, and the PCS, in this order. Next, the experimenter measured the size of the participant's non-dominant hand. The 
participant was asked to hold his or her non-dominant hand flat, palm up, with the fingers together. The length of the hand was measured from the tip of the longest finger to the first fold below the palm of the hand. The width of the hand was measured from the tip of the thumb to the outside knuckle. The hand also was measured around the outside knuckle across to the thumb. The purpose of this hand size index is to control for the sizes of the physical surfaces of the participants' hands in later statistical analyses.

Next, the participants either received the intervention or were read the instructions for the control condition, depending on the group to which they had been randomized.

Following the intervention or control group activity, participants were asked to complete the HSR and respond to three questions on the answer sheet (see Appendix H). First, they were asked, "On a scale of 0 to 10 , with 0 being "not at all important' and 10 being 'extremely important,' how important is it to you that you do well on the task?" Second, they were asked, "On a scale of 0 to 10 , with 0 being "no pain at all' and 10 being 'the worst pain I ever experienced,' how much do you expect the pain to hurt?" Last, they were asked, "On a scale of 0 to 10 , with 0 being 'there is nothing I can do to make the task easier for me' and 10 being 'I have complete control over how difficult the task is for me,' how much control do you perceive that you have in completing the task?" (Appendix H). While the participants completed the HSR and the pre-task questions, the experimenter recorded the temperature of the 
CPT water (out of the sight of the participant) in order to control for slight fluctuations of water temperature in the statistical analyses.

To preclude the possibility that experimenter expectations influenced the participant's performance on the task, a different experimenter unaware of the participant's group assignment prepared the participant to perform the cold pressor task. More specifically, the following instructions were delivered:

"When I say so, you will immerse your hand in the bin of water up to the wrist. State when you first feel pain by saying the word "pain." When the pain is no longer tolerable, you can withdraw your hand from the bin."

The research participants were asked if they have any remaining questions, and the instructions were repeated to make sure that they understood that they were to report when the water first was experienced as painful and were to remove their hands from the bin when the pain is no longer tolerable. After ensuring the clarity of the instructions, they were asked to "Begin" the CPT.

The participants were not allowed to exceed 300 seconds of immersion in the water, but were not informed of this limit prior to the task. This limit was used to preclude the possibility of any tissue damage related to the task. Most research uses at least a three- to five-minute duration (Meagher, Arnau, \& Rhudy, 2001; Myers et al., 2001; Williams \& Kinney, 1991).

Time for the first report of pain and hand immersion was recorded via a stopwatch kept out of sight of the research participant. Upon removal of the hand 
from the bin, research participants were given a towel to dry and warm their hands. Next, participants completed the SMPQ and the PTQ.

Participants were asked to sign a statement as to whether they still were experiencing pain or discomfort (Appendix O). Finally, the research participants were verbally debriefed about the study and were given a written copy of the debriefing (Appendix P).

\section{Statistical Analyses}

The sample was described in terms of demographics, mean scores on assessments (i.e., HSR, PANAS, SPS, PCS, SMPQ, and PTQ scores; importance ratings, pain expectancy ratings, self-efficacy ratings), and the mean time of tolerance, pain threshold, and severity ratings. In addition, a correlation coefficients table was generated for all continuous variables to determine relationships among demographic variables, assessment scores, and the pain dependent variables. An a priori decision was made to evaluate subscale scores rather than overall scale scores

(i.e., HSR, PANAS, SPS, PCS, SMPQ) for the cases in which the subscales correlated less than .70, as a lower correlation suggests that these subscales are assessing distinct constructs. However, this decision was reassessed for cases in which subscales showed similar trends in relationships among other variables and multicollinearity was a concern.

A MANCOVA was used to test the effectiveness of the intervention in enhancing hope and pain coping. Preliminary steps were taken to evaluate the covariates that should be included in the final analysis of the relationships of the 
condition and gender independent variables to change in hope and the dependent variables of: (1) pain tolerance, (2) pain threshold, (3) pain severity, and (4) SMPQ scores (an ancillary outcome variable). In order to evaluate the effects of the hope intervention on HSR scores, a repeated-measures MANCOVA was run entering condition, gender, and condition $\mathrm{x}$ gender as the independent variables and HSR scores as the dependent variables, after controlling for the covariates selected. To evaluate the pain dependent variables, a MANCOVA was run entering condition, gender, and condition x gender as the between subjects factors (i.e., independent variables) and entering pain tolerance, pain threshold, pain severity, and SMPQ subscale scores as the dependent variables, after controlling for the covariates selected.

To test possible moderators of the relationships of gender and condition to the pain dependent variables, the main effects, condition $\mathrm{x}$ variable interaction effects, and gender $\mathrm{x}$ variable interaction effects of the following variables were entered separately into the MANCOVA: self-efficacy expectancy, pain expectancy, PA, NA, SPS-Attributive, SPS-Repudiative, PCS-Rumination, PCS-Magnification, and PCSHelplessness. In addition, genders of the experimenters were evaluated as moderators. Self-efficacy expectancy, pain expectancy, and the use of pain coping strategies (per the PTQ) were investigated as possible mediators of the relationship between condition assignment and the pain dependent variables by determining between group differences in regard to these variables as well as the correlations between these factors and the pain dependent variables. 
Chapter 3: Results

\section{Demographics}

Of the 172 participants included in our analysis, over half $(66.28 \%)$ were female, and the majority were white $(88.95 \%)$. The average age was 19.17 years of age $(S D=2.02)$, and the majority of participants $(90.70 \%)$ were college freshman or sophomores. The annual family household income of these participants was $\$ 78,820$ $(\mathrm{SD}=\$ 56,470 ;$ see Table 1$)$.

See Table 1, page 125

\section{Baseline Assessments}

Table 2 shows mean baseline assessment data for the sample. The average HSR score for the Fall, 2005 testing pool was $6.18(S D=0.98 ; N=1050)$. The average HSR scores for the Spring, 2006 testing pool was $6.15(S D=0.93 ; N=580)$. An independent samples t-test showed that there were no significant differences in HSR scores between semesters $(t(1628)=1.09, n s)$. Participants with low to moderate HSR scores were selected for the study; thus, average HSR scores for the study sample was $5.10(S D=.58)$, with average Goals, Pathways, and Agency subscale scores of $4.94(S D=.91), 5.05(S D=.79)$, and $5.30(S D=.81)$, respectively. Other baseline survey score averages are included in Table 2.

See Table 2, page 126 


\section{Post-Intervention Assessments}

Table 3 shows mean post-intervention psychological assessment scores, pain measures, and post-task assessment scores. The average post-intervention HSR score was $5.51(S D=.77)$, with average Goals, Pathways, and Agency subscale scores of $5.32(S D=1.03), 5.46(S D=.93)$, and $5.74(S D=.89)$, respectively. Mean pain tolerance was 117.49 seconds $(S D=109.19)$, mean pain threshold was 24.05 seconds $(S D=36.43)$, and the mean pain severity rating was $5.68(S D=1.90)$ on a 10 -point scale (see Table 3).

See Table 3, page 127

Among the 83 participants (52 women, 31 men) in the control group, 9 participants (10.8\%; 4 women, 5 men) tolerated the pain for five minutes. Among the 89 participants (62 women, 27 men) in the hope intervention group, 29 participants (32.6\%; 18 women, 11 men) tolerated the pain for five minutes.

\section{Correlations}

Table 4 shows correlations between HSR scores and demographics, psychological assessments, and pain variables. Baseline HSR scores showed a significant positive correlation with SPS scores and negative correlations with NA and PCS scores. PA scores were not related to baseline HSR scores but were significantly correlated with post-intervention HSR scores. Change in hope was 
related to PA and SPS scores, as well as the perceived helpfulness of strategies (per the PTQ).

See Table 4, page 128

Table 5 shows relationships of the pain variables to each other, demographics, and psychological measures. Demographic variables, specifically age and year in school, as well as hand size and CPT water temperature were highly correlated to the pain dependent variables. In addition, each of the pain dependent variables was correlated with one another $(\mathrm{p}<.001$; see Table 5$)$, such that higher pain tolerance, higher pain threshold, and less reported severity of pain were related, and these pain variable relationships were found among the hope intervention group and the control group. SMPQ-Sensory scores showed a significant negative correlation with pain tolerance, but SMPQ-Affective scores were not correlated with pain tolerance. In addition, both SMPQ subscale scores were related to greater pain severity ratings but showed no relationship to pain threshold. PCS scores were related to greater pain severity ratings. Higher pain expectancy ratings were related to lower pain thresholds and greater pain severity ratings. Greater self-efficacy expectancy ratings were related to higher pain thresholds, whereas the perceived helpfulness of strategy use was related to greater pain tolerance and less reported pain severity.

See Table 5, page 129 
Complete correlation matrix information can be found in Appendix R to T. Of note from the correlation matrix, all subscales showed correlations of less than .70 with their related subscales. Neither PA and NA nor SPS-Attributive and SPSRepudiative subscale scores showed similar trends in their relationships to other variables. The PCS subscales and the SMPQ subscales showed significant correlations $(p<.05)$ and did show similar trends in relation to other variables. Thus, PA, NA, SPS-Attributive, and SPS-Repudiative were evaluated separately, whereas the composite scores of the PCS and SMPQ scales were evaluated in the multivariate analyses.

\section{Study Hypotheses}

Hypothesis 1a: Participants in the hope intervention condition, in comparison to those in the control condition, will report a greater increase in hope.

Hypothesis 2a: Individual differences variables such as affect, pain catastrophizing, and self-presentation as well as experimenter 1 gender will moderate the relationships of group and gender to change in hope.

A repeated-measures MANCOVA was run for both the overall HSR and the separate subscales in order to evaluate the effects of the hope intervention on change in HSR scores. Condition, gender, and condition $\mathrm{x}$ gender were entered as the between subjects factors (i.e., the independent variables). Age, family annual household income, experimenter 1 gender, and PA, NA, SPS-Attributive, SPSRepudiative, and PCS scores were entered as potential covariates. The interaction 
effects of these variables with condition and gender also were examined to evaluate potential moderating effects. A backwards stepwise approach was used to eliminate those potential covariates that did not contribute significantly to the model. PA and SPS-Repudiative scores contributed significantly to the model (Wilks' lambda $=.915$, $F(1,166)=15.35, p<.001 ;$ Wilks' lambda $=.977, F(1,166)=3.97, p<.05$, respectively). Thus, PA and SPS-Repudiative scores were entered as covariates.

Results of the multivariate test showed that condition assignment accounted for a significant amount of variance in change in hope from baseline to postintervention (Wilks' lambda $=.957, F(1,166)=7.45, p<.01$ ). The tests of withinsubjects contrasts showed an expected time x condition interaction $(F(1,166)=7.45$, $p<.01$, see Table 6), such that those participants in the hope intervention condition reported a greater increase in hope in comparison to those in the control group. The tests of between-subjects effects showed a significant condition $\mathrm{x}$ gender interaction effect $(F(1,166)=3.94, p<.05$; see Table 6$)$, such that women receiving the intervention experienced a greater increase in hope than men, who showed a substantial increase in hope in both the hope and control conditions (see Figure 4).

See Table 6, page 130

A MANCOVA was calculated to evaluate changes in the separate subscales (i.e. goals, pathways, and agency) from baseline to post-intervention. Intervention condition, gender, and condition $\mathrm{x}$ gender were entered as the independent variables. 
Age, family annual household income, experimenter 1 gender, and PA, NA, SPSAttributive, SPS-Repudiative, and PCS scores were entered as potential covariates. The interaction effects of these variables with condition and gender also were examined to evaluate potential moderating effects. A backwards stepwise approach was used to eliminate those potential covariates that did not contribute significantly to the model. PA scores contributed significantly to the model (Wilks' lambda $=.893$, $F(3,165)=6.62, p<.001)$. Thus, PA scores were entered as a covariate.

Results of the multivariate test showed a marginal time $\mathrm{x}$ condition effect $($ Wilks' lambda $=.954, F(3,165)=2.64, p=.05)$ and a marginal time $\mathrm{x}$ gender effect (Wilks' lambda $=.961, F(3,165)=2.25, p=.08)$ on this group of dependent variables. Overall, the condition $\mathrm{x}$ gender interaction effect trends found for the goals and agency subscales were similar to the trends found for the overall HSR scores.

Goal-Directed Thinking. There was a within subjects time x condition effect on goals thinking $(F(1,167)=4.70, p<.05$, see Table 6$)$, such that those in the hope condition reported a greater increase in goals thinking than those in the control condition.

Pathways Thinking. Neither the tests of with-in subjects contrasts nor the tests of between-subjects contrasts showed significant effects of time, condition, or gender on the pathways thinking component of hope.

Agency. The tests of within-subjects contrasts showed a time x condition effect on agency $(F(1,167)=6.75, p=.01$, see Table 6$)$, such that there was a greater increase in agency from baseline to follow-up for those in the hope intervention 
condition. The tests of between-subjects effects showed an interaction effect of condition $\mathrm{x}$ gender on agency $(F(1,167)=6.51, p<.05$, see Table 6$)$, such that women receiving the intervention, in comparison to those in the control group, reported a greater increase in agency, whereas men reported an increase in agency regardless of condition assignment.

Although people who received the hope intervention had higher levels of hope after the intervention, these differences were qualified by condition $\mathrm{x}$ gender interactions. Post-hoc comparisons using Tukey's HSD statistic were performed to investigate gender differences in response to the intervention $\left(H S D_{.05}=.26\right.$ for change in overall HSR scores and $H S D_{.05}=.35$ for change in the agency subscale). The results of the post-hoc tests showed that women in the hope condition reported a significantly greater increase in hope and the agency component of hope than women in the control condition (see Table 6). However, men in the hope intervention condition did not increase in hope or subscale scores significantly more than those in the control condition.

Hypothesis 1b: Participants in the hope intervention condition, in comparison to those in the control condition, will demonstrate (1) longer pain tolerance, (2) higher pain thresholds, and (3) lower reported pain severity.

Hypothesis 2b: Individual differences variables such as affect, pain catastrophizing, and self-presentation as well as experimenter gender will moderate the relationships of group and gender to the pain dependent variables. 
To test the effect of the intervention on the pain dependent variables, a MANCOVA was used entering condition, gender, and condition $\mathrm{x}$ gender as the independent variables and pain tolerance, pain threshold, pain severity ratings, and SMPQ scores as the dependent variables. Age, family annual household income, baseline HSR, PA, NA, SPS-Attributive, SPS-Repudiative, and PCS scores, importance, pain expectancy, self-efficacy expectancy, distance around the hand, water temperature, experimenter 1 gender, and experimenter 2 gender were entered as potential covariates. In addition, the interaction effects of these variables with condition and gender were evaluated to determine potential moderator effects that needed to be included in the model. A backwards stepwise approach was used to eliminate those potential covariates that did not contribute significantly to the model. Main effects of age, PCS scores, and water temperature contributed significantly to the model (Wilks' lambda $=.905, F(4,160)=4.22, p<.01 ;$ Wilks' lambda $=.857$, $F(4,160)=6.69, p<.001 ;$ Wilks' lambda $=.933, F(4,160)=3.39, p=.01$, respectively). In addition, an interaction effect of participant gender x experimenter 2 gender on the set of dependent variables was significant (Wilks' lambda $=.927, F(4$, $160)=3.17, p<.05)$; the main effect of experimenter 2 gender was not (Wilks' lambda $=.982, F(4,160)=.74, n s)$. The interaction effect of gender $\mathrm{x}$ condition $\mathrm{x}$ experimenter 2 gender was examined but did not contribute significantly to the model $(p>.05)$. Thus, the main effects of age, PCS scores, water temperature, and experimenter 2 gender and the interaction of participant gender $\mathrm{x}$ experimenter 2 gender were entered into the MANCOVA. 
Results of the multivariate test showed that condition (Wilks' lambda $=.840$, $F(4,160)=7.61, p<.001)$ accounted for a significant amount of variance in the set of dependent variables. Adjusted means for this model are shown in Table 7.

See Table 7, page 131

Pain Tolerance. Using this model, main effects of gender $(F(1,163)=4.35, p$ $<.05$, see Table 7$)$ and condition assignment $(F(1,163)=13.88, p<.001$, see Table 7) on pain tolerance were found, such that men, in comparison to women, and those in the hope intervention condition, in comparison to those in the control condition, tolerated the pain longer (see Figure 5).

In addition, an interaction effect of participant gender $\mathrm{x}$ experimenter 2 gender was found $(F(1,163)=7.11, p<.01$, Male-Male: $M=117.19, S D=19.47$, MaleFemale: $M=159.33, S D=17.46$, Female-Male: $M=126.07, S D=13.34$, FemaleFemale: $M=83.29, S D=12.77$; see Figure 6), such that participants tolerated the pain longer if they were tested by an opposite-gender experimenter. Post-hoc analysis using a Tukey's $H S D\left(H S D_{.05}=56.95\right)$ found that men $(M=159.33, S D=17.46)$ tolerated the pain significantly longer than women $(M=83.29, S D=12.76)$ when they were tested by a woman experimenter, but no other differences in tolerance among these groups were significant.

Pain Threshold. No significant condition, gender, or condition x gender effects were found related to pain threshold (see Table 7). 
Pain Severity. No significant condition, gender, or condition x gender effects were found related to pain severity ratings, although the main effects of gender and condition on pain severity approached significance $(F(1,163)=3.14, p=.08 ; F(1$, 163) $=2.94, p=.09$, respectively; see Table 7), such that women, in comparison to men, and those in the hope intervention condition, in comparison to those in the control condition, reported marginally greater pain. After controlling for pain tolerance, MANCOVA results indicated that pain severity differed significantly between the conditions $(F(1,162)=10.25, p<.01$, Hope: $M=6.05, S D=.20$, Control: $M=5.15, S D=.19)$, such that those in the hope intervention condition reported greater pain.

Given the unexpected finding that hope intervention group participants reported more pain than the control group participants taken together with the finding that those participants in the hope intervention demonstrated greater pain tolerance than those in the control condition, further analyses were needed to evaluate these trends. Thus, I examined a curvilinear relationship between pain tolerance and pain severity. Using regression analyses, pain severity was regressed on gender, condition, and pain tolerance, and in each group, pain tolerance was inversely related to pain severity. No evidence of a curvilinear effect of pain tolerance on pain severity was found. In addition, scatteplots were done plotting pain tolerance against pain severity ratings for all participants, the control group participants, and the hope intervention group. These scatterplots showed evidence of butterfly heteroscedasticity, indicating greater error at the extreme ends of the distribution of pain tolerance for both the 
control group and the hope intervention group (Darlington, 1990). Thus, interpretation of these findings should be made with caution.

In addition, an interaction effect of gender $\mathrm{x}$ experimenter 2 gender was found $(F(1,163)=3.98, p<.05$, Male-Male: $M=5.61, S D=.36$, Male-Female: $M=5.01$, $S D=.32$, Female-Male: $M=5.55, S D=.24$, Female-Female: $M=6.12, S D=.23$, see

Figure 7), such that participants rated the pain as less severe when they were tested by an opposite-gender experimenter. However, post-hoc analysis using a Tukey's HSD $\left(H S D_{.05}=1.04\right)$ found no significant differences in pain severity ratings among the gender $\mathrm{x}$ experimenter 2 gender groups.

$S M P Q$ Scores. A main effect of condition was found on experience of pain as measured by the SMPQ scale $(F(1,163)=6.86, p=.01$, see Table 7$)$, such that those participants in the hope intervention group rated the pain as having more of the sensory and affective characteristics than participants in the control group. After controlling for the effects of amount of time with hand submerged in the water (i.e., pain tolerance), this main effect of condition on SMPQ scores remained significant $(F(1,162)=9.42, p<.01$, Hope: $M=21.13, S D=.90$, Control: $M=17.23, S D=.85)$.

Hypothesis 3: Self-efficacy expectancy, pain expectancy, and the use of pain coping strategies (per the PTQ) will serve as mediators in the relationship of gender and condition assignment to the pain dependent variables. Self-efficacy expectancy, pain expectancy, and the use of pain coping strategies did not differ significantly by gender, condition, or the gender $\mathrm{x}$ condition interaction. Thus, they were not 
investigated as mediators of the relationship of condition, gender, or condition $\mathrm{x}$ gender to the pain dependent variables.

Chapter 4: Discussion and Conclusions

The purpose of the present study was to develop and evaluate the effectiveness of an intervention designed to enhance hope for coping with pain. This study used an experimental pain induction cold pressor task and a college-aged sample to evaluate the effectiveness of this intervention. The findings indicated that the intervention was successful in enhancing hope and pain tolerance.

This was the first study investigating the effectiveness a brief intervention designed to enhance hopeful thinking. This multi-component intervention was shown to be effective in increasing hope, even after controlling for positive affect and repudiative self-presentation (i.e., denial of negative characteristics). This held true for both the goal-directed thinking and the agency components of hope, but not the pathways thinking component. Ideally, this intervention would have had the desired effects on each of the factors that provide the basis for hope theory. The fact that it did not effectively enhance pathways thinking may have several explanations. One possibility is that hope is domain-specific. Thus, the use of a global measure of hope rather than a pain-specific measure of hope may have precluded this study from detecting changes in pathways thinking specific to pain management. Perhaps the goal-directed thinking and agency components of hope are more global and less domain-specific than pathways thinking. It also may be the case that the intervention 
did not attend sufficiently to the pathways component of hope or that pathways thinking may be more difficult to enhance.

The intervention designed for this study also was effective in enhancing the ability to endure pain for a longer period of time. In fact, those participants in the hope intervention condition were three times as likely to endure the pain for the fiveminute time limit than those in the control condition. Pain tolerance has been used extensively in previous pain coping research as an objective behavioral marker of the ability to cope with pain (e.g., Bandura et al., 1987; Geisser, Robinson, \& Pickern, 1992; Keefe, Lefebvre, Maixner, Salley, \& Calwell, 1997; Litt, 1988; Vallis \& Bucher, 1986; Williams \& Kinney, 1991) and is considered the gold standard in regard to measuring pain coping ability. The intervention did not significantly impact pain threshold. However, pain threshold may be a more convoluted marker of pain coping than pain tolerance, given that it requires participants to attend to the physical sensations associated with the CPT, which may be inconsistent with their preferred strategies for coping (e.g., distraction, ignoring). Furthermore, monitoring for the pain threshold requires participants to distinguish the moment that the sensation transitions from discomfort to pain, which is likely to be influenced by a variety of factors including previous pain experience, expectancy, attention, and affect. Nonetheless, pain threshold was significantly related to pain tolerance and did demonstrate the anticipated trend among conditions.

Unexpectedly, our findings indicated that those in the hope intervention condition reported that the pain was more severe, specifically after controlling for 
length of pain tolerance. Moreover, they reported elevated levels of the negative sensory and affective characteristics of the pain. One possible reason for this finding is that the intervention may have primed the participants to attend to the pain. Despite rating the pain as more severe, people in the hope condition were able to cope with the pain longer. Contrary to between-group differences, however, bivariate analyses indicated a negative correlation between pain severity and pain tolerance. However, the relationships among condition assignment, pain tolerance, and pain severity ratings should be interpreted with caution because of the trend of butterfly heteroscedasticity with this data.

Given that the intervention was effective in both enhancing hope and increasing pain tolerance, the effect of this intervention on pain tolerance may be directly related to the enhancement of hope. The basis for the current study was provided by previous research documenting the relationship between hope and pain tolerance (Snyder, Berg et al., 2005). Consistent with these initial quasi-experimental findings, the current experiment showed that a hope manipulation resulted in greater pain tolerance. The compilation of increasingly rigorous experimental evidence regarding the connection between hope and pain tolerance highlights the validity of this relationship as well as the need to continue to apply hope theory to the area of pain management in research and clinical practice.

The present findings suggest that the hope intervention may have altered psychological processes that play a role in the Gate Control Model (GCM). The GCM holds that cognitive, affective, and motivational factors influence pain perception and, 
therefore, pain tolerance. Hope is a construct related to more effective cognitions, affect, and motivation (e.g., Kwon, 2002; Snyder, 1996; Snyder, Harris et al., 1991; Snyder, Sympson et al., 1996). Hope can be decomposed into the components of goal-directed thinking, pathways thinking, and agency. The goal-directed thinking component encompasses skills such as clearly defining goals, setting challenging goals, and the ability to invest in goals. Pathways thinking involves the ability to plan and create strategies to reach goals and the ability to generate new pathways to goals when previously used pathways are ineffective or blocked. Agency entails the belief that one is capable of achieving goals and the ability to call upon motivation in order to maintain commitment to goals. The hope-based intervention designed for this study was successful in enhancing hope (per the Revised Hope Scale). As such, enhancing hope, specifically the agency and goal-directed thinking components, may have had important implications on participants' abilities to cope with pain, and processes involved in the GCM may have mediated these effects.

The GCM suggests that painful stimuli is processed in the context of the individual's (1) thoughts, expectancies, and attentional states (i.e., cognitions); and (2) current mood and level of motivation (Melzack \& Wall, 1965). Although a significant effect of the intervention was found on pain tolerance such that it likely altered these GCM-related processes, the mechanisms by which this was achieved are unclear. The present study did not find differences between the groups in regard to importance ratings (i.e., motivation), self-efficacy expectancies, pain expectancies, or the usage or helpfulness of strategies to tolerate the pain. It follows, then, that 
cognitions specific to hopeful thinking and distinct from these specific factors may have contributed to the ability to cope with the pain. For example, this intervention may have been effective in helping participants to establish realistic expectations about the painful experience, conceptualize the cold pressor task as a challenge, direct their attention toward coping with the pain, produce more effective thoughts related to the meaning of the painful stimuli, or prepare to be more flexible in their use of strategies.

Contrary to expectations, initial analyses indicated that people in the hope condition attended to the sensory components of the pain more and rated pain as more aversive (i.e., the affective component of the pain) than people in the control condition. While Leventhal's parallel processing theory (1993) and Cioffi's cognitive-perceptual model (1991) predict that attending to the sensory components of the pain and ignoring the affective components of the pain may facilitate better pain tolerance (which has been shown in previous studies; Ahles, Blanchard, \& Leventhal, 1983; Cioffi, 1991; Dar \& Leventhal, 1993; McCaul, Malott, 1984; Suls \& Fletcher, 1985), the increased reports of the affective dimension of the pain paired with increased pain tolerance among the hope intervention participants are inconsistent with these theories. Given that these findings were not anticipated, further analyses were done that found trends between pain tolerance and pain severity ratings (i.e., butterfly heteroscedasticity) that suggest that these findings should be interpreted with caution. Nonetheless, we can speculate about why this relationship may have occurred. Perhaps this intervention was effective in achieving greater pain 
tolerance by increasing participants' mindfulness about the experience of the cold pressor task. Mindfulness (i.e., enhanced attention to and open awareness of current experience; Deikman, 1982; Martin, 1997) involves the practice of disengaging individuals from automatic thoughts, habits, and unhealthy behavior patterns while engaging them in identifying their experiences non-judgmentally. In the context of pain, mindfulness allows the sensory and affective characteristics of the pain to be identified and experienced without engaging in catastrophic or self-debilitating thinking. In doing so, mindfulness may facilitate the use of intentional strategies for coping and, in fact, has been shown to relate to better coping with pain (Kabat-Zinn et al., 1985, 1987). Both mindfulness and hope seem to be characteristics that involve intentional attention and awareness; thus, neither are avoidant processes. In some cases, hopeful or mindful people may choose to use distraction as a strategy, but theoretically, this would occur as a result of an intentional decision. An intervention based on mindfulness (also involving relaxation treatments, cognitive skills enhancement, and problem-solving) has been shown to be effective in enhancing mindfulness and resulting in declines in mood disturbance and stress experience among cancer patients (Brown \& Ryan, 2003; Speca et al., 2000) and has resulted in less reported pain among chronic pain patients (Kabat-Zinn et al., 1985, 1987). Thus, it may be through similar processes that the current hope-based intervention was related to better pain tolerance.

The intervention did significantly increase hope and pain tolerance among both men and women. However, the effects of the intervention on hope itself 
appeared to be specific to women. Men's hopefulness ratings increased from baseline to post-intervention regardless of whether they were in the hope intervention condition or the control condition. The reason for this finding is unclear. One possible explanation may be the small number of men that participated in the study, and thus lower power to detect differences in conditions among men. This is likely the case given that the anticipated trends in change in hope, especially the goal-directed thinking and agency components, were found. Another possibility is that the men's reports of hope at the time of the intervention may have been influenced more by positive self-presentation even though baseline measures of self-presentation did not show gender difference. It also is interesting that the differences in pain tolerance among the men were not as robust either. However, there are well-known sex differences in pain tolerance that may have played a role in the study outcomes. Research has shown that men tolerate pain longer (e.g., Snyder, Berg et al., 2005) and report less severe pain (e.g., Fillingim \& Maixner, 1995; Riley, Robinson, Wise, Myers, \& Fillingim, 1998). Therefore, the time limit established for the cold pressor task may have played a role in the less robust pain tolerance differences among men.

The gender of the experimenter conducting the cold pressor task was a significant factor in pain tolerance and pain severity ratings in the present study. Participants tolerated the pain longer when they were tested by an opposite-gender experimenter, especially among male participants, which has been documented in previous research (Kallai, Barke, \& Vosse, 2004; Levine \& De Simone, 1991). It also has been found that people report more severe pain to female experimenters (Kallai, 
Barke, \& Vosse, 2004). In the present study, participants rated the pain as more severe when they were tested by same-gender experimenters.

The present study provides interesting findings that may drive many trajectories of future research. First, the mechanisms by which the intervention affected better pain tolerance remain unclear. The Gate Control Model provides us with a framework for understanding the influence of psychological factors on pain experience; however, research in this area is still quite new. Thus, future research should examine the relationships between psychological factors and pain experience as well as the processes the hope intervention may have activated that allowed the participants to endure the pain longer. Moreover, given that theorists and research suggest contradictions regarding the role of attention in coping with pain, more research should be directed toward exploring this factor and potential moderators that may be involved.

Second, this intervention involved a guided imagery component, a debriefing aimed at eliciting information from the guided imagery, a skills enhancement component, and a worksheet aimed at exercising the skills. Because this intervention was multi-faceted, future research investigating the effectiveness of this intervention may benefit from investigating the individual contributions of these components of the intervention in the overall effect on hope and pain tolerance. A related concern is the potential demand characteristics involved in the study. Because the study involved a control condition that did not receive the nonspecific components of the hope intervention (i.e., interaction with the experimenter, etc.), it is difficult to ascertain the 
extent to which group differences were a result of the specific techniques involved in the intervention rather than the nonspecific factors. Thus, future research should attend to this confound.

Third, the intervention was more effective in enhancing goal-directed thinking and agency than pathways thinking. This may be related to the use of a global assessment of hope rather than a pain-specific hope measure. Thus, future investigation of this intervention should aim to develop a pain-specific hope measure in order to ensure that the measure is assessing the factors that are targeted by this intervention. Moreover, research could be done regarding the possibility of differential domain specificity of the components of hope. For example, agency and goal-directed thinking may be less domain-specific than pathways thinking.

The present study has important limitations that should be addressed in future research. One major concern is the use of an experimental pain induction method. As with all research using experimental pain induction methods rather than clinical pain, the clinical relevance and generalizability of the research are controversial issues. However, it is important to note that the laboratory-based CPT has the advantage of being free from the influence of potentially confounding variables such as nausea, fatigue, and anxiety related to illness and painful medical procedures often found in the clinical setting. Thus, research such as this provides a solid platform upon which to build future studies using clinical samples. Future studies could investigate the effectiveness of this intervention in coping with acute clinical pain. Moreover, this 
intervention may provide a framework upon which to build a more extensive treatment to enhance the ability to cope with chronic pain.

On a related point, another limitation is the nature of the sample used in this study. Participants were university students that were predominantly white and middle- to upper-class. Therefore, these findings may not generalize to other population groups. Specifically, it would be interesting to investigate ethnic differences, SES differences, educational differences, and age in relationship to the effectiveness of this intervention.

A significant limitation to this study is the lack of pre-intervention cold pressor task performance assessment. The present study assumed that the groups did not significantly differ on baseline pain tolerance. Although randomization of participants to the groups hypothetically mitigates this concern, we cannot be certain that the groups did not differ at baseline. Future studies should assess baseline pain tolerance in order to control for any group differences that may exist prior to the intervention.

Despite the limitations of this study, the demonstrated effectiveness of this intervention may have many implications for clinical practice. First, these findings may heighten the awareness and attention of clinicians to the psychological factors that play a role in the suffering associated with pain. By healthcare providers identifying hope-consistent processes as well as those inconsistent with hope among patients, they may be better able to intervene in order to impact patients' experiences of pain. Pain patients may be able to bolster hope-related skills, such as reminding 
themselves that they have overcome pain in the past, planning for ways to deal with pain, and setting realistic expectations and goals regarding their pain. Moreover, healthcare providers may be more effective in treating the psychological sequelae associated with pain by attending to the context of the patients' pain, such as their pain history, specific barriers to coping with pain, and their cognitive and affective reactions to pain. Although conventional cognitive treatments address these factors, this intervention uses hope as a framework for conceptualizing patient strengths (i.e., high motivation, social support, problem-solving skills, attending to other life goals) and weaknesses (i.e., unrealistic pain goals, barriers to pain management, feelings of helplessness in impacting the pain experience). In doing so, the intervention and the theory providing the basis for it (i.e., hope theory) provide specific targets related to goal pursuits upon which healthcare providers may intervene. This research may heighten clinicians' attention to other health-related areas that have been found to be related to hope. Perhaps clinicians may impact these other domains by using modifications of this intervention or by developing other techniques that target hoperelated processes.

Overall, the advancing scientific rigor applied to this line of research validates the relationship between hope and pain tolerance and the need for continued research in this area. The demonstrated effectiveness of the hope intervention using this sample and an experimental pain induction method provides justification for future research using this paradigm on other populations and with other types of pain. Moreover, results from this study highlight the need to further investigate the 
mechanisms by which people are able to cope with pain, as research to date is contradictory in its findings, specifically in regard to the role that attention to the sensory and affective components of pain might play. Additionally, this study emphasizes the fact that interventions do not equally affect all populations. Thus, future research may be directed at discerning the patient characteristics that facilitate the effectiveness of interventions such as the one developed for the present study. 


\section{References}

Achterberg, J. M., \& Lawlis, G. F. (1980). Bridges of the bodymind: Behavioral approaches to health care. New York: Random House.

Adams, E. R., \& McGuire, F. A. (1986). Is laughter the best medicine? A study of the effects of humor on perceived pain and affect. Activities, Adaptation, \& Aging, 8(3-4), 157-175.

Affleck, G., \& Tennen, H. (1996). Construing benefits from adversity: Adaptational significance and dispositional underpinnings. Journal of Personality, 64, 899922.

Affleck, G., Tennen, H., Urrows, S., \& Higgins, P. (1991). Individual differences in the day-to-day experience of chronic pain: A prospective daily study of rheumatoid arthritis patients. Health Psychology, 10, 419-426.

Ahles, T. A., Blanchard, E. B., \& Leventhal, H. (1983). Cognitive control of pain: Attention to the sensory aspects of the cold pressor stimulus. Cognitive Therapy and Research, 7(2), 159-178.

Allen, K., Blascovich, J., \& Mendes, W. B. (2002). Cardiovascular reactivity in the presence of pets, friends, and spouses: The truth about cats and dogs. Psychosomatic Medicine, 64(5), 727-739.

Anderson, D. B., \& Pennebaker, J. W. (1980). Pain and pleasure: Alternative interpretations for identical stimulation. European Journal of Social Psychology, 10, 207-212.

Anderson, J. R. (1988). The role of hope in appraisal, goal setting, expectancy, and 
coping. Unpublished Doctoral dissertation, University of Kansas, Lawrence, Kansas.

Appenzeller, O. (1970). The autonomic nervous system. New York: American Elsevier.

Arendt-Nielsen, L., \& Lautenbacher, S. (2004). Assessment of pain perception. In S. Lautenbacher \& R. B. Fillingim (Eds.), Pathophysiology of pain perception (pp. 25-42). New York, NY: Kluwer Academic.

Arntz, A., Dreesen, L., \& DeJong, P. (1994). The influence of anxiety on pain: Attentional and attributional mediators. Pain, 56, 307-314.

Arntz, A., Dreesen, L., \& Merckelback, H. (1991). Attention, not anxiety, influences pain. Behavior Research and Therapy, 29, 41-50.

Austenfeld, J. L., \& Stanton, A. L. (2004). Coping through emotional approach: A new look at emotion, coping, and health-related outcomes. Journal of Personality, 72(6), 1335-1363.

Babyak, M., Snyder, C. R., \& Yoshinobu, L. (1993). Psychometric properties of the Hope Scale: A confirmatory factor analysis. Journal of Research in Personality, 27, 154-169.

Baker, S. L., \& Kirsch, I. (1991). Cognitive mediators of pain perception and tolerance. Journal of Personality and Social Psychology, 61(3), 504-510.

Bandura, A. (1982). Self-efficacy mechanism in human agency. American Psychologist, 37, 122-147.

Bandura, A. (1997). Self efficacy: The exercise of control. New York: Freeman. 
Bandura, A., Adams, N. E., \& Beyer, J. (1977). Cognitive processes mediating behavior change. Journal of Personality and Social Psychology, 35, 125-139.

Barasi, S. (1991). The Physiology of pain. Surgical Nurse, 4(5), 14-20.

Barber, T. X., \& Hahn, K. W., Jr. (1962). Psychological and subjective responses to pain producing stimulation under hypnotically suggested and wakingimagined "analgesia." Journal of Abnormal and Social Psychology, 65, 411418.

Barber, T. X., \& Hahn, K. W., Jr. (1964). Experimental studies in "hypnotic" behavior: Physiological and subjective effects of imagined pain. Journal of Nervous and Mental Disease, 139, 416-425.

Bardiau, F. M., Braeckman, M. M., Seidal, L., Albert, A., \& Boogaerts, J. G. (1999). Effectiveness of an acute pain service inception in a general hospital. Journal of Clinical Anesthesiology, 11, 583-589.

Barnum, D. D., Snyder, C. R., Rapoff, M. A., Mani, M. M., \& Thompson, R. (1998). Hope and social support in the psychological adjustment of pediatric burn survivors and matched controls. Children's Health Care, 27, 15-30.

Baron, R. S., Logan, H., \& Hoppe, S. (1993). Emotional and sensory focus as mediators of dental pain among patients differing in desired and felt dental control. Health Psychology, 12(5), 381-389.

Bayer, T. L., Baer, P. E., \& Early, C. (1991). Situational and psychophysiological factors in psychologically induced pain. Pain, 44, 45-50.

Beck, A. T. (1967). Depression. New York: Harper and Row. 
Beck, A. T., Ward, C. H., Mendelson, M., Mock, J., \& Erbaugh, J. (1961). An inventory for measuring depression. Archives of General Psychiatry, 4, 561571.

Beecher, H. K. (1956). Relationship of significance of wound to pain experienced. Journal of the American Medical Association, 161, 1609-1613.

Berkley, K. J. (1997). Sex differences in pain. Behavioral Brain Science, 20, 371-380.

Besson, J. M., \& Chaouch, A. (1987). Peripheral and spinal mechanisms of nociception. Physiological Review, 67(1), 67-186.

Biederman, J. J., \& Schefft, B. K. (1994). Behavioral, physiological, and selfevaluative effects of anxiety on the self-control of pain. Behavior Modification, 18(1), 89-105.

Bishop, S. R. (1999). Attention mediates the relationship between catastrophizing and pain. Dissertation Abstracts International, 60(3-B), 1321.

Blitz, B., \& Dinnerstein, A. J. (1971). Role of attentional focus in pain perception: Manipulation of response to noxious stimulation by instructions. Journal of Abnormal Psychology, 77, 42-45.

Block, A. R., Kremer, E. F., \& Gaylor, M. (1980). Behavioral treatment of chronic pain: The spouse as a discrimative cue for pain behavior. Pain, 9, 243-252.

Bonica, J. J. (1987). Importance of the problem. In S. Anderson, M. Bond, M. Mehta, \& M. Swedlow (Eds.), Chronic non-cancer pain. Lancaster, UK: MTP Press. 
Boothby, J. L., Thorn, B. E., Stroud, M. W., \& Jensen, M. P. (1999). Coping with pain. In R. J. Gatchel \& D. C. Turk (Eds.), Psychosocial factors in pain (pp. 343-359). Edinburgh: Guilford Press.

Brody, H. (2000). The vast majority of drug studies offer little if any evidence to support the physiologic effects of the placebo. Advances in Mind-Body Medicine, 16(1), 13-16.

Brown, M., Curry, L. A., Hagstrom, H., \& Sandstedt, S. (1999, August). Female teenage athletes, sports participation, self-esteem, and hope. Paper presented at the Association for the Advancement of Applied Sport Psychology, Banff, Alberta, Canada.

Brown, K. W., \& Ryan, R. M. (2003). The benefits of being present: Mindfulness and its role in psychological well-being. Journal of Personality and Social Psychology, 84(4), 822-848.

Brownlee, S., \& Schrof, J. M. (1997, March). The quality of mercy. U. S. News \& World Report, 54-67.

Buckalew, S. P., Conway, R. C., Shutty, M. S., Lawrence, J. A., Grafing, M. R., Anderson, S. K., Hewett, J. E., \& Keefe, F. J. (1992). Spontaneous coping strategies to manage acute pain and anxiety during electrodiagnostic studies. Archives of Physiological Medicine and Rehabilitation, 73(6), 594-598.

Calvino, B., Besson, J. M., Mounier, F., Kordon, C., \& Bluet-Pajot, M. T. (1992). 
Chronic pain induces a paradoxical increase in growth hormone secretion without affecting other hormones related to acute stress in the rat. Pain, 49, $27-32$.

Casten, R. J., Laston, M. P., Winter, L., Kieban, M., \& Sando, R. L. (1997). The relationship of health to affect assessed in both state and trait form: How does age impact the relationships? Aging and Mental Health, 1, 230-237.

Caudill, M. A. (2002). Managing pain before it manages you. New York: Guilford Press.

Cervero, F., \& Iggo, A. (1980). The substantia gelatinosa of the spinal cord-a critical review. Brain, 103, 717-772.

Chambers, C. T., Craig, K. D., \& Bennett, S. M. (2002). The impact of maternal behavior on children's pain experiences: An experimental analysis. Journal of Pediatric Psychology, 27(3), 293-301.

Chang, E. C. (1998). Hope, problem-solving ability, and coping in a college student population: Some implications for theory and practice. Journal of Clinical Psychology, 54, 953-962.

Cheng, S. F., Foster, R. L., \& Hester, N. O. (2003). A review of factors predicting children's pain experiences. Issues in Comprehensive Pediatric Nursing, 26(4), 203-216.

Cioffi, D. (1991). Sensory awareness versus sensory impression: Affect and attention interact to produce somatic meaning. Cognition and Emotion, 5(4), 275-294.

Cioffi, D., \& Holloway, J. (1993). Delayed costs of suppressed pain. Journal of 
Personality and Social Psychology, 64, 274-282.

Cipher, D. J., Fernandez, E., \& Clifford, A. P. (2001). Cost-effectiveness and health care utilization in a multidisciplinary pain center: Comparison of three treatment groups. Journal of Clinical Psychology in Medical Settings, 8, 237244.

Compton, P., Athanasos, P., \& Elashoff, D. (2003). Withdrawal hyperalgesia after acute opioid physical dependence in nonaddicted humans: A preliminary study. Journal of Pain, 4(9), 511-519.

Cornwall, A., \& Donderi, D. C. (1988). The effect of experimentally induced anxiety on the experience of pressure pain. Pain, 35, 105-113.

Costa, P. T., Jr., \& McCrae, R. R. (1980). Influence of extraversion and neuroticism on subjective well-being: Happy and unhappy people. Journal of Personality and Social Psychology, 38, 668-678.

Coyne, J. C., \& Racioppo, M. W. (2000). Never the twain shall meet? Closing the gap between coping research and clinical intervention research. American Psychologist, 55, 655-664.

Cramer, K. M., \& Dyrkacz, L. (1998). Differential prediction of maladjustment scores with the Snyder hope subscales. Psychological Reports, 83, 1035-1041.

Crombez, G., Eccleston, C., Vlaeyen, J. W. S., Vansteenwegen, D., Lysens, R., \& Eelen, P. (2002). Exposure to physical movements in low back pain patients. Restricted effects of generalization. Health Psychology, 21, 573-578.

Crombez, G., Vlaeyen, J. W. S., Heuts, P. H. T. G., \& Lysens, R. (1999). Pain-related 
fear is more disabling than pain itself: Evidence on the role of pain-related fear in chronic back pain disability. Pain, 80, 329-339.

Crowne, D. P., \& Marlowe, D. (1960). A new scale of social desirability independent of psychopathology. Journal of Consulting Psychology, 24, 349-354.

Culver, N. F. (1992). A validation of the Encouragement Scale-Teacher Form. Unpublished Doctoral dissertation, University of Georgia, Athens, Georgia.

Curry, L. A., \& Maniar, S. D. (2003). Academic course combining psychological skills training and life skills education for university students and studentathletes. Journal of Applied Sports Psychology, 15, 270-277.

Curry, L. A., \& Maniar, S. D. (2004). Academic course for enhancing student-athlete performance in sport. The Sport Psychologist, 18, 297-316.

Curry, L. A., Mania, S. D., Sondag, K. A., \& Sandstedt, S. (1999). An optimal performance academic course for university students and student-athletes. Unpublished manuscript, University of Montana, Missoula, Montana.

Curry, L. A., \& Snyder, C. R. (2000). Hope takes the field: Mind matters in athletic performances. In C. R. Snyder (Ed.), Handbook of hope: Theory, measures, and applications (pp. 243-260). San Diego, CA: Academic Press.

Curry, L. A., Snyder, C. R., Cook, D. L., Ruby, B. C., \& Rehm, M. (1997). The role of hope in student-athlete academic and sport achievement. Journal of Personality and Social Psychology, 73, 1257-1267.

Daake, D. R., \& Gueldner, S. H. (1989). Imagery, instruction, and the control of postsurgical pain. Applied Nursing Research, 2, 114-120. 
Dar, R., \& Leventhal, H. (1993). Schematic processes in pain perception. Cognitive Therapy and Research, 17(4), 341-357.

Darlington, R. (1990). Regression in Linear Models. New York: McGraw Hill.

Davis, P. J., Reeves, J. L., Hastie, B. A., Graff-Radford, S. B., \& Naliboff, B. D. (2000). Depression determines illness conviction and pain impact: A structural equation modeling analysis. Pain Medicine, 1(3), 238-246.

de Grier, M., Peters, M. L., \& Vlaeyen, J. W. S. (2003). Fear of pain, physical performance, and attentional processes in patients with fibromyalgia. Pain, 104, 121-130.

Deikman, A. J. (1982). The observing self. Boston: Beacon Press.

Dembroski, T. M., \& MacDougall, J. M. (1985). Beyond global Type A:

Relationships of paralinguistic attributes, hostility, and anger-in to coronary heart disease. In T Field, P. McCabe, \& N. Schneiderman (Eds.), Stress and coping (pp. 223-241). Hillsdale, NJ: Erlbaum.

Dembroski, T. M., MacDougall, J. M., Williams, R. B., Haney, T. L., \& Blumenthal, J. A. (1985). Components of Type A, hostility, and anger-in: Relationship to angiographic findings. Psychosomatic Medicine, 47, 219-233.

Deshields, T. L., Tait, R. C., Gfeller, J. D., \& Chibnall, J. T. (1995). Relationship between social desirability and self-report in chronic pain patients. Clinical Journal of Pain, 6, 189-193.

Dickens, C., McGowan, L., Clark-Carter, D., \& Creed, F. (2002). Depression in 
rheumatoid arthritis: A systematic review of the literature with meta-analysis. Psychosomatic Medicine, 64(1), 52-60.

Dickenson, A. H. (1991). Mechanisms of the analgesic actions of opiates and opioids. In J. C. D. Wells \& C. J. Woolf (Eds.), Pain mechanisms and management (pp. 690-702). Edinburgh: Churchill Livingstone.

DiClimente, C. C., \& Prochaska, J. O. (1982). Self-change and therapy change of smoking behavior: A comparison of process of change in cessation and maintenance. Addictive Behaviors, 71, 133-144.

Dolce, J. J., Crocker, M. F., \& Doleys, D. M. (1986). Prediction of outcome among chronic pain patients. Behavior Research and Therapy, 24, 313-319.

Dougher, M. J., Goldstein, D., \& Leight, K. A. (1987). Induced anxiety and pain. Journal of Anxiety Disorders, 1, 259-264.

Eccleston, C., \& Crombez, G. (1999). Pain demands attention: A cognitive-affective model of the interruptive function of pain. Psychological Bulletin, 125, 356366.

Eisenberg, D. M., Kessler, R. C., Foster, C., Norlock, F. E., Calkins, D. R., \& Delbanco, T. L. (1993). Unconventional medicine in the United States: Prevalence, costs, and patterns of use. New England Journal of Medicine, $328(4), 246-252$.

Elliot, T. R., \& Kurylo, M. (2000). Hope over acquired disability: Lessons of a young woman's triumph. In C. R. Snyder (Ed.), Handbook of hope: Theory, measures, and applications (pp. 373-386). San Diego: Academic Press. 
Elliot, T. R., Witty, T. E., Herrick, S., \& Hoffman, J. T. (1991). Negotiating reality after physical loss: Hope, depression, and disability. Journal Personality and Social Psychology, 61, 608-613.

Ellis, J. A., \& D’Eon, J. L. (2002). Pain, emotion, and the situational specificity of catastrophizing. Cognition and Emotion, 16(4), 519-532.

Esdaile, J. (1957). Hypnosis in medicine and surgery. New York: Julian Press. (Original work published 1850).

Feldman, D. B., \& Snyder, C. R. (2001). Natural companions: Hope and meaning. Unpublished manuscript, University of Kansas, Lawrence, Kansas.

Fernandez, E., \& Turk, D. (1989). The utility of cognitive coping strategies for altering pain perception: A meta-analysis. Pain, 38, 123-135.

Ferrell, B. R., Ferrell, B. A., Ahn, C., \& Tran, K. (1994). Pain management for elderly patients with cancer at home. Cancer, 74(Suppl. 7), 2139-2146.

Fields, H. L. (1988). Sources of variability in the sensation of pain. Pain, 33, 195200.

Fillingim, R. B., \& Maixner, W. (1995). Gender differences in the responses to noxious stimuli. Pain Forum, 4, 209-221.

Fishbain, D. A. (2002). The pain-depression relationship. Psychosomatics: Journal of Consultation Liaison Psychiatry, 43(4), 341.

Flor, H., Fydrich, T., \& Turk, D. C. (1992). Efficacy of multidisciplinary pain treatment centers: A meta-analytic review. Pain, 49, 221-230. 
Flor, H., Turk, D. C., \& Rudy, T. E. (1989). Relationship of pain impact and significant other reinforcement of pain behaviors: Mediating role of gender, marital status, and marital satisfaction. Pain, 38, 34-50.

Floyd, R. K., \& McDermott, D. (1998, August). Hope and sexual risk-taking in gay men. Presented at the American Psychological Association, San Francisco.

Fordyce, W. E. (1976). Behavioral methods for chronic pain and illness. St. Louis, MO: Mosby.

Fordyce, W. E., Roberts, A. H., \& Sternbach, R. A. (1985). The behavioral management of chronic pain: Response to critic. Pain, 22, 113-115.

Frank, J. D. (1982). Therapeutic components shared by all psychotherapy. In J. H. Harvey \& M. M. Parsk (Eds.), The master lecture series: Psychotherapy research and behavior change (Vol. 1, pp. 5-38). Washington, DC: American Psychological Association.

Frenk, H., Cannon, J. T., Lewis, J. W., \& Liebeskind, J. C. (1986). Neural and neurochemical mechanisms of pain inhibition. In R. A. Sternbach (Ed.), The psychology of pain (2 $2^{\text {nd }}$ ed., pp. 25-47). New York: Raven Press.

Friedman, H. J. (1963). Patient expectancy and symptom reduction. Archives of General Psychiatry, 8, 61-67.

Friedman, M., \& Rosenman, R. H. (1959). Association of specific overt behavior pattern with blood and cardiovascular findings. Journal of the American Medical Association, 169, 1286-1296. 
Friedman, M., \& Rosenman, R. H. (1974). Type A behavior and your heart. New York: Knopf.

Gearan, P., \& Kirsch, I. (1993). Response expectancy as a mediator of hypnotizability modification: A brief communication. International Journal of Clinical and Experimental Hypnosis, 41(2), 84-91.

Geden, E., Beck, N., Hauge, G., \& Pohlman, S. (1983). Self-report and psychophysiological effects of five pain-coping strategies. Nursing Research, $33,260-265$.

Geisser, M. E., Robinson, M. E., \& Pickren, W. E. (1992). Differences in cognitive coping strategies among pain-sensitive and pain-tolerant individuals on the cold-pressor test. Behavior Therapy, 23(1), 31-41.

Geisser, M. E., Robinson, M. E., \& Riley, J. L. (1999). Pain beliefs, coping, and adjustment to chronic pain-Let's focus more on the negative. Pain Forum, 8, 161-168.

Genest, M. (1979). A cognitive-behavioural biblio-therapy to ameliorate pain. Unpublished Master's Thesis, University of Waterloo.

Gil, K. M., Carson, J. W., Porter, L. S., Ready, J., Valrie, C., Redding-Lallinger, R., \& Daeschner, C. (2003). Daily stress and mood and their association with pain, health-care use, and school activity in adolescents with sickle cell disease. Journal of Pediatric Psychology, 28, 363-373.

Gil, K. M., Carson, J. W., Porter, L. S., Scipio, C., Bediako, S. M., \& Orringer, E. (2004). Daily mood and stress predict pain, health care use, and work activity 
in African American adults with sickle-cell disease. Health Psychology, 23, 267-274.

Goldstein, A. P. (1960). Patient's expectations and non-specific therapy as a basis for spontaneous remission. Journal of Clinical Psychology, 16, 399-403.

Goubert, L., Francken, G., Crombez, G., Vansteenwegen, D., \& Lysens, R. (2002). Exposure to physical movement in chronic back pain patients: No evidence for generalization. Behavior Research and Therapy, 40(4), 415-429.

Greenberg, R. P., Bornstein, R. F., Zborowski, M. J., Fisher, S., \& Greenberg, R. L. (1994). A meta-analysis of fluoxetine outcome in the treatment of depression. Journal of Nervous and Mental Disease, 182(10), 547-551.

Greenberg, R. P., \& Fisher, S. (1989). Examining antidepressant effectiveness: Findings, ambiguities, and some vexing puzzles. In R. P. Greenberg \& Fisher, S. (Eds.), The limits of biological treatments for psychological distress: Comparisons with psychotherapy and placebo (pp. 1-37). Hillsdale, N. J., England: Lawrence Erlbaum Associates.

Guadagnoli, E., \& Mor, V. (1989). Measuring cancer patients' affect: Revision and psychometric properties of profile of mood states (POMS). Psychological Assessment, 1, 150-154.

Haanen, H. C., Hoenderdos, H. T., Van Romunde, L. K., Hop, W. C., Malle, C. E., Terwiel, J. P., \& Hekster, G. G. (1991). Controlled trial of hypnotherapy in the treatment of refractory fibromyalgia. Journal of Rheumatology, 18, 72-75.

Hagbarth, K. E., \& Kerr, D. I. B. (1954). Central influences on spinal afferent 
conduction. Journal of Neurophysiology, 17, 295-307.

Handwerker, H. O., \& Kobal, G. (1993). Psychophysiology of experimentally induced pain. Physiological Review, 73, 639-671.

Hardy, G. E., Barkham, M., Shapiro, D. A. Reynolds, S., Reese, A., \& Stiles, W. B. (1995). Credibility and outcome of cognitive-behavioural and psychodynamic-interpersonal therapy. British Journal of Clinical Psychology, $34,555-569$.

Harney, P. (1990). The Hope Scale: Exploration of construct validity and its influence on health. Unpublished Master's Thesis, University of Kansas, Lawrence.

Hadjistavropoulos, H. D., Craig, K. D., \& Hadjistavropoulos, T. (1998). Cognitive and behavioral responses to illness information: The role of health anxiety. Behavior Research and Therapy, 36, 149-164.

Heavner, J. E., \& Willis, W. D. (2000). Pain pathways: Anatomy and physiology. In P. P. Raj (Ed.), Practical Management of Pain ( $3^{\text {rd }}$ Ed.; pp. 107-116). St. Louis: Mosby.

Helfer, S. G., \& McCubbin, J. A. (2001). Does gender affect the relation between blood pressure and pain sensitivity? International Journal of Behavioral Medicine, 8(3), 220-229.

Hilgard, E. R., Cooper, L. M., Lenox, J., Morgan, A. H., \& Voevodsky, J. (1967). The use of pain-state reports in the study of hypnotic analgesia to the pain of ice water. Journal of Nervous and Mental Disease, 144, 507-513. 
Hitchcock, P. B., \& Mathews, A. (1992). Interpretation of bodily symptoms in hypochondriasis. Behaviour Research and Therapy, 30(3), 223-234.

Hodes, R. L., Howland, E. W., Lightfoot, N., \& Cleeland, C. S. (1990). The effects of distraction on responses to cold pressor pain. Pain, 41, 109-114.

Hoon, E. (1980). Biofeedback-assisted sexual arousal in females: A comparison of visual and auditory modalities. Biofeedback and Self-Regulation, 5(2), 175191.

Horan, J. J., Hackett, G., Nicholas, W. C., Linberg, S. E., Stone, C. I., \& Lukaski, H. C. (1977). Rapid smoking: A cautionary note. Journal of Consulting and Clinical Psychology, 45, 341-343.

Horvath, P. (1990). Treatment expectancy as a function of the amount of information presented in therapeutic rationales. Journal of Clinical Psychology, 46, 636642.

Hosobuchi, Y., Adams, J. E., \& Linchitz, R. (1977). Pain relief by electrical stimulation of the central gray matter in humans and its reversal by naloxone. Science, 197, 183-186.

Ikemi, Y., \& Nakagawa, S. (1972). Psychosomatic approaches in Japan. Journal of the American Society of Psychosomatic Dentistry and Medicine, 19(4), 142145.

Ilardi, S. S., \& Craighead, W. E. (1994). The role of nonspecific factors in cognitivebehavoiral therapy for depression. Clinical Psychology: Science and Practice, $1,138-156$. 
International Association for the Study of Pain. (2003). How prevalent is chronic pain? Pain: Clinical Updates, XI(2), online.

International Association for the Study of Pain. (1993). Pain control: The new "whys" and "hows." Pain: Clinical Updates, I(1), online.

Irving, L. M., Crenshaw, W., Snyder, C. R., Francis, R., \& Gentry, G. (1998). Hope and its correlates in a psychiatric setting. Paper presented at the Midwestern Psychological Association, Chicago.

Irving, L. M., Seidner, A. L., Burling, T. A., Pagliarini, R., \& Robbins-Sisco, D. (1998). Hope and recovery from drug/alcohol dependence in homeless veterans. Journal of Social and Clinical Psychology, 17(4), 389-406.

Irving, L. M., Snyder, C. R., \& Crowson, J. J., Jr. (1998). Hope and the negotiation of cancer facts by college women. Journal of Personality, 66, 195-214.

Irving, L. M., Tefler, L., \& Blake, D. (1997). Hope, coping, and social support in combat-related posttraumatic stress disorder. Journal of Traumatic Stress, 10, 463-477.

Jackson, T., Iezzi, T., Nagasaka, T., Fritch, A., \& Gunderson, J. (2002). Does the mere presence of over-the-counter pain medication affect pain perception? Some preliminary findings. Psychology, Health, and Medicine, 7(2), 215-222.

Jackson, W. T., Taylor, R. E., Palmatier, A. D., Elliott, T. R., \& Elliott, J. L. (1998). Negotiating the reality of visual impairment: Hope, coping, and functional ability. Journal of Clinical Psychology in Medical Settings, 5, 173-185. 
Jacobsen, P. B., \& Butler, R. W. (1996). Relation of cognitive coping and catastrophizing to acute pain and analgesic use following breast cancer surgery. Journal of Behavioral Medicine, 19(1), 17-29.

James, J. E., \& Hardardottir, D. (2002). Influence of attention focus and trait anxiety on tolerance of acute pain. British Journal of Health Psychology, 7(2), 149162.

Janssen, S. A. (2002). Negative affect and sensitization to pain. Scandinavian Journal of Psychology, 43(2), 1331-138.

Janssen, S. A., Arntz, A., \& Bouts, S. (1998). Anxiety and pain: Epinephrine-induced hyperalgesia and attentional influence. Pain, 76, 309-316.

Janssen, S. A., Spinhoven, P., \& Brosschot, J. F. (2001). Experimentally induced anger, cardiovascular reactivity, and pain sensitivity. Journal of Psychosomatic Research, 51(3), 479-485.

Jensen, M. P. (1996). Enhancing motivation to change in pain treatment. In R. J. Gatchel \& D. C. Turk (Eds.), Psychological approaches to pain management: A practitioner's handbook (pp. 78-111). New York: Guilford Press.

Jensen, M. P., Turner, J. A., \& Romano, J. M. (1991). Self-efficacy and outcome expectancies: Relationship to chronic pain coping strategies and adjustment. Pain, 44, 263-269.

Jensen, M. P., Turner, J. A., Romano, J. M., \& Lawler, B. K. (1994). Relationship of pain specific beliefs to chronic pain adjustment. Pain, 57, 301-309. 
Joffe, R., Sokolov, S., \& Streiner, D. (1996). Antidepressant treatment of depression: A meta-analysis. Canadian Journal of Psychiatry, 41(10), 613-616.

Johnson, M. (2003). The vulnerability status of neuroticism: Over-reporting or genuine complaints? Personality and Individual Differences, 35(4), 877-887.

Kabat-Zinn, J., Lipworth, L., \& Burney, R. (1985). The clinical use of mindfulness meditation for the self-regulation of chronic pain. Journal of Behavioral Medicine, 8(2), 163-190.

Kabat-Zinn, J., Lipworth, L., Burney, R., \& Sellers, W. (1987). Four-year follow-up of a mediation-based program for the self-regulation of chronic pain: Treatment outcome and compliance. Clinical Journal of Pain, 2, 159-173.

Kalauokalani, D., Sherman, K. J., \& Cherkin, D. C. (2001). Acupuncture for chronic low back pain: Diagnosis and treatment patterns among acupuncturists evaluating the same patient. Southern Medical Journal, 94, 486-492.

Kallai, I., Barke, A., \& Voss, U. (2004). The effects of experimenter characteristics on pain reports in women and men. Pain, 112(1-2), 142-147.

Keefe, F. J., Dunsmore, J., \& Burnett, R. (1992). Behavioral and cognitive-behavioral approaches to chronic pain: Recent advances and future directions. Journal of Consulting and Clinical Psychology, 60, 528-536.

Keefe, F. J., Gil, K. N., \& Rose, S. C. (1986). Behavioral approaches in the multidisciplinary management of chronic pain. Clinical Psychology Review, 6, 87-113. 
Keefe, F. J., Lefebvre, J. C., Maixner, W., Salley, A. N., \& Caldwell, D. S. (1997). Self-efficacy for arthritis pain: Relationship to perception of thermal laboratory pain stimuli. Arthritis Care and Research, 10(3), 177-184.

Keefe, F. J., Lefebvre, J. C., \& Smith, S. J. (1999). Catastrophizing researchAvoiding conceptual errors and maintaining a balanced perspective. Pain Forum, 8, 176-180.

Keefe, F. J., Salley, A. N., \& Lefebvre, J. C. (1992). Coping with pain: Conceptual concerns and future directions. Pain, 51(2), 131-134.

Kellner, R., Abbott, P., Winslow, W. W., \& Pathak, D. (1987). Fears, beliefs, and attitudes in DSM-III hypochondriasis. The Journal of Nervous and Mental Disease, 175(1), 20-25.

Keogh, E., \& Chaloner, N. (2002). The moderating effect of anxiety sensitivity on caffeine-induced hypoalgesia in healthy women. Psychopharmacology, 164(4), 429-431.

Keogh, E., \& Herdenfeldt, M. (2002). Gender, coping and the perception of pain. Pain, 97(3), 195-201.

Keogh, E., \& Mansoor, L. (2001). Investigating the effects of anxiety sensitivity and coping on the perception of cold pressor pain in health women. European Journal of Pain, 5(1), 11-22.

Kihlstrom, J. F. (1985). Hypnosis. Annual Review of Psychology, 36, 385-418.

Kirsch, I. (1990). Changing expectations: A key to effective psychotherapy. Belmont, CA: Brooks/Cole Publishing Co. 
Kirsch, I. (1994). Clinical hypnosis as a nondeceptive placebo: Empirically derived techniques. American Journal of Clinical Hypnosis, 37(2), 95-106.

Kirsch, I. (1997). Response expectancy theory and application: A decennial review. Applied and Preventive Psychology, 6(2), 69-79.

Kirsch, I. (1999). How expectancies shape experience. Washington, D.C.: American Psychological Association.

Kirsch, I. (1999). Hypnosis and placebos: Response expectancy as a mediator of suggestion effects. Anales de Psicologia, 15(1), 99-110.

Kirsch, I., \& Lynn, S. J. (1995). Dissociation, trauma, memory, and hypnosis book series. In I. Kirsch \& Capafons, A. (Eds.), Clinical hypnosis and selfregulation: Cognitive-behavioral perspectives (pp. 49-72). Washington, D. C.: American Psychological Association.

Kirsch, I., \& Sapirstein, G. (1999). The role of expectancy in antidepressant medication. In I. Kirsch (Ed.), How expectancies shape experience (pp. 303320). Washington, D. C.: American Psychological Association.

Klausner, E. J., Clarkin, J. F., Spielman, L., Pupo, C., Abrams, R., \& Alexopoulus, G. S. (1998). Late-life depression and functional disability: The role of goalfocused group psychotherapy. International Journal of Geriatric Psychology, 13, 707-716.

Kole-Snijder, A. M., Vlaeyen, J. W., Goossens, M. E. Rutten-van Molken, M. P., Heuts, P. H., van Breukelen, G., \& van Eek, H. (1999). Chronic low-back pain: What does cognitive coping skills training add to operant behavioral 
treatment? Results of a randomized clinical trial. Journal of Consulting and Clinical Psychology, 67, 931-944.

Kvaal, S. A., \& Patodia, S. (2000). Relations among positive affect, negative affect, and somatic symptoms in a medically ill patient sample. Psychological Reports, 87, 227-233.

Kwekkeboom, K., Huseby-Moore, K., \& Ward, S. (1998). Imaging ability and effective use of guided imagery. Research in Nursing \& Health, 21, 189-198.

Kwon, P. (2000). Hope and dysphoria: The moderating role of defense mechanisms. Journal of Personality, 68, 199-233.

Kwon, P. (2002). Hope, defense mechanisms, and adjustment: Implications for false hope and defensive hopelessness. Journal of Personality, 70, 207-231.

Laird, S. (1992). A preliminary investigation into prayer as a coping technique for adult patients with arthritis. Unpublished doctoral dissertation, University of Kansas, Lawrence, Kansas.

Lambert, S. A. (1996). The effects of hypnosis/guided imagery on the postoperative course of children. Journal of Developmental and Behavioral Pediatrics, 17, 307-310.

Lasagna, L., Laties, V. G., \& Dohan, J. L. (1958). Further studies on the "pharmacology" of placebo administration. Journal of Clinical Investigation, $37,533-537$.

Lazarus, R. S. (1999). Stress and emotion: A new synthesis. New York: Springer.

Lazarus, R. S., \& Folkman, S. (1984). Stress, appraisal, and coping. New York: 
Springer.

Le Bars, D., \& Willer, J. C. (1988). Letter to the editor. Pain, 32, 259-260.

Leriche, R. (1937). The surgery of pain. Translated by A. Young. London: Balliere, Tindall and Cox.

Leventhal, H. (1993). The pain system: A multilevel model for the study of motivation and emotion. Motivation and Emotion, 17(3), 139-146.

Leventhal, H., Brown, D., Shacham, S., \& Engquist, G. (1979). Effects of preparatory information about sensations, threat of pain, and attention on cold pressor distress. Journal of Personality and Social Psychology, 37(5), 688-714.

Leventhal, H., \& Everhart, D. (1979). Emotion, pain, and physical illness. In C. E. Izard (Ed.), Emotions in Personality and Psychopathology (pp. 263-298). New York: Plenum Press.

Lewith, G. T., \& Kenyon, J. N. (1984). Physiological and psychological explanations for the mechanism of acupuncture as a treatment for chronic pain. Social Science and Medicine, 19(12), 1367-1378.

Linton, S. J. (2000). Psychological risk factors for neck and back pain. In A. L., Nachemson \& E. Jonsson (Eds.), Neck and back pain. The scientific evidence of causes, diagnosis and treatment (pp. 57-78). Philadelphia, PA: Lippincott Williams \& Wilkins.

Liossi, C., \& Hatira, P. (1999). Clinical hypnosis versus cognitive behavioral training for pain management with pediatric cancer patients undergoing bone marrow 
aspirations. International Journal of Clinical and Experimental Hypnosis, 47, 104-116.

Litt, M. D. (1988). Self-efficacy and perceived control: Cognitive mediators of pain tolerance. Journal of Personality and Social Psychology, 54(1), 149-160.

Logan, H. L., Baron, R. S., \& Kohout, F. (1995). Sensory focus as therapeutic treatments for acute pain. Psychosomatic Medicine, 57(5), 475-484.

Lopez, S. J., Floyd, R. K., Ulven, J. C., \& Snyder, C. R. (2000). Hope therapy: Helping clients build a house of hope. In C. R. Snyder (Ed.), Handbook of hope: Theory, measures, and applications (pp. 123-150). San Diego, CA: Academic Press.

Lovallo, W. (1975). The cold pressor test and autonomic function: A review and integration. Psychophysiology, 12(3), 268-282.

Lovallo, W., \& Zeiner, A. R. (1975). Some factors influencing the vasomotor response to cold pressor stimulation. Psychophysiology, 12, 499-505.

Luparello, T. J. (1970). Features of fugue: A unified hypothesis of regression. Journal of the American Psychoanalytic Association, 18(2), 379-398.

Lynn, S. J., \& Rhue, J. W. (1988). Fantasy proneness: Hypnosis, developmental antecedents, and psychopathology. American Psychologist, 43(1), 35-44.

MacAndrew, C., \& Edgerton, R. B. (1969). Drunken comportment: A social explanation. Oxford, England: Aldine.

Malone, M. D., \& Strube, M. J. (1988). Meta-analysis of non-medical treatment for chronic pain. Pain, 34, 231-234. 
Malow, R. W. (1981). The effects of induced anxiety on pain perception: A signal detection analysis. Pain, 11, 397-405.

Mannix, L. K., Chandurkar, R. S., Rybicki, L. A., Tusek, D. L., \& Solomon, G. D. (1999). Effect of guided imagery on quality of life for patients with chronic tension-type headache. Headache, 39, 326-334.

Martin, J. R. (1997). Mindfulness: A proposed common factor. Journal of Psychotherapy Integration, 7, 291-312.

Martin, P. J., Sterne, A. L., Moore, J. E., \& Lindsey, C. J. (1977). Patients' expectancies and hospital outcome. Journal of Clinical Psychology, 33(1), 254-258.

Mauer, M. H., Burnett, K. F., Oulette, E. A., Ironson, G. H., \& Dandes, H. M. (1999). Medical hypnosis and orthopedic hand surgery: Pain perception, postoperative recovery, and therapeutic comfort. International Journal of Clinical and Experimental Hypnosis, 47, 144-161.

McCaul, K. D., \& Malott, J. M. (1984). Distraction and coping with pain. Psychological Bulletin, 95, 516-533.

McCracken, L. M., \& Gross, R. T. (1993). Does anxiety affect coping with chronic pain? Clinical Journal of Pain, 9, 253-259.

McDermott, D., \& Snyder, C. R. (1999). Making hope happen. Oakland, CA: New Harbinger Publications.

McHugh, J. M., \& McHugh, W. B. (2000). Pain: Neuroanatomy, chemical mediators, and clinical implications. AACN Clinical Issues, 11(2), 168-178. 
McQuay, H. J., Moore, R. A., Eccleston, C., Morley, S., \& Williams, A. (1997). Systematic review of outpatient services for chronic pain control. Health Technology Assessment, 1(i-iv), 1-135.

Meagher, M. W., Arnau, R. C., \& Rhudy, J. L. (2001). Pain and emotion: Effects of affective picture modulation. Psychosomatic Medicine, 63(1), 79-90.

Meichenbaum, D. L. (1977). Cognitive-behavior modification. New York: Plenum Press.

Melzack, R. (1983a). Acupuncture and related forms of folk medicine. In P. D. Wall \& R. Melzack (Eds.), Textbook of pain (1 ${ }^{\text {st }}$ ed., pp. 691-700). Edinburgh: Churchill Livingstone.

Melzack, R. (1975). The McGill Pain Questionnaire: Major properties and scoring methods. Pain, 1, 277-299.

Melzack, R. (1986). Neurophysiology foundations of pain. In R. A. Sternbach (Ed.), The psychology of pain ( $2^{\text {nd }}$ ed., pp. 1-24). New York: Raven Press.

Melzack, R. (1987). The short-form McGill Pain Questionnaire. Pain, 30, 191-197.

Melzack, R., \& Casey, K. L. (1967). Sensory, motivational and central control determinants of pain: A new conceptual model. In D. Kenshalo (Ed.), The skin senses (pp. 423-438). Springfield, Illinois: Charles C. Thomas.

Melzack, R., \& Wall, P. D. (1965). Pain mechanisms: A new theory. Science, 150, 971-979.

Melzack, R., \& Wall, P. D. (1970). Psychophysiology of pain. International Anaesthesiology Clinics, 8, 3-34. 
Melzack, R., \& Wall, P. D. (Eds.). (1989). The challenges of pain ( $\left.1^{\text {st }} \mathrm{ed}.\right)$. Harmondsworth: Penguin.

Merskey, H., Albe-Fessard, D. G., Bonica, J. J., Carmen, A., Dubner, R., Kerr, F. W. L., Lindblom, U., Mumford, J. M., Nathan, P. W., Noordenbos, W., Pagni, C. A., Renaer, M. J., Sternbach, R. A., \& Sunderland, S. (1979). IASP subcommittee on taxonomy. Pain, 6(3), 249-252.

Michael, S. T. (2000). Hope conquers fear: Overcoming anxiety and panic attacks. In C. R. Snyder (Ed.), Handbook of hope: Theory, measures, and applications (pp. 355-378). San Diego, CA: Academic Press.

Miller, W. R., \& Rollnick, S. (2002). Motivational interviewing: Preparing people for change $\left(2^{\text {nd }}\right.$ ed.). New York: Guilford Press.

Mitchell, L. A., MacDonald, R. A., \& Brodie, E. E. (2004). Temperature and the cold pressor test. Journal of Pain, 5, 233-237.

Mobily, P. R., Herr, K. A., \& Kelley, L. S. (1993). Cognitive-behavioral techniques to reduce pain: A validation study. International Journal of Nursing Studies, $30,537-548$.

Montgomery, G. H., DuHamel, K. N., \& Redd, W. H. (2000). A meta-analysis of hypnotically induced analgesia: How effective is hypnosis? International Journal of Clinical and Experimental Hypnosis, 48(2), 138-153.

Moon, C., Snyder, C. R., \& Rapoff, M. (2001). The relationship of hope to children's asthma treatment adherence. Unpublished manuscript, University of Kansas, Lawrence, Kansas. 
Moran, K. J. (1989). The effects of self-guided imagery and other guided imagery on chronic low back pain. In S. D. Funk, E. M. Tornquist, M. T. Champagne, L. A. Copp, \& R. A. Wiese (Eds.), Key aspects of comfort: Management of pain, nausea and fatigue (pp. 160-166). New York: Springer.

Morley, S., Eccleston, C., \& Williams, A. (1999). Systematic review and metaanalysis of randomized controlled trials of cognitive behaviour therapy and behaviour therapy for chronic pain in adults, excluding headache. Pain, 80, 113.

Myers, C. D., (2000). Sex and gender: Relative contributions to cardiovascular reactivity and experimental pain report. Dissertation Abstracts International: Section B: The Sciences and Engineering, 60(9-B), 4899.

Myers, C. D., Robinson, M. E., Riley III, J. L., \& Sheffield, D. (2001). Sex, gender, and blood pressure: Contributions to experimental pain report. Psychosomatic Medicine, 63(4), 545-550.

National Institutes of Health (NIH) Technology Assessment Panel. (1996). Integration of behavioral and relaxation approaches into the treatment of chronic pain and insomnia. Journal of the American Medical Association, 276, 313-318.

Nau, S. D., Caputo, J. A., \& Borkovec, T. D. (1974). The relationship between credibility of therapy and simulated therapeutic effects. Journal of Behavior Therapy and Experimental Psychiatry, 5, 129-133.

Nicholas, M. K. (1992). Chronic pain. In P. H. Wilson (Ed.), Principles of practice of 
relapse prevention (pp. 255-289). New York: Guilford.

Noordenbos, W. (1995). Pain-Problems pertaining to the transmission of nerve impulses which give rise to pain: Preliminary statement. Amsterdam: Elsevier.

Novy, D. M. (2004). Psychological approaches for managing chronic pain. Journal of Psychopathology and Behavioral Assessment, 26(4), 279-288.

Novy, D. M., Nelson, D. V., Francis, D. J., \& Turk, D. C. (1995). Perspectives of chronic pain: An evaluative comparison of restrictive and comprehensive models. Psychological Bulletin, 118, 238-247.

Olton, D. S., \& Noonberg, A. R. (1980). Biofeedback clinical applications in behavioural medicine. Englewood Cliffs: Prentice-Hall Inc.

Onwuegbuzie, A. J. (1998). Role of hope in predicting anxiety about statistics. Psychological Reports, 82, 1315-1320.

Onwuegbuzie, A. J. (1999). Relation of hope to self-perception. Perceptual and Motor Skills, 88, 535-540.

Onwuegbuzie, A. J., \& Snyder, C. R. (2000). Relations between hope and graduate students' studying and test-taking strategies. Psychological Reports, 86, 803806.

Ottoson, D. (1983). Physiology of the nervous system. London: Macmillan.

Owens, M. K., \& Ehrenreich, D. (1991). Literature review of nonpharmocologic methods for the treatment of chronic pain. Holistic Nursing Practice, 6(1), 2431. 
Patterson, D. R. (2004). Treating pain with hypnosis. Current Directions in Psychological Science, 13(6), 252-255.

Patterson, D. R., Everett, J. J., Burns, G. L., \& Marvin, J. A. (1992). Hypnosis for the treatment of burn pain. Journal of Consulting and Clinical Psychology, 60, 713-717.

Patterson, D. R., \& Jensen, M. (2003). Hypnosis for clinical pain control. Psychological Bulletin, 129, 495-521.

Patterson, D. R., \& Ptacek, J. T. (1997). Baseline pain as a moderator of hypnotic analgesia for burn injury treatment. Journal of Consulting and Clinical Psychology, 65, 60-67.

Peckerman, A., Hurwitz, B. E., Saab, P. G., Llabre, M. M., McCabe, P. M., \& Schneiderman, N. (1994). Stimulus dimensions of the cold pressor test and the associated patterns of cardiovascular response. Psychophysiology, 31, 282290.

Pennebaker, J. W. (1982). The Psychology of Physical Symptoms. New York: Springer.

Penzien, D. B., Rains, J. C., \& Andrasik, F. (2002). Behavioral management of recurrent headache: Three decades of experience and empiricism. Applied Psychophysiology and Biofeedback, 27, 163-181.

Peters, M. L., Schmidt, A. J. M., Van den Hout, M. A., Koopmans, R., \& Sluijter, M. E. (1992). Chronic back pain, acute postoperative pain and the activation of diffuse noxious inhibitory controls (DNIC). Pain, 50, 177-187. 
Phillips, J. M., \& Gatchel, R. J. (2000). Extroversion-introversion and chronic pain. In R. J. Gatchel \& J. N. Weisberg (Eds.), Personality characteristics of patients with pain (181-202). Washington, DC: American Psychological Association.

Podmore, F. (1963). From Mesmer to Christian Science: A short history of mental healing. New York: University Books. (Original work published 1909).

Potter, P. T., Zatura, A. J., \& Reich, J. W. (2000). Stressful events and information processing dispositions moderate the relationship between positive and negative affect: Implications for pain patients. Annals of Behavioral Medicine, 22(3), 191-198.

Pressman, S. D., \& Cohen, S. (2005). Does positive affect influence health? Psychological Bulletin, 131(6), 925-971.

Price, D. D. (1988). Psychological and neurological mechanisms of pain. New York: Raven Press.

Rains, J. C., Penzien, D. B., McCrory, D. C., \& Gray, R. N. (2005). Behavioral headache treatment: History, review of the empirical literature, and methodological critique. Headache, 45(Suppl. 2), S92-S109.

Rainville, P., Duncan, G. H., Price, D. D., Carrier, B., \& Bushnell, M. (1997). Pain affect encoded in human anterior cingulated but not somatosensory cortex. Science, 277(5328), 968-971.

Reich, J. W., Zautra, A. J., \& Potter, P. T. (2001). Cognitive structure and the 
independence of positive and negative affect. Journal of Social and Clinical Psychology, 20, 99-115.

Reynolds, D. V. (1969). Surgery in the rat during electrical analgesia by focal brain stimulation. Science, 164, 444-445.

Rhudy, J. L., \& Meagher, M. W. (2000). Fear and anxiety: Divergent effects on human pain thresholds. Pain, 84, 65-75.

Riley, J. L., III, Robinson, M. E., Wise, E. A., Myers, C. D., \& Fillingim, R. B. (1998). Sex differences in the perception of noxious experimental stimuli: A meta-analysis. Pain, 74 (2-3), 181-187.

Roberts, A. H., Kewman, D. G., Mercier, L., \& Hovell, M. (1993). The power of nonspecific effects in healing: Implications for psychosocial and biological treatments. Clinical Psychology Review, 13, 375-391.

Robinson, M. E., \& Wise, E. A. (2004). Prior pain experience: Influence on the observation of experimental pain in men and women. Journal of Pain, 5(5), 264-269.

Rokke, P. D., \& Lall, R. (1992). The role of choice in enhancing tolerance to acute pain. Cognitive Therapy and Research, 16, 53-65.

Rosen, G. (1946). Mesmerism and surgery: A strange chapter in the history of anesthesia. Journal of the History of Medicine, 1, 527-550.

Roth, D. L., Snyder, C. R., \& Pace, L. M. (1986). Dimensions of favorable selfpresentation. Journal of Personality and Social Psychology, 51 (4), 867-874. 
Roth, D. L., Harris, R. H., \& Snyder, C. R. (1988). An individual differences measure of attributive and reputative tactics of favorable self-presentation. Journal of Social and Clinical Psychology, 2, 159-170.

Ryan, R. M., \& Deci, E. L. (2001). On happiness and human potentials: A review of research on hedonic and eudaimonic well-being. Annual Review of Psychology, 52, 141-166.

Ryding, E. L., Wijma, B., Wijma, K., \& Rydhstrom, H. (1998). Fear of childbirth during pregnancy may increase the risk of emergency caesarean section. Acta Obstetric Gynecology Scandanavia, 77, 542-547.

Sanford, S. D., Kersh, B. C., Thorn, B. E., Rich, M. A., \& Ward, L. C. (2002). Psychosocial mediators of sex differences in pain responsivity. Journal of Pain, 3(1), 58-64.

Schmidt, A. J. M. (1985). Cognitive factors in the performance level of chronic low back pain patients. Journal of Psychosomatic Research, 29, 183-189.

Seaton, K., \& Snyder, C. R. (2001). Hope and remaining in a treatment program for drug abuse. Unpublished manuscript, University of Kansas, Lawrence, Kansas.

Sherwin, E. D., Elliott, T. R., Rybarcysk, B. D., Frank, R. G., Hanson, S., \& Hoffman, J. (1992). Negotiating the reality of care giving: Hope, burnout, and nursing. Journal of Social and Clinical Psychology, 11, 129-139. 
Shorey, H. S., \& Snyder, C. R. (July, 2004). Exploring the possibility of a revised Hope Scale. Poster presented at the American Psychological Association Convention, Honolulu, Hawaii.

Skevington, S. M. (1995). Psychology of pain. New York: Wiley.

Snow, M. G., \& Kerns, R. D., Rosenberg, R., Jarvis, J. A., McCourt, M. S., \& Prochaska, J. O. (1993). Stages of change for chronic pain patients. Development of a questionnaire to assess readiness to change. Poster presented at the $14^{\text {th }}$ annual scientific sessions of the Society of Behavioral Medicine.

Snyder, C. R. (1993). Hope for the journey. In A.P. Turnball, J. M. Paterson, S. K. Behr, D. L. Murphy, J. G. Marquis, \& M. J. Blue-Banning (Eds.), Cognitive coping, families and disability (pp. 271-286). Baltimore, MD: Brookes.

Snyder, C. R. (1994a). Hope and optimism. In V. S. Ramachandren (Ed.), Encyclopedia of human behavior (Vol. 2; pp. 535-542). San Diego, CA: Academic Press.

Snyder, C. R. (1994b). The psychology of hope: You can get there from here. New York: Free Press.

Snyder, C. R. (1996). To hope, lose, and hope again. Journal of Personal and Interpersonal Loss, 1, 3-16.

Snyder, C. R. (1998). A case for hope in pain, loss, and suffering. In J. H. Harvey, J. Omarzu, \& E. Miller (Eds.), Perspectives on loss: A sourcebook (pp. 63-79). Washington, DC: Taylor \& Francis, Ltd. 
Snyder, C. R. (1999). Hope, goal blocking thoughts, and test-related anxieties. Psychological Reports, 84, 206-208.

Snyder, C. R. (Ed.). (2000). Handbook of hope: Theory, measures, and applications. San Diego, CA: Academic Press.

Snyder, C. R. (2002). Hope theory: Rainbows in the mind. Psychological Inquiry, 13, 249-275.

Snyder, C. R., Berg, C. J., Woodward, J. T., Gum, A., Rand, K. L., Wrobleski, K. K., Brown, J., Hackman, A. (2005). Hope against the cold: Individual differences in trait hope and acute pain tolerance on the cold pressor task. Journal of Personality, 73(2), 287-312.

Snyder, C. R., Cheavens, J., \& Michael, S. T. (1999). Hoping. In C.R. Snyder (Ed.), Coping: The psychology of what works (pp. 205-231). New York: Oxford University Press.

Snyder, C. R., Cheavens, J., \& Sympson, S. (1997). Hope: An individual motive for social commerce. Group Dynamics: Theory, Research, and Practice, 1, 1-12.

Snyder, C. R., Crowson, J. J., Jr., Houston, B. K., Kurylo, M., \& Poirier, J. (1997). Assessing hostile automatic thoughts: Development and Validation of the HAT Scale. Cognitive Therapy and Research, 4, 477-492.

Snyder, C. R., Harris, C., Anderson, J. R., Holleran, S. A., Irving, L. M., Sigmon, S. T., Yoshinobu, L., Gibb, J., Langelle, C., \& Harney, P. (1991). The will and the ways: Development and validation of an individual differences measure of hope. Journal of Personality and Social Psychology, 60(4), 570-585. 
Snyder, C. R., Hoza, B., Pelham, W. E., Rapoff, M., Ware, L., Danovsky, M., Highberger, L., Rubinstein, H., \& Stahl, K. (1997). The development and validation of the Children's Hope Scale. Journal of Pediatric Psychology, 22(3), 399-421.

Snyder, C. R., Ilardi, S. S., Cheavens, J., Michaels, S. T., Yamhure, L., \& Sympson, S. (2000a). The role of hope in cognitive behavioral therapies. Cognitive Therapy and Research, 24, 747-762.

Snyder, C. R., Ilardi, S. S., Michael, S. T., \& Cheavens, J. (2000b). Hope theory: Updating a common process for psychological change. In C. R. Snyder \& R. E. Ingram (Eds.), Handbook of psychological change: Psychotherapy processes and practices for the $21^{\text {st }}$ century (pp. 128-153). New York: Wiley.

Snyder, C. R., Kahle, K., Parenteau, S., \& Berg, C. (In press). The role of hope in suffering from medical illnesses. In L. J. Hass (Ed.), Handbook of psychology in primary care. New York: Oxford University Press.

Snyder, C. R., LaPointe, A. B., Crowson, J. J., Jr., \& Early, S. (1998). Preferences of high- and low-hoe people for self-referential input. Cognition \& Emotion, 12, 807-823.

Snyder, C. R., McDermott, D., Cook, W., \& Rapoff, M. (1997). Hope for the journey: Leading children through the good times and the bad. San Francisco, CA: Westview/Harper Collings.

Snyder, C. R., McDermott, D., Cook, W., \& Rapoff, M. (2002). Hope for the journey (revised edition). Clinton Corners, NY: Percheron Press. 
Snyder, C. R., Parenteau, S., Shorey, H. S., Kahle, K., \& Berg, C. J., (2002). Hope as the underlying process in Gestalt and other psychotherapies approaches. International Gestalt Journal, 25, 11-29.

Snyder, C. R., Rand, K. L., King, E., Feldman, D., \& Taylor, J. (2002). "False” hope. Journal of Clinical Psychology, 58, 1003-1022.

Snyder, C. R., Shorey, H., Cheavens, J., Pulvers, K. M., Adams III, V. H., \& Wiklund, C. (2002). Hope and academic success in college. Journal of Educational Psychology, 94, 820-826.

Snyder, C. R., Sympson, S. C., Michael, S. T., \& Cheavens, J. (2000). The optimism and hope constructs: Variants on a positive expectancy theme. In E. Chang (Ed.), Optimism and pessimism (pp. 103-124). Washington, DC: American Psychological Association.

Snyder, C. R., Sympson, S. C., Ybasco, F. C., Borders, T. F., Babyak, M. A., \& Higgins, R. L. (1996). Development and validation of the State Hope Scale. Journal of Personality and Social Psychology, 2, 321-335.

Snyder, C. R., \& Taylor, J. D. (2000). Hope as a common factor across psychotherapy approaches: A lesson from the "Dodo's Verdict." In C. R. Snyder (Ed.), Handbook of hope: Theory, measures, and applications (pp. 89-108). San Diego, CA: Academic Press.

Snyder, C. R., Taylor, J. D., Gum, A., Rand, K. L., Kahle, K. E., Brown, J., \& Hackman, A. (2001). Hope and physical pain tolerance. Unpublished material. 
Snyder, C. R., Tran, T., Schroeder, L. L., Pulvers, K. M., Adams, V., \& Laub, L. (2000). Teaching the hope recipe: Setting goals, finding pathways to those goals, and getting motivated. Reaching Today's Youth, 4(4), 46-50.

Speca, M., Carlson, L. E., Goodey, E., \& Angen, M. (2000). A randomized, wait-list controlled clinical trial: The effect of a mindfulness meditation-based stress reduction program on mood and symptoms of stress in cancer outpatients. Psychosomatic Medicine, 62, 613-622.

Spielberger, C. D., Gorsuch, R., \& Lushene, R. (1970). Manual for the State-Trait Anxiety Inventory. Palo Alto, CA: Consulting Psychologists Press.

Spinhoven, P., \& Linssen, C. G. (1991). Behavioral treatment of chronic low back pain: Relation of coping strategy to use outcome. Pain, 45, 29-34.

Stanton, A. L., Danoff-Burg, S., Cameron, C., Bishop, M., Collins, C. A., Kirk, S. B., Sworowski, L. A., \& Twillman, R. (2000). Emotionally expressive coping predicts psychological and physical adjustment to breast cancer. Journal of Consulting and Clinical Psychology, 68, 875-882.

Stevenson, M. K., Kanfer, F. H., \& Higgins, J. M. (1984). Effects of goal specificity and time cues on pain tolerance. Cognitive Therapy and Research, 8(4), 4.

Sullivan, M. J. L., Bishop, S. R., \& Pivik, J. (1995). The Pain Catastrophizing Scale: Development and Validation. Psychological Assessment, 7(4), 524-532.

Sullivan, M. J. L., Thorn, B., Haythornthwaite, J., Keefe, F. J., Martin, M., Bradley, L., \& Lefebvre, J. C. (2001). Theoretical perspectives on the relation between catastrophizing and pain. Journal of Clinical Psychology, 17, 52- 
64.

Suls, J., \& Fletcher, B. (1985). The relative efficacy of avoidant and nonavoidant coping strategies: A meta-analysis. Health Psychology, 4, 249-288.

Syrjala, K. L., Cummings, C., \& Donaldson, G. W. (1992). Hypnosis or cognitive behavioral training for the reduction of pain and nausea during cancer treatment: A controlled clinical trial. Pain, 48, 137-146.

Tennen, H., \& Affleck, G. (1999). Finding benefits in adversity. In C. R. Snyder (Ed.), Coping: The psychology of what works (pp. 279-304). New York: Oxford Press.

Terenius, L. (1981). Endorphins and pain. Frontiers of the Royal Society of London, A, 376, 35-60.

Thordason, D. S. (1993). Health anxiety and perceived vulnerability to illness. Unpublished data. University of British Columbia, Vancouver, B. C.

Thorn, B. E., Clements, K. L., Ward, L. C., Dixon, K. E., Kersh, B. C., Boothby, J. L., \& Chaplin, W. F. (2004). Personality factors in the explanation of sex differences in pain catastrophizing and response to experimental pain. Clinical Journal of Pain, 20(5), 275-282.

Tierney, A. M. (1995). Analysis of a new theory of hope and personality as measured by the California Psychological Inventory. Dissertation Abstracts, 55(10-B): 4616.

Tolle, T. R., Castro-Lopez, J. M., Evan, G., \& Zieglgansberger, W. (1991). C-fos 
induction in the spinal cord following noxious stimulations: Prevention by opiates but not by NMDA antagonists. In M. R. Bond, J. E. Charlton, \& C. J. Woolf (Eds.), Proceedings of the VIth World Congress on Pain (pp. 299-305). Amsterdam: Elsevier.

Tsao, J. C. I., Glover, D. A., Bursch, B., Ifekwunigwe, M., \& Zeltner, L. K. (2002). Laboratory pain reactivity and gender: Relationship to school nurse visits and school absences. Journal of Developmental and Behavioral Pediatrics, 23(4), 217-224.

Tsao, J. C. I., Myers, C. D., Craske, M. G., Bursch, B., Kim, S. C., \& Zeltzer, L. K. (2004). Roles of anticipatory anxiety and anxiety sensitivity in children's and adolescents' laboratory pain responses. Journal of Pediatric Psychology, 29(5), 379-388.

Turk, D. C. (1975). Cognitive control of pain. Unpublished master's thesis, University of Waterloo, Waterloo, Ontario, Canada.

Turk, D. C. (1977). A coping skills-training approach for the control of experimentally produced pain. Unpublished doctoral dissertation, University of Waterloo, Waterloo, Ontario, Canada.

Turk, D. C. (1990). Customizing treatment for chronic pain patient: Who, what, and why. Clinical Journal of Pain, 6, 255-270.

Turk, D. C., \& Kerns, R. D. (1983). Conceptual issues in the assessment of clinical pain. International Journal of Psychiatry Medicine, 13, 57-68.

Turk, D. C., Meichenbaum, D., \& Genest, M. (1983). Pain and behavioral medicine: 
A cognitive-behavioral perspective. New York: Guilford Press.

Turk, D. C., \& Melzack, R. (Eds.). (1992). Handbook of pain assessment. New York: The Guilford Press.

Turk, D. C., \& Rudy, T. E. (1992). Cognitive factors and persistent pain: A glimpse into Pandora's box. Cognitive Therapy and Research, 16, 99-122.

Turk, D. C., \& Rudy, T. E. (1990). Neglected factors in chronic pain treatment outcome studies—-referral patterns, failure to enter treatment, and attrition. Pain, 43, 7-25.

Turk, D. C., \& Rudy, T. E. (1991). Neglected topics in the treatment of chronic pain patients: Relapse, noncompliance, and adherence enhancement. Pain, 44, 528.

Vallis, T. M., \& Bucher, B. (1986). Self-efficacy as a predictor of behavior change: Interaction with type of training for pain tolerance. Cognitive Therapy and Research, 10, 79-94.

Vlaeyen, J. W. S., \& Morley, S. (2005). Cognitive-behavioral treatments for chronic pain: What works for whom? Clinical Journal of Pain, 21(1), 1-8.

Walach, H., \& Maidhoff, C. (1999). Placebo in clinical trials. In I. Kirsch (Ed.), How expectancies shape experience (pp. 321-332). Washington, D.C.: American Psychological Association.

Wall, P. D. (1989). Introduction. In P. D. Wall \& R. Melzack (Eds.), Textook of pain $\left(2^{\text {nd }}\right.$ ed.). Edinburgh: Churchill Livingston. 
Wall, P. D. (1991). Neurogenic pain syndromes and their management. In J. C. D. Wells \& C. J. Woolf (Eds.), Pain mechanisms and management (pp. 631643). Edinburgh: Churchill Livingstone.

Wall, P. D., \& Melzack, R. (Eds.). (1983). Textbook of pain ( $1^{\text {st }}$ ed.). Edinburgh: Churchill Livingstone.

Wall, P. D., \& Melzack, R. (1989). Why the definition of pain is crucial. In P. D. Wall \& R. Melzack (Eds.), Textbook of pain (2 ${ }^{\text {nd }}$ ed., pp. 11-38). Edinburgh: Churchill Livingstone.

Wall, P. D., \& Sweet, W. H. (1967). Temporary abolition of pain in man. Science, $155,108-109$.

Walsh, N. E., Schoenfeld, L., Ramamurthy, S., Hoffman, J. (1989). Normative model for cold pressor test. American Journal of Physiological Medicine and Rehabilitation, 68, 6-11.

Warwick, H. M., \& Salkovskis, P. M. (1990). Hypochondriasis. Behaviour Research and Therapy, 28(2), 105-117.

Watson, D., \& Clark, L. A. (1984). Negative affectivity: The disposition to experience aversive emotional states. Psychological Bulletin, 96, 465-490.

Watson, D., Clark, A. L., \& Tellegen, A. (1988). Development and validation of brief measures of positive and negative affect: The PANAS scales. Journal of Personality and Social Psychology, 54, 1063-1070. 
Wegner, D. M., Schneider, D., Carter, S. R., \& White, T. L. (1987). Paradoxical effects of thought suppression. Journal of Personality and Social Psychology, $53,5-13$.

Weinberger, J. (1995). Common factors in psychotherapy: The common factors dilemma. Clinical Psychology Science Practice, 2, 45-69.

Weinberger, J. \& Eig, A. (1999). Expectancies: The ignored common factor in psychotherapy. In I. Kirsch (Ed.), How expectancies shape experience (pp. 357-374). Washington, DC: American Psychological Association.

Weisenberg, M., Aviram, O., Wolf, Y., \& Raphaeli, N. (1984). Relevant and irrelevant anxiety in the reaction to pain. Pain, 20, 371-383.

Weisse, C. S., Foster, K. K., \& Fisher, E. A. (2005). The influence of experimenter gender and race on pain reporting: Does racial or gender concordance matter? Pain Medicine, 6(1), 80-87.

Wilcox, G. L. (1991). Excitatory neurotransmitters and pain. In M. R. Bond, J. E. Charlton, \& C. J. Woolf (Eds.), Proceedings of the VIth World Congress on pain (pp. 97-118). Amsterdam: Elsevier.

Williams, S. L., \& Kinney, P. J. (1991). Performance and nonperformance strategies for coping with acute pain: The role of perceived self-efficacy, expected outcomes, and attention. Cognitive Therapy and Research, 15(1), 1-19.

Willis, W. D. (1985). The pain system-The neural basis of nonceptive transmission in the mammalian nervous system. Basel: Karger Press.

Willis, W. D., Jr. (1995). From nociceptor to cortical activity. In B. Bromm \& J. E. 
Desmedt (Eds.), Pain and the brain: From nociceptor to cognition (pp. 89104). New York: Raven Press, Ltd.

Willoughby, S. G., Hailey, B. J., Mulkana, S., \& Rowe, J. (2002). The effect of laboratory-induced depressed mood state on responses to pain. Behavioral Medicine, 28(1), 23-31.

Wolf, S. (1950). Effects of suggestion and conditioning on the action of chemical agents in human subjects-the pharmacology of placebos. Journal of Clinical Investigation, 29, 100.

Wolf, S., \& Hardy, J. D. (1941). Studies on pain. Observations on pain due to local cooling and on factors involved in the "cold pressor" effect. Journal of Clinical Investigations, 20, 521-533.

Wolf, S., \& Hardy, J. D. (1943). Studies on pain: Observations on pain due to local cooling on factors involved in the "cold pressor" effect. Research Publications of the Association for Research in Nervous and Mental Diseases, $23,123-142$.

Woolf, C. J. (1991). Central mechanisms of acute pain. In M. R. Bond, J. E. Charlton, \& C. J. Woolf (Eds.), Proceedings of the VIth World Congress on Pain (pp. 25-34). Amsterdam: Elsevier.

Worthington Jr., E. L., Hight, T. L., Ripley, J. S., Perrone, K. M., Kurusu, T. A., \& Jones, D. R. (1997). Strategic hope-focused relationship-enrichment counseling with individuals. Journal of Counseling Psychology, 44, 381-389.

Wright, J., Thase, M., Beck, A., \& Ludgate, J. W. (1993). Cognitive therapy with 
inpatients: Developing a cognitive milieu. New York: Guilford Press.

Zautra, A. J., Burleson, M. H., Smith, C. A., Blalock, S. J., Wallston, K. A., Devellis, R. F., Develis, B. M., \& Smith, T. W. (1995). Arthritis and perceptions of quality of life: An examination of positive and negative affect in rheumatoid arthritis patients. Health Psychology, 14, 399-408.

Zautra, A. J., Potter, P. T., \& Reich, J. W. (1997). The independence of affects is context-dependent: An integrative model of the relationship between positive and negative affect. In M. P. Lawton (Series Ed.) \& K. W. Schale \& M. P. Lawton (Vol. Eds.), Annual review of gerontology and geriatrics: Vol. 17. Focus on adult development (pp. 75-103). New York: Springer.

Zautra, A. J., Reich, J. W., Davis, M. C., Nicolson, N. A., \& Potter, P. T. (2000). The role of stressful events in the independence of affective states: Evidence from field and experimental studies. Journal of Personality, 68, 927-950.

Zitman, F. G., van Dyck, R., Spinhoven, P. E., Linssen, A. C., \& Corrie, G. H. (1992). Hypnosis and autogenic training in the treatment of tension headaches: A two-phase constructive design study with follow-up. Journal of Psychosomatic Research, 36, 219-228. 


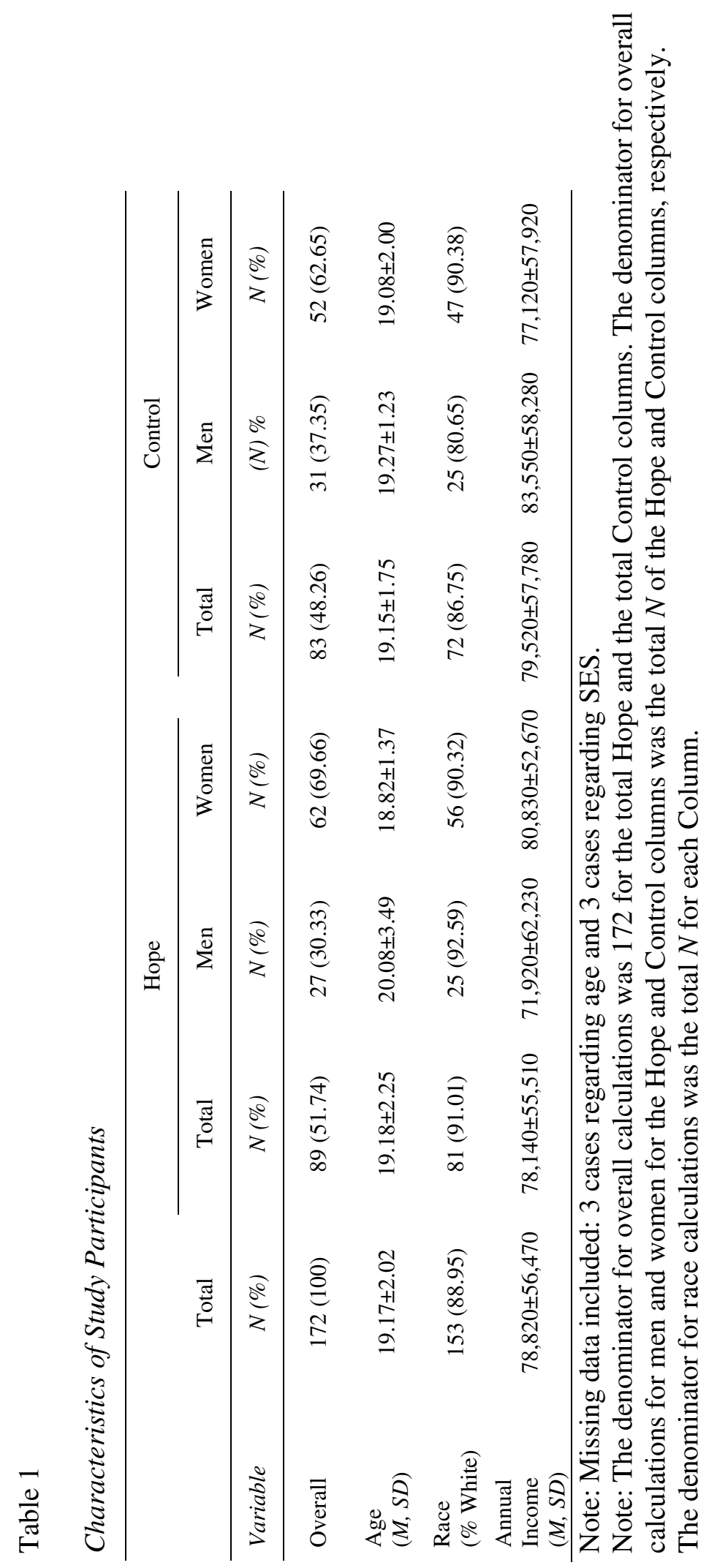




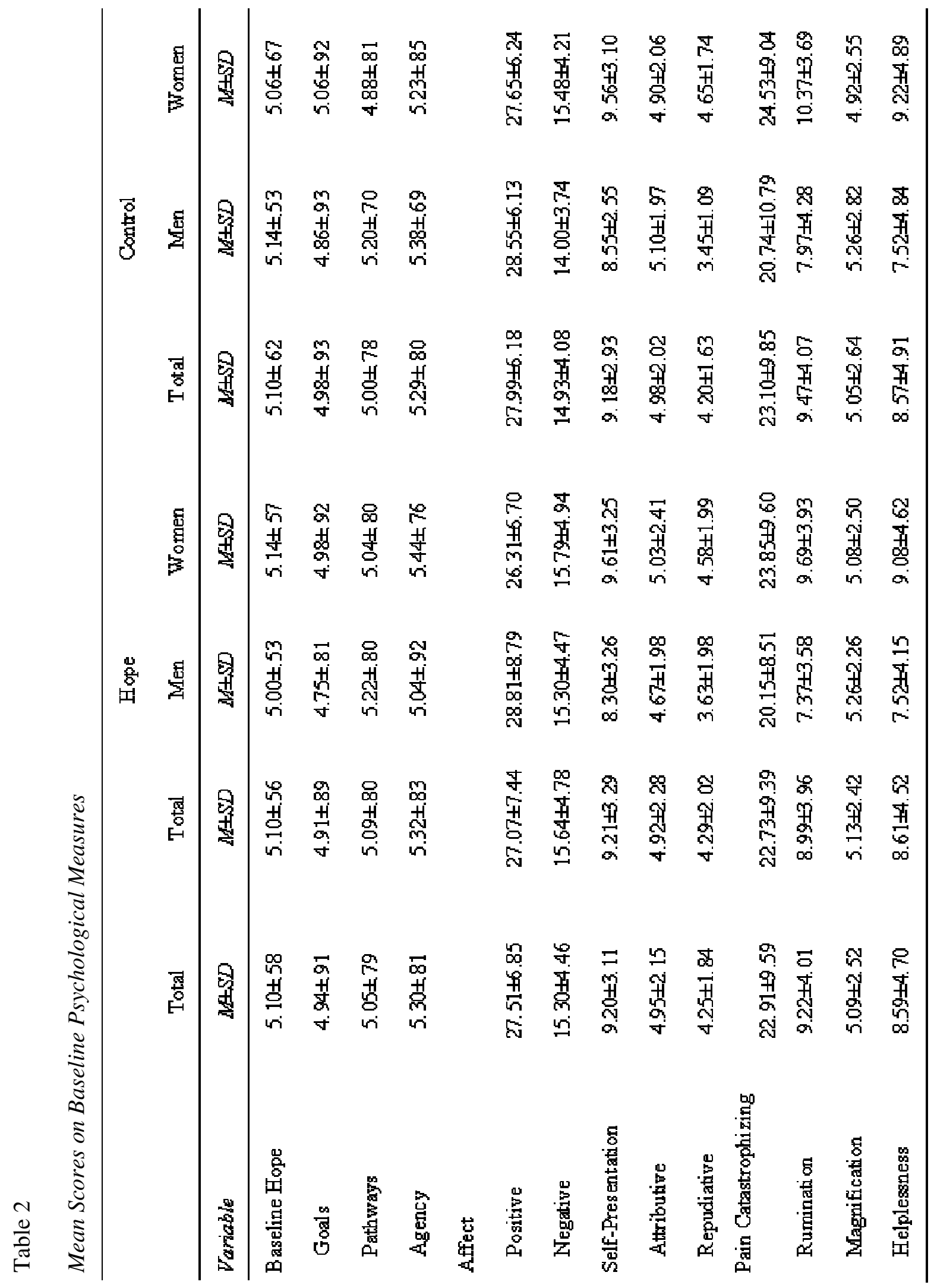




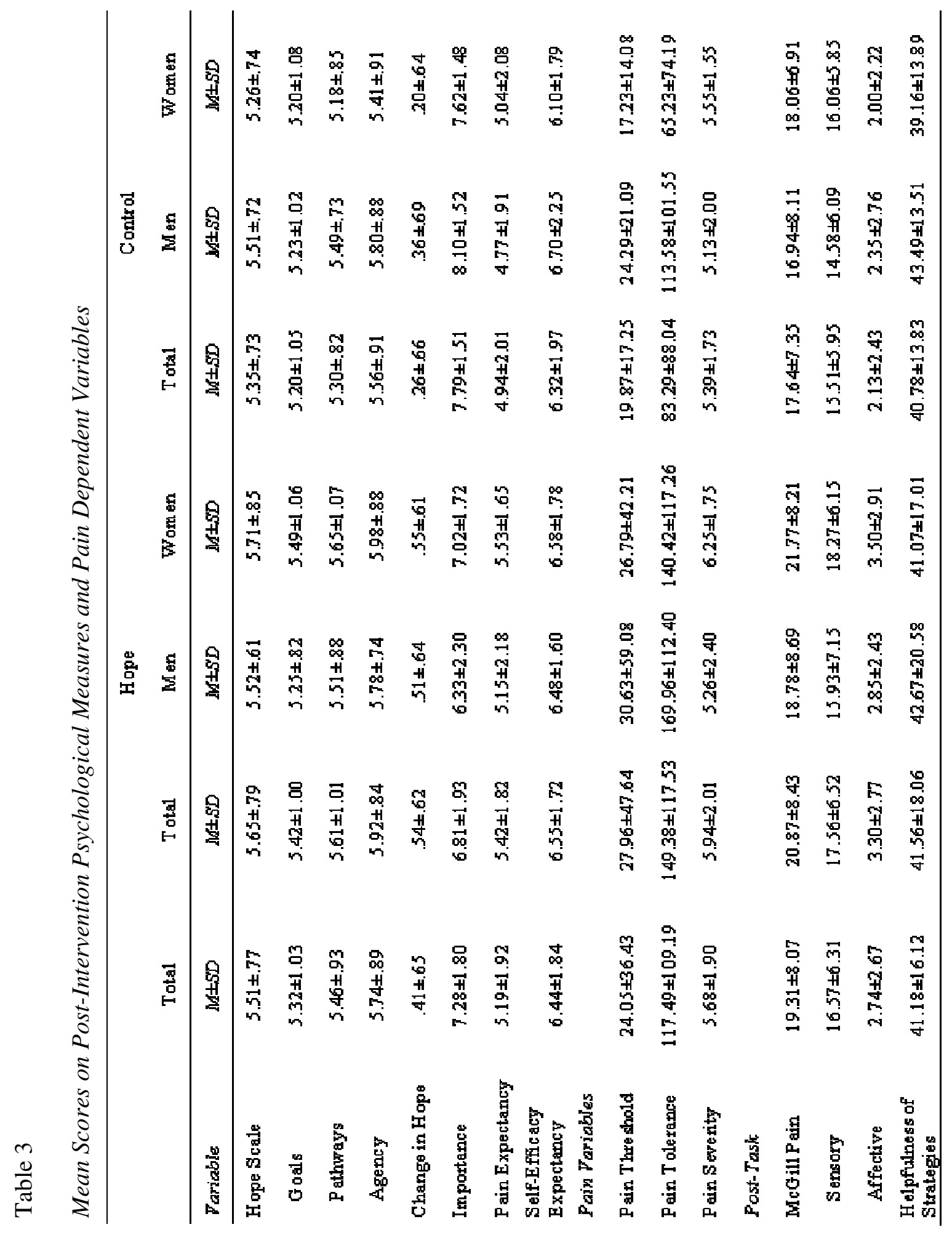


Table 4

Correlations of Hope Scale Scores to Demographic and Psychological Variables

\begin{tabular}{|c|c|c|c|c|c|c|}
\hline \multirow[b]{2}{*}{ Variable } & \multicolumn{2}{|c|}{ Baseline Hope } & \multicolumn{2}{|c|}{$\begin{array}{c}\text { Post-Intervention } \\
\text { Hope }\end{array}$} & \multicolumn{2}{|c|}{ Change in Hope } \\
\hline & $r$ & $p$ & $r$ & $p$ & $r$ & $p$ \\
\hline \multicolumn{7}{|l|}{ Ancillary Variables } \\
\hline Age & -.03 & .68 & -.02 & .77 & .002 & .98 \\
\hline Year in school & -.11 & .16 & -.01 & .94 & .10 & .22 \\
\hline \multicolumn{7}{|l|}{ Dependent Variables } \\
\hline Pain threshold & -.09 & .23 & .05 & .56 & .14 & .06 \\
\hline Pain tolerance & -.08 & .31 & .02 & .84 & .10 & .22 \\
\hline Pain severity & .10 & .22 & .09 & .23 & .03 & .73 \\
\hline \multicolumn{7}{|l|}{ Psychological Measures } \\
\hline Positive affect & -.03 & .65 & .19 & .01 & .24 & .001 \\
\hline Negative affect & -.21 & .005 & -.18 & .02 & -.03 & .69 \\
\hline Self-presentation & .33 & $<.001$ & .38 & $<.001$ & .15 & .06 \\
\hline Attributive & .36 & $<.001$ & .37 & $<.001$ & .12 & .11 \\
\hline Repudiative & .14 & .06 & .21 & .006 & .10 & .20 \\
\hline Pain Catastrophization & -.16 & .045 & -.13 & .096 & -.02 & .80 \\
\hline Rumination & -.11 & .15 & -.05 & .54 & .04 & .64 \\
\hline Magnification & -.13 & .09 & -.17 & .02 & -.09 & .23 \\
\hline Helplessness & -.15 & .05 & -.13 & .10 & -.02 & .78 \\
\hline Importance ratings & .20 & .009 & .14 & .07 & .03 & .75 \\
\hline Pain expectancy & -.07 & .37 & -.03 & .71 & .02 & .80 \\
\hline Self-efficacy expectancy & .10 & .19 & .18 & .02 & .12 & .13 \\
\hline SMPQ score & -.02 & .84 & .08 & .27 & .11 & .16 \\
\hline Sensory & -.02 & .81 & .08 & .31 & .11 & .18 \\
\hline Affective & -.002 & .98 & .07 & .36 & .08 & .29 \\
\hline Helpfulness of strategies & -.05 & .57 & .13 & .09 & .19 & .02 \\
\hline
\end{tabular}


Table 5

Correlations of Pain Threshold, Tolerance, and Severity to Demographic and Psychological Variables

\begin{tabular}{|c|c|c|c|c|c|c|}
\hline \multirow[b]{2}{*}{ Variable } & \multicolumn{2}{|c|}{ Pain Threshold } & \multicolumn{2}{|c|}{ Pain Tolerance } & \multicolumn{2}{|c|}{ Pain Severity } \\
\hline & $r$ & $p$ & $r$ & $p$ & $r$ & $p$ \\
\hline Age & .16 & .045 & .29 & $<.001$ & -.16 & .04 \\
\hline Year in school & .24 & .001 & .20 & .008 & -.15 & .06 \\
\hline $\begin{array}{l}\text { Annual household } \\
\text { income }\end{array}$ & -.02 & .82 & -.08 & .31 & .17 & .03 \\
\hline Distance around hand & .08 & .30 & .16 & .04 & -.15 & .045 \\
\hline Water temperature & .11 & .15 & .16 & .04 & -.21 & .01 \\
\hline \multicolumn{7}{|l|}{ Dependent Variables } \\
\hline Pain threshold & -- & -- & .37 & $<.001$ & -.27 & $<.001$ \\
\hline Pain tolerance & .37 & $<.001$ & -- & -- & -.36 & $<.001$ \\
\hline Pain severity & -.27 & $<.001$ & -.36 & $<.001$ & -- & -- \\
\hline \multicolumn{7}{|l|}{ Psychological Measures } \\
\hline Post-Intervention Hope & .05 & .56 & .02 & .84 & .09 & .23 \\
\hline Goals & .05 & .54 & -.03 & .69 & .08 & .28 \\
\hline Pathways & .06 & .47 & .04 & .62 & .07 & .34 \\
\hline Agency & .01 & .94 & .04 & .63 & .07 & .38 \\
\hline Positive affect & .15 & .05 & .01 & .87 & -.03 & .69 \\
\hline Negative affect & .02 & .77 & .01 & .91 & .13 & .09 \\
\hline Self-Presentation & .04 & .64 & -.11 & .14 & .09 & .25 \\
\hline Attributive & .08 & .29 & -.02 & .78 & .02 & .82 \\
\hline Repudiative & -.03 & .65 & -.17 & .03 & .13 & .09 \\
\hline Pain Catastrophization & .01 & .99 & .02 & .77 & .23 & .003 \\
\hline Rumination & -.07 & .35 & -.05 & .51 & .22 & .005 \\
\hline Magnification & .05 & .53 & .06 & .43 & .18 & .02 \\
\hline Helplessness & .04 & .65 & .06 & .46 & .18 & .02 \\
\hline Importance ratings & .06 & .46 & -.01 & .95 & -.01 & .90 \\
\hline Pain expectancy & -.14 & .07 & .01 & .89 & .38 & $<.001$ \\
\hline Self-efficacy expectancy & .19 & .01 & .12 & .11 & -.07 & .40 \\
\hline SMPQ score & -.14 & .06 & -.11 & .16 & .47 & $<.001$ \\
\hline Sensory & -.16 & .04 & -.12 & .13 & .43 & $<.001$ \\
\hline Affective & -.07 & .37 & -.05 & .56 & .39 & $<.001$ \\
\hline Helpfulness of strategies & .14 & .07 & .38 & $<.001$ & -.34 & $<.001$ \\
\hline
\end{tabular}




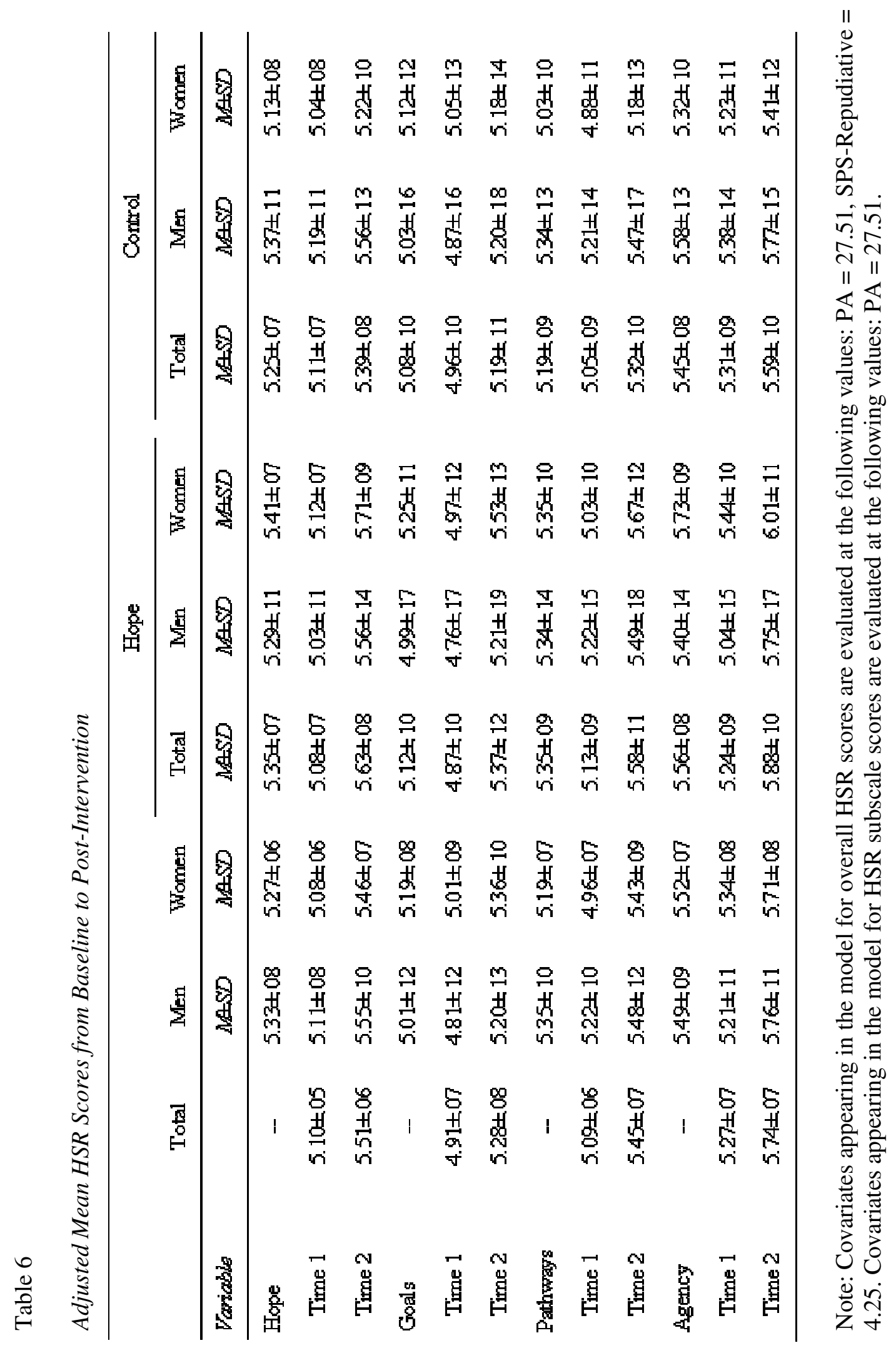




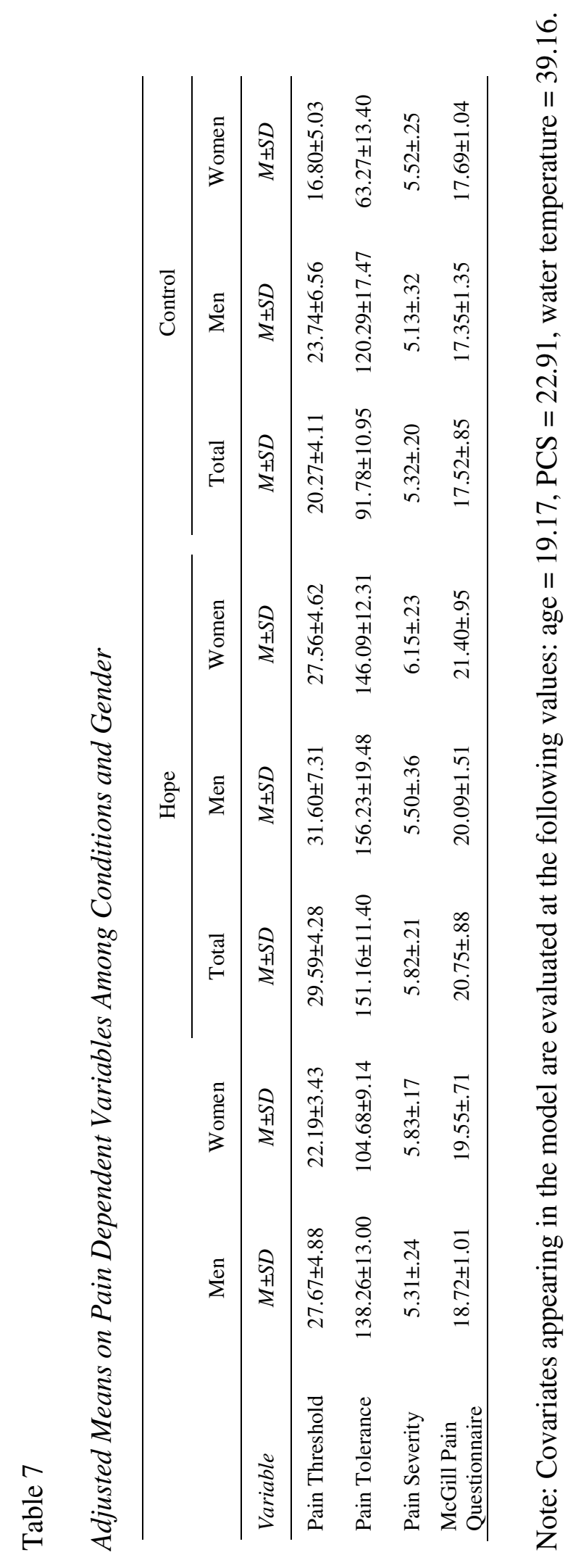


Figure 1. Diagram illustrating the ascending system and descending systems.

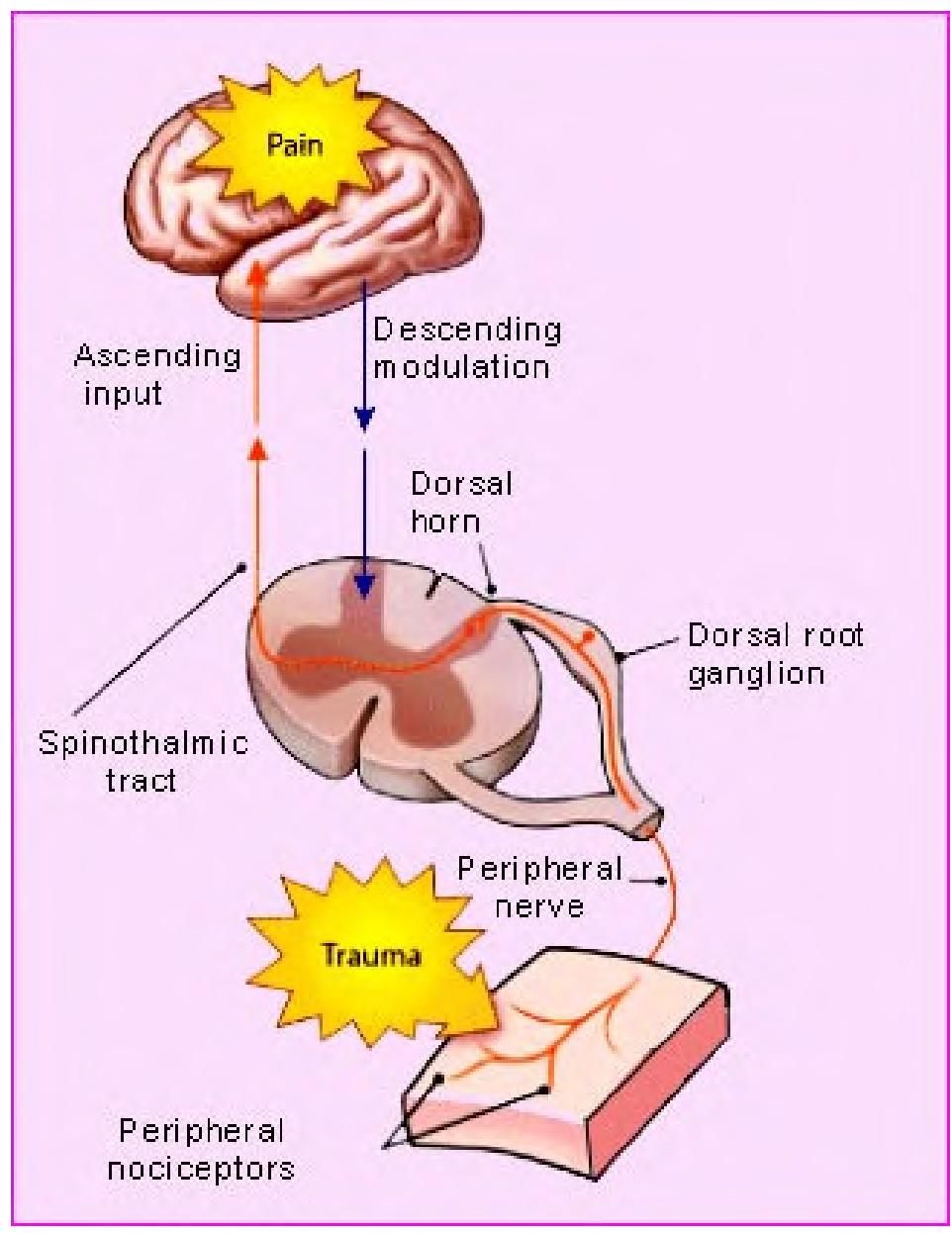

http://hsc.uwe.ac.uk/pmm/physiology/processing.asp 
Figure 2. Recruitment flowchart.

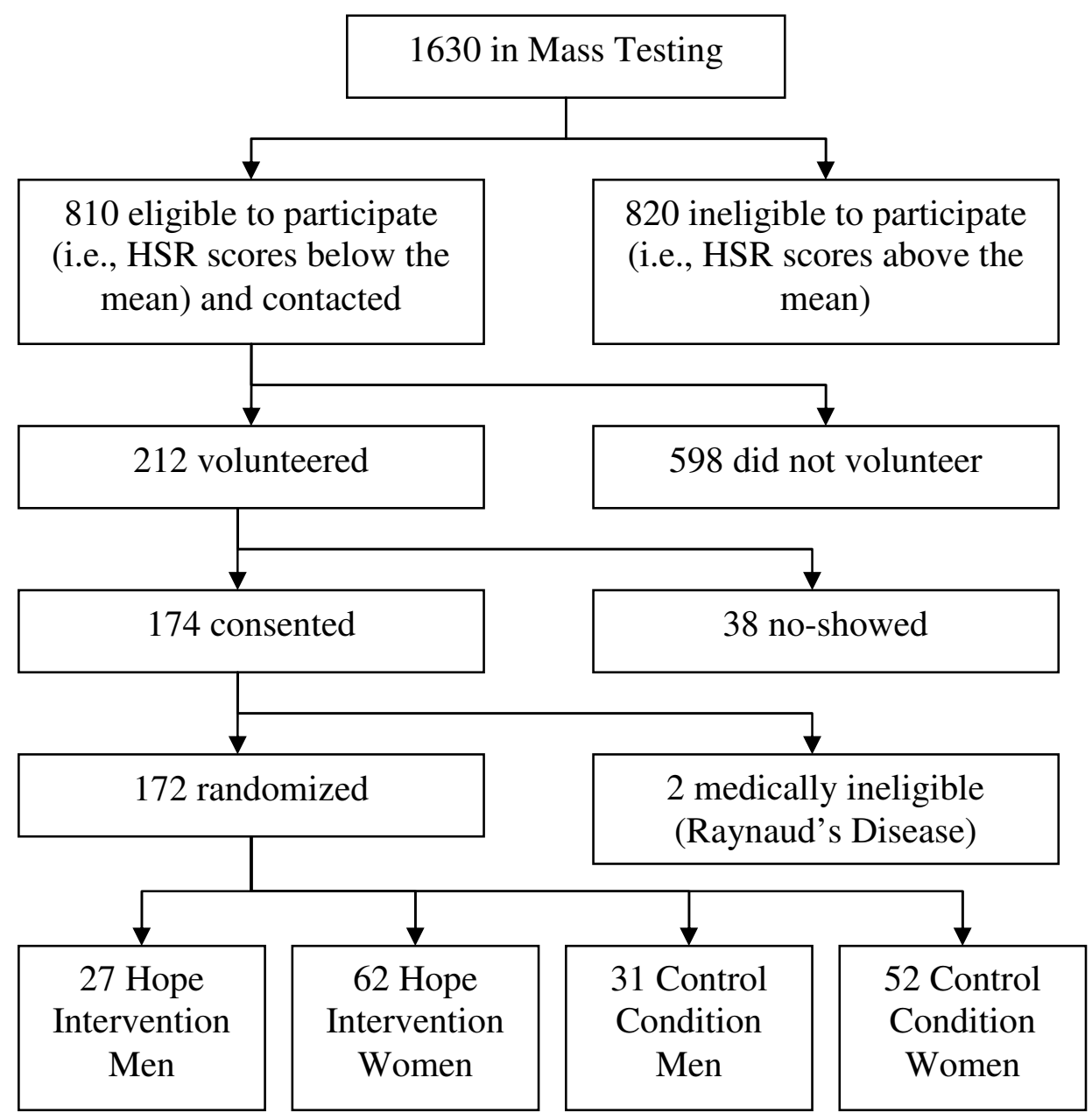




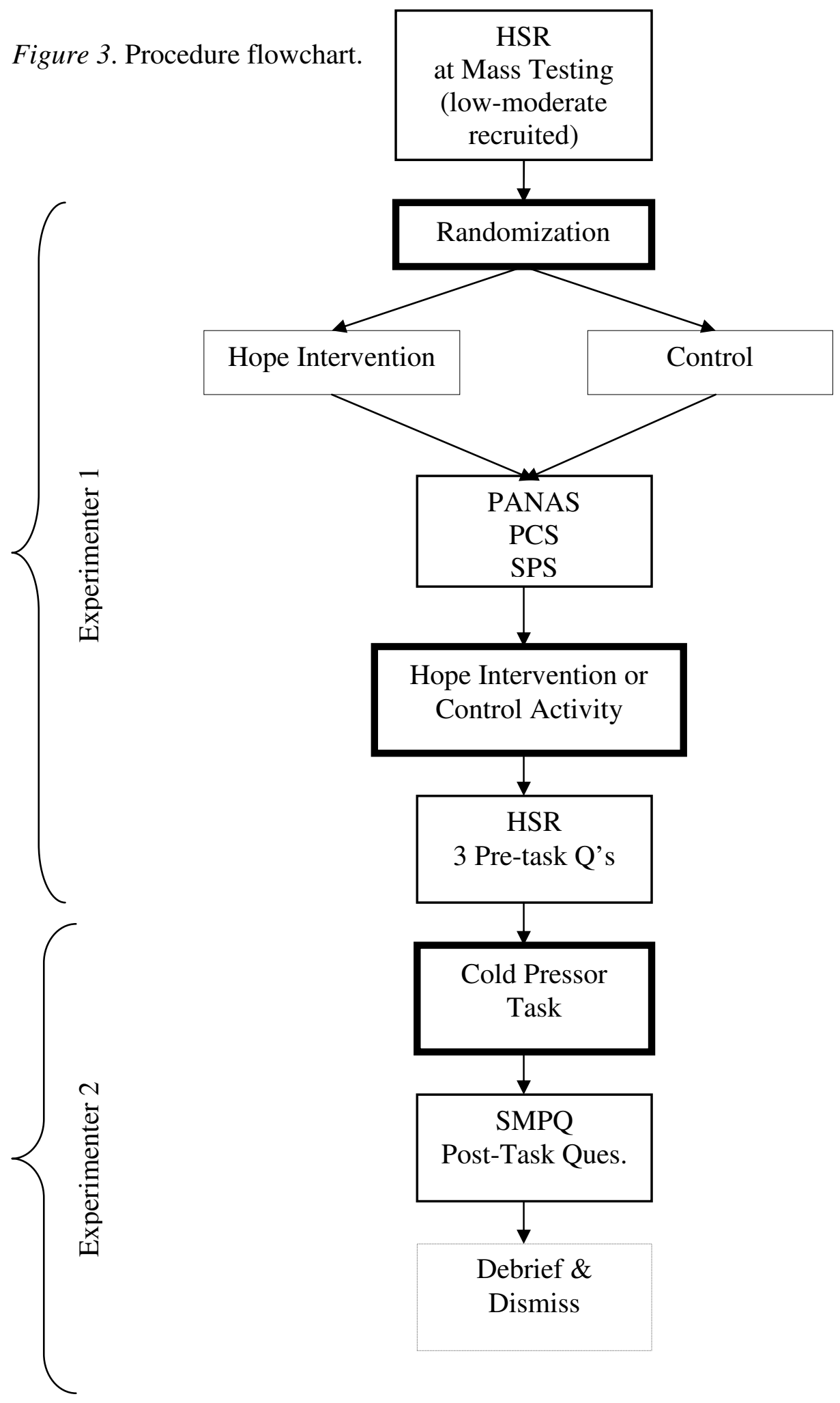


Figure 4. Line graph illustrating the interaction effect of gender $\mathrm{x}$ condition on change in hope.

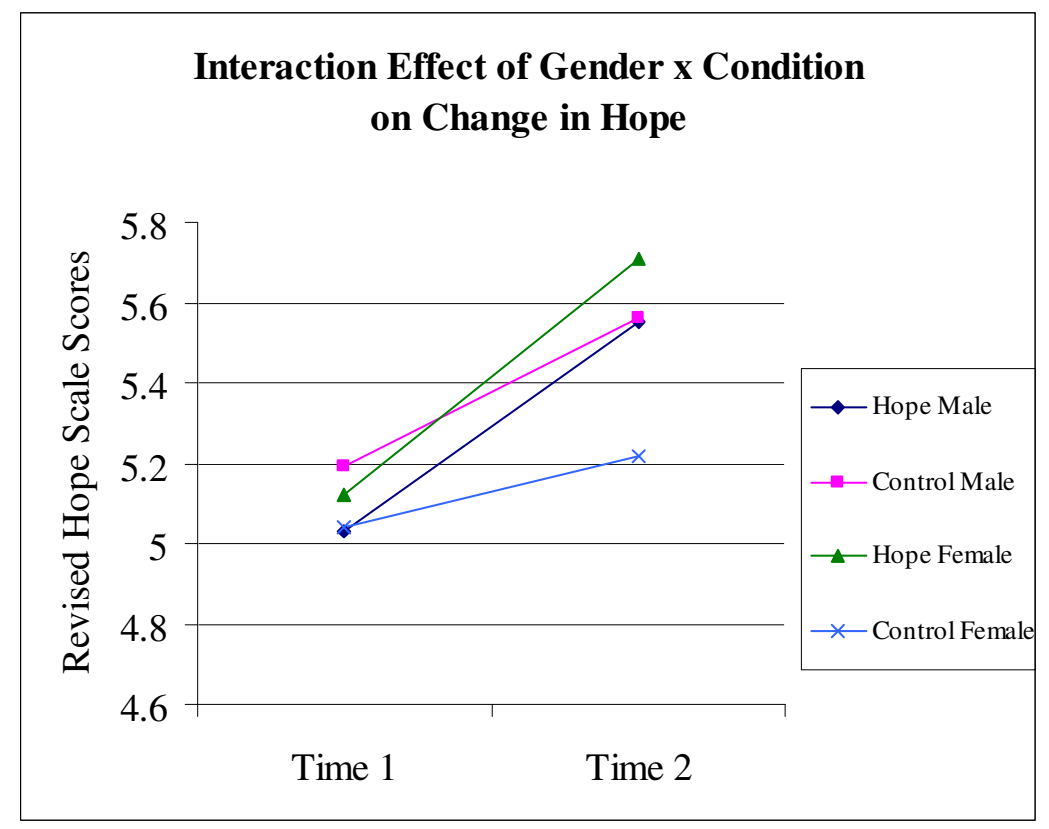


Figure 5. Bar graph illustrating pain tolerance among the condition x gender groups.

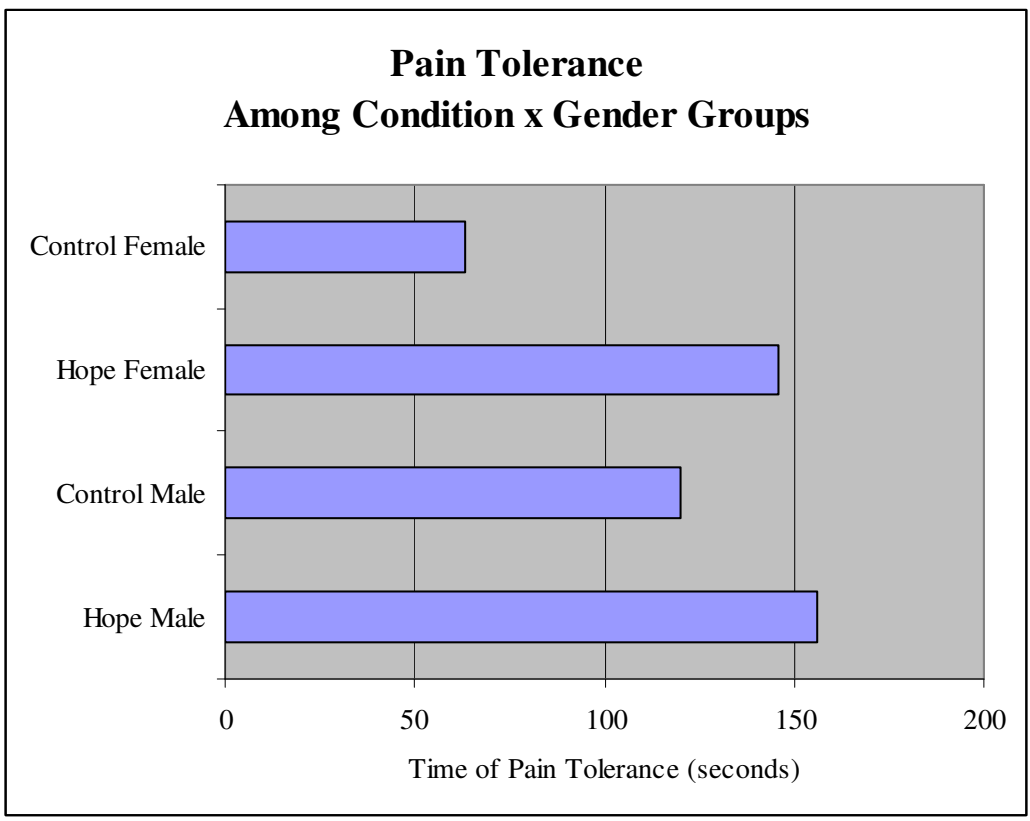


Figure 6. Line graph illustrating the interaction effect of gender $\mathrm{x}$ experimenter 2 gender on pain tolerance.

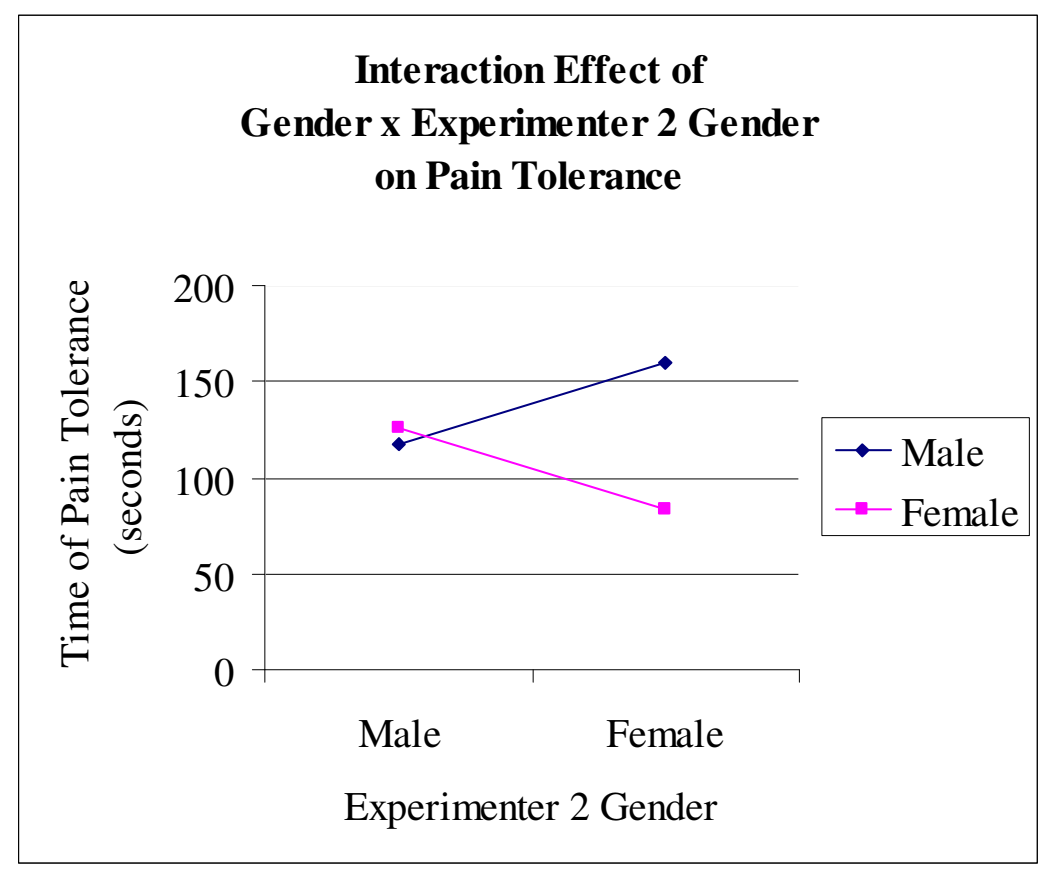


Figure 7. Line graph illustrating the interaction effect of gender $\mathrm{x}$ experimenter 2 gender on pain severity ratings.

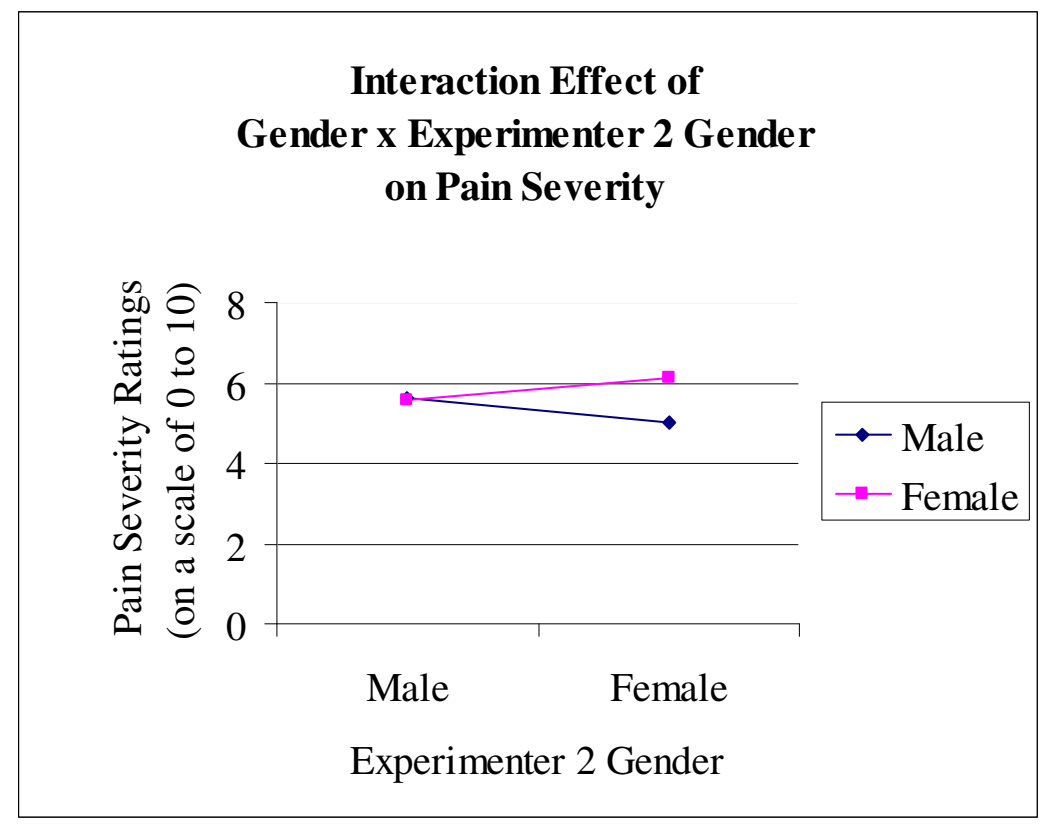




\section{Appendix A: E-mail Recruitment Message}

SUBJECT: Psych 104 Experiment for 2 credits

As a result of your mass testing data, your participation is requested in a study for 2 credits entitled "Berg Interventions." Please log into the sona systems site, click on "Berg Interventions", enter the password "Berg", and sign up for a time slot. Thanks for your time!

http://ku.sona-systems.com/

Sincerely,

Carla Berg 
Appendix B: Revised Trait Hope Scale

\section{Goals Scale}

Directions: Read each item carefully. Using the scale shown below, please select the number that best describes YOU and put that number in the blank provided.

\begin{tabular}{|c|c|c|c|c|c|c|c|}
\hline 1 & 2 & 3 & 4 & 5 & 6 & 7 & 8 \\
$\begin{array}{c}\text { Definitely } \\
\text { False }\end{array}$ & $\begin{array}{c}\text { Mostly } \\
\text { False }\end{array}$ & $\begin{array}{c}\text { Somewhat } \\
\text { False }\end{array}$ & $\begin{array}{c}\text { Slightly } \\
\text { False }\end{array}$ & $\begin{array}{c}\text { Slightly } \\
\text { True }\end{array}$ & $\begin{array}{c}\text { Somewhat } \\
\text { True }\end{array}$ & $\begin{array}{c}\text { Mostly } \\
\text { True }\end{array}$ & $\begin{array}{c}\text { Definitely } \\
\text { True }\end{array}$ \\
\hline
\end{tabular}

1. I have trouble getting what I want in life

2. I have found that I can overcome challenges

3. I clearly define the goals that I pursue

4. I'm not good at planning how to get things done

5. I can think of many ways to get out of a jam

6. I have many goals that I am pursuing

7. I prefer easy goals over hard goals

8. I have what it takes to get the job done

9. I have difficulty finding ways to solve problems

10. I do not have very many goals

11. I give up easily

12. I'm not good at coming up with solutions

13. I'm good at coming up with new ways to solve problems

14. I'm successful at getting what I want

15. I create alternate plans when blocked

16. I do not try hard enough to overcome challenges

17. I go after goals that are difficult and challenging

18. I do not care about the goals I am pursuing

From Shorey, H. S., \& Snyder, C. R. (July, 2004). Exploring the possibility of a revised Hope Scale. Poster presented at the American Psychological Association Convention, Honolulu, Hawaii.

Goals items $=3,6,7^{*}, 10^{*}, 17,18^{*}$

Pathways items $=4^{*}, 5,9^{*}, 12^{*}, 13,15$

Agency items $=1 *, 2,8,11^{*}, 14,16^{*}$

* Item is reverse scored. 
Appendix C: Positive and Negative Affect Schedule

\section{PANAS}

This scale consists of a number of words that describe different feelings and emotions. Read each item and then mark the appropriate answer on the separate answer sheet. Indicate to what extent you feel this way right now, that is, how you feel at this very moment. Use the following scale as you record your answers.

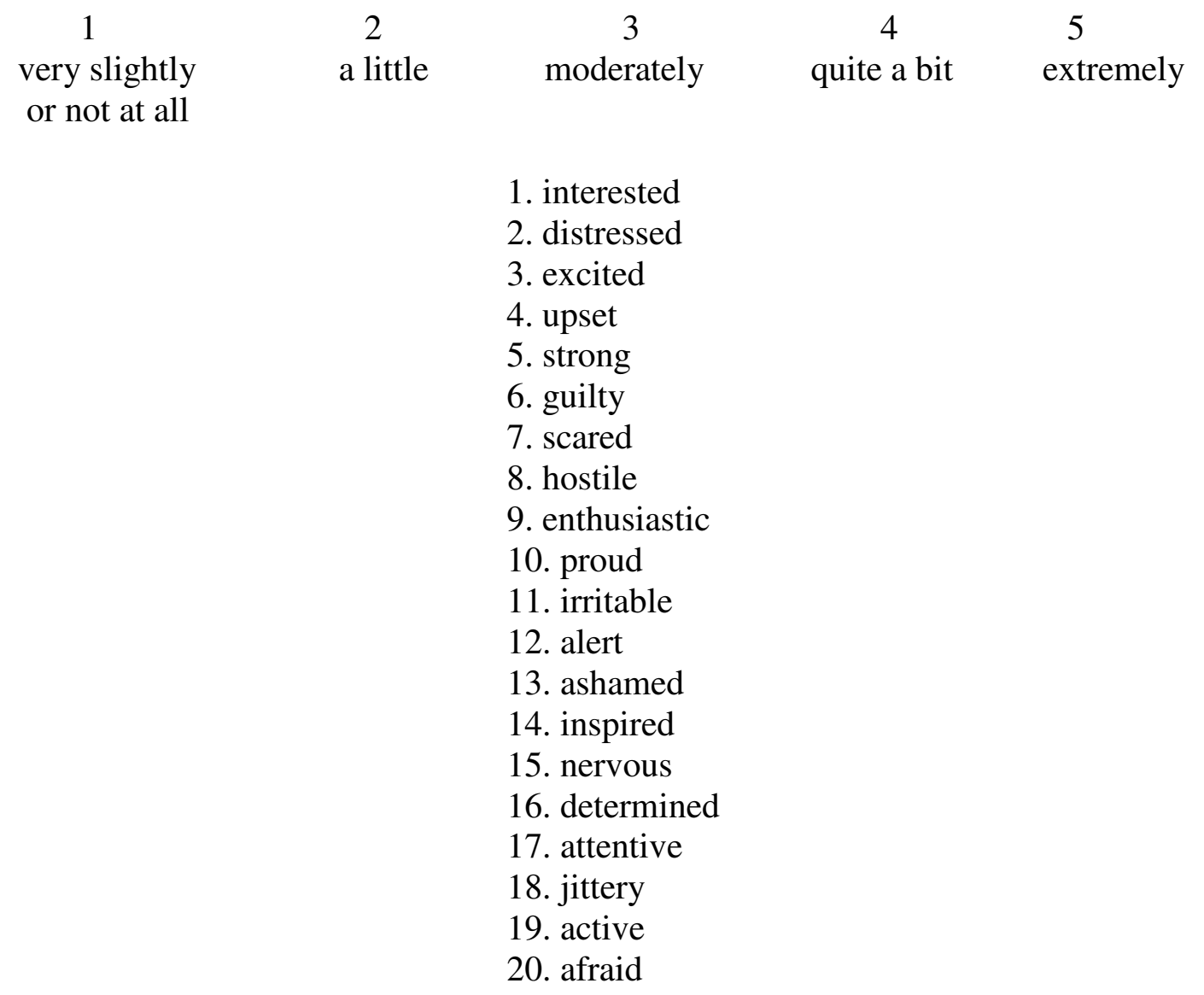

From Watson, D., Clark, A. L., \& Tellegen, A. (1988). Development and validation of brief measures of positive and negative affect: the PANAS scales. Journal of Personality and Social Psychology, 54, 1063-1070.

Scoring: Positive affect scores are determined by summing items 1, 3, 5, 9, 10, 12, 14, 16,17 , and 19. Negative affect scores are determined by summing items $2,4,6,7,8$, $11,13,15,18$, and 20. 


\section{Appendix D: Self-Presentation Scale}

\section{SPS}

Instructions: For the following statements, think about your life, and indicate whether the particular statement is true or false. For true, circle the "T", and for false circle the "F."

\begin{tabular}{|c|c|c|}
\hline & $\mathrm{F}$ & 1. I would lie to get out of trouble. \\
\hline & $\mathrm{F}$ & 2. All of my successes can be explained by my abilities. \\
\hline $\mathrm{T}$ & $\mathrm{F}$ & 3. I sometimes think about attacking others physically. \\
\hline $\mathrm{T}$ & $\mathrm{F}$ & 4. Before voting, I thoroughly investigate the issues and candidates. \\
\hline $\mathrm{T}$ & $\mathrm{F}$ & 5. My solutions to problems are always original and effective. \\
\hline $\mathrm{T}$ & $\mathrm{F}$ & $\begin{array}{l}\text { 6. I evaluate the physical attractiveness of persons the same sex as } \\
\text { myself. }\end{array}$ \\
\hline $\mathrm{T}$ & $\mathrm{F}$ & 7. I argue only when I know I'm right. \\
\hline $\mathrm{T}$ & $\mathrm{F}$ & 8. I am always on time for appointments. \\
\hline $\mathrm{T}$ & $\mathrm{F}$ & 9. Pornography arouses me. \\
\hline $\mathrm{T}$ & $\mathrm{F}$ & 10. I am completely happy with the way my life is going. \\
\hline $\mathrm{T}$ & $\mathrm{F}$ & 11. When angry, I sometimes feel like smashing things. \\
\hline $\mathrm{T}$ & $\mathrm{F}$ & 12. I sometimes avoid people I not wish to speak to. \\
\hline $\mathrm{T}$ & $\mathrm{F}$ & 13. I always enjoy accepting new responsibilities. \\
\hline $\mathrm{T}$ & $\mathrm{F}$ & 14. In my private thoughts, I laugh at the incompetencies of others. \\
\hline $\mathrm{T}$ & $\mathrm{F}$ & 15. I always help people who are lonely. \\
\hline $\mathrm{T}$ & $\mathrm{F}$ & 16. I am always courteous, even to disagreeable people. \\
\hline $\mathrm{T}$ & $\mathrm{F}$ & 17. I feel sad sometimes. \\
\hline $\mathrm{T}$ & $\mathrm{F}$ & 18. I feel sexually attracted toward many people. \\
\hline $\mathrm{T}$ & $\mathrm{F}$ & 19. I worry about my own death. \\
\hline & $\mathrm{F}$ & 20. I completely control my own destiny. \\
\hline
\end{tabular}

From Roth, D. L., Harris, R. H., \& Snyder, C. R. (1988). An individual differences measure of attributive and reputative tactics of favorable self-presentation. Journal of Social and Clinical Psychology, 2, 159-170.

Scoring: Attributive self-presentation is measured by summing the "Trues" to items 2 , $4,5,7,8,10,13,15,16$, and 20 . Repudiative self-presentation is measured by summing the "Falses" to items 1, 3, 6, 9, 11, 12, 14, 17, 18, and 19. The total selfpresentation score is the sum of the attributive and repudiative scores. 


\section{Appendix E: The Pain Catastrophizing Scale}

\section{PCS}

Please reflect on past painful experiences. Please indicate the degree to which you experienced each of the following thoughts or feelings when experiencing pain on the following:

$0=$ not at all

$1=\mathrm{a}$ little of the time

$2=$ some of the time

$3=$ most of the time

$4=$ all the time

1. I worry all the time about whether the pain will end.

2. I feel I can't go on.

3. It's terrible and I think it's never going to get any better.

4. It's awful and I feel that it overwhelms me.

5. I feel I can't stand it any more.

6. I become afraid that the pain may get worse.

7. I think of other painful experiences.

8. I anxiously want the pain to go away.

9. I can't seem to keep it out of my mind.

10. I keep thinking about how much it hurts.

11. I keep thinking about how badly I want the pain to stop.

12. There is nothing I can do to reduce the intensity of the pain.

13. I wonder whether something serious may happen.

From Sullivan, M. J. L., Bishop, S. R., \& Pivik, J. (1995). The Pain Catastrophizing Scale: Development and Validation. Psychological Assessment, 7(4), 524-532.

Scoring:

Rumination: 8, 9, 10, 11

Magnification: 6, 7, 13

Helplessness: 1, 2, 3, 4, 5, 12 


\section{Appendix F: Short-form McGill Pain Questionnaire}

\section{SMPQ}

Use the following scale of 0 to 3 to describe the extent to which you experienced the cold pressor pain as feeling like each of the adjectives below.

$$
\begin{aligned}
& 0=\text { None } \\
& 1=\text { Mild } \\
& 2=\text { Moderate } \\
& 3=\text { Severe }
\end{aligned}
$$

For example, if you experienced the pain as severely throbbing, you would give it a 3. If you felt no throbbing, you would give it a 0 .

1. Throbbing

2. Shooting

3. Stabbing

4. Sharp

5. Cramping

6. Gnawing

7. Hot-burning

8. Aching

9. Heavy

10. Tender

11. Splitting

12. Tiring-exhausting

13. Sickening

14. Fearful

15. Punishing-cruel

Rank the overall pain that you experienced during your participation in the cold pressor task using the following scale by circling the corresponding number:

No Pain Worst Possible Pain

$\begin{array}{ll}0 & \text { No Pain } \\ 1 & \text { Mild } \\ 2 & \text { Discomforting } \\ 3 & \text { Distressing } \\ 4 & \text { Horrible } \\ 5 & \text { Excruciating }\end{array}$

From Melzack, R. (1987). The short-form McGill Pain Questionnaire. Pain, 30, 191197.

Scoring: Descriptors 1-11 represent the sensory dimensions of the pain experience and 12-15 represent the affective dimension. Scores are determined based on intensity and number of descriptors endorsed. 


\section{Appendix G: Post-Task Questionnaire}

\section{$\underline{\text { Part A }}$}

\section{Post-Task Questionnaire}

1. How cold do you think the water was?

degrees Fahrenheit

2. On a scale of 0 to 10 , with 0 being "no pain at all" and 10 being "the worst pain I ever experienced," how would you rate the overall pain you experienced during the task?

$\begin{array}{lllllllllll}0 & 1 & 2 & 3 & 4 & 5 & 6 & 7 & 8 & 9 & 10\end{array}$

3. On a scale of 0 to 10 with 0 being "not at all important" and 10 being "extremely important," how important was doing well on the task for you?

$\begin{array}{lllllllllll}0 & 1 & 2 & 3 & 4 & 5 & 6 & 7 & 8 & 9 & 10\end{array}$

4. On a scale of 0 to 10 with 0 being "I didn't try at all" and 10 being "I tried as hard as I could," how hard did you try on this task?

$\begin{array}{lllllllllll}0 & 1 & 2 & 3 & 4 & 5 & 6 & 7 & 8 & 9 & 10\end{array}$

5. On a scale of 0 to 10 with 0 being "I didn't use any of the information presented before the task" and 10 being "I used the information presented before the task as much as I possibly could," how much did you use the information presented prior to the task?

$\begin{array}{lllllllllll}0 & 1 & 2 & 3 & 4 & 5 & 6 & 7 & 8 & 9 & 10\end{array}$

\section{$\underline{\text { Part } B}$}

We are interested in the number of ways that you can come up for coping with the pain of the cold water that you just experienced. After the following numbers, please briefly list any strategy that you used to deal with pain in the experiment. (You do not need to fill all 10 blanks.) Then, go back and beside each rate how helpful you found that strategy to be using the following scale:

$$
\begin{aligned}
& 1=\text { not helpful } \\
& 2=\text { slightly helpful } \\
& 3=\text { somewhat helpful } \\
& 4=\text { moderately helpful } \\
& 5=\text { more than moderately helpful } \\
& 6=\text { fairly helpful } \\
& 7=\text { very helpful } \\
& 8=\text { extremely helpful } \\
& 9=\text { the most helpful }
\end{aligned}
$$


1.

2.

3.

4.

5.

6.

7.

8.

9.

10.

On the same 1 to 9 scale above, rank the helpfulness of the following strategies in your coping with the pain.

When I felt the pain of the cold water...

1. I tried to feel distant from the pain, almost as if the pain was in somebody else's body.

2. I don't think of it as pain but rather as a dull or warm feeling.

3. I just thought of it as some other sensation, such as numbness.

4. I tried not to think of it as my body, but rather as something separate from me.

5. I didn't think about the pain.

6. I told myself it doesn't hurt.

7. I didn't pay any attention to the pain.

8. I pretended it was not there.

9. I imagined that the pain was outside of my body.

10. I ignored it. 
Appendix H: Answer Sheet

Demographics Questionnaire

Name

1. Year in School (circle one): FR
Phone \#

SO

$\mathrm{JR}$

SR

GR

2. Gender (circle one): $\quad M \quad F$

3. Age

4. Race (circle one): Caucasian African American Asian American Hispanic Other

5. SES (indicate your approximate annual household income):

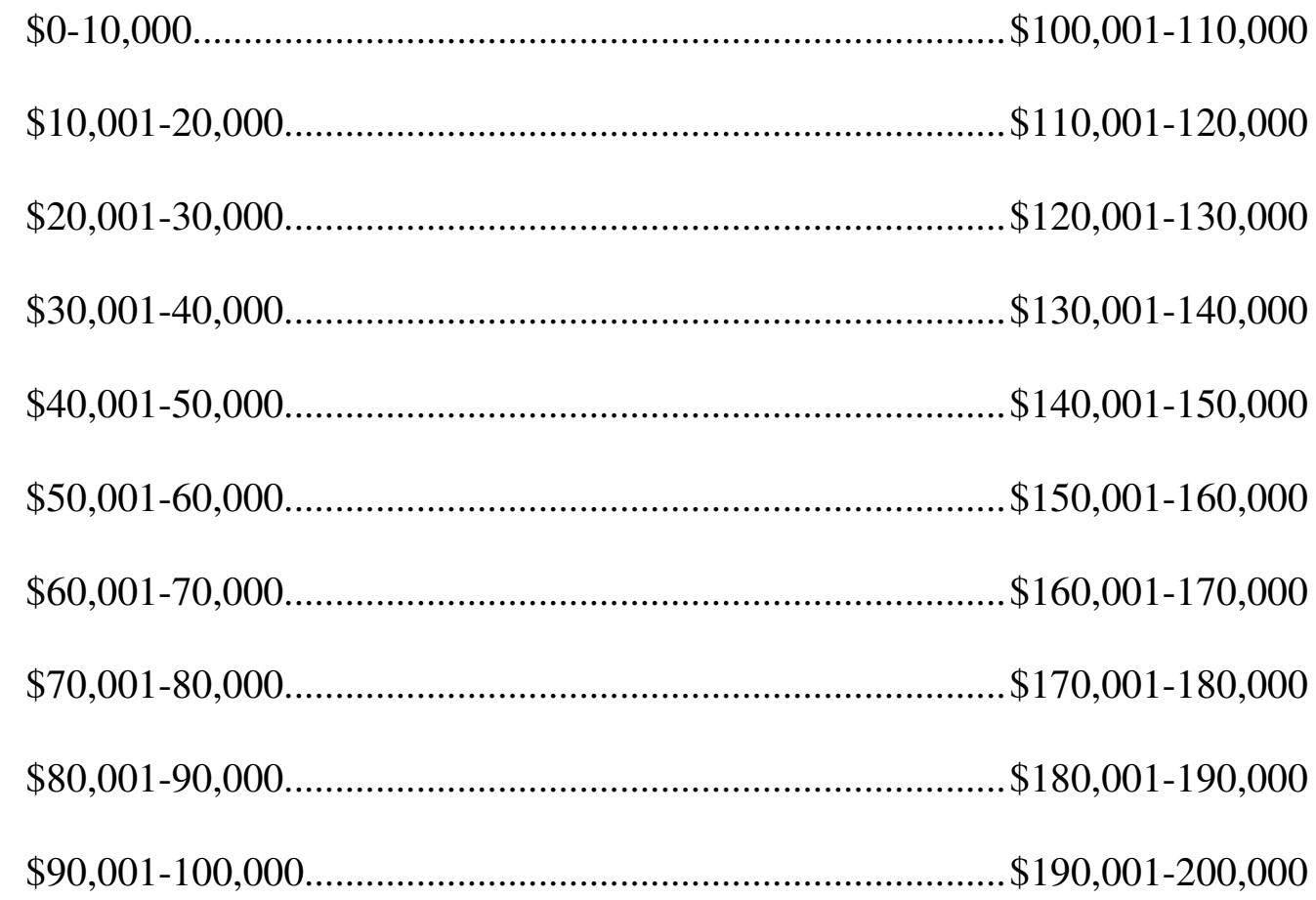

Questionnaire A

1.

2.

3.

4.

5.

6.

7.

8.

9.

10.

11.

12.

13.

14.

15.

16.

17.

18.

19.

20. 
Questionnaire B

1.

2.

3.

4.

5.

5.
6.

7.

8.

9.

10.

5.

6.

7.

8.
11.

12.

13.

14.

15.
16.

17.

18.

19.

20.

Questionnaire C

1.

2.

3.

4.

\section{STOP!}

Questionnaire D

1.

2.

3.

4.

5.

5.
6.

7.

8.

9.

10.
9.

10.

11.

12.

13.

\section{Circle your answer:}

On a scale of 0 to 10 , with 0 being "not at all important" and 10 being "extremely important," how important is it to you that you do well on the task?

$\begin{array}{lllllllllll}0 & 1 & 2 & 3 & 4 & 5 & 6 & 7 & 8 & 9 & 10\end{array}$

On a scale of 0 to 10 , with 0 being "no pain at all" and 10 being "the worst pain I ever experienced," how much do you expect the pain to hurt?

$\begin{array}{lllllllllll}0 & 1 & 2 & 3 & 4 & 5 & 6 & 7 & 8 & 9 & 10\end{array}$

On a scale of 0 to 10 , with 0 being "there is nothing I can do to make the task easier for me" and 10 being "I have complete control over how difficult the task is for me," how much control do you perceive that you have in completing the task?

$\begin{array}{lllllllllll}0 & 1 & 2 & 3 & 4 & 5 & 6 & 7 & 8 & 9 & 10\end{array}$

Post-experimental questionnaires—attached.

Thank you for your participation!!!

Sincerely,

Carla Berg

Principal Investigator 


\section{Appendix I: Informed Statement of Consent}

\section{Informed Statement of Consent}

The Department of Psychology at the University of Kansas supports the practice of protection for human subjects participating in research. The following information is provided for you to decide whether you wish to participate in the present study. You should be aware that even if you agree to participate, you are free to withdraw at any time without penalty.

We are studying the connection between hopeful thinking and pain tolerance and pain threshold. You will be asked to complete some surveys assessing different dispositional constructs and then perform the Cold Pressor Task, which is a task in which you submerse your hand in cold water. You then will be required to fill out additional surveys. It is estimated that your participation will take no more than 1 hour of your time.

The content of the questionnaires should cause minimal discomfort, no more than would be expected from answering simple questions about how perceive everyday situations. While the Cold Pressor Task may cause discomfort, it will in no way cause you harm. Although your participation may not directly benefit you, we believe that the information will be useful in evaluating how people solve problems.

Your participation is solicited although strictly voluntary. The information will be identified only by a code number and your name will not be associated in any way with the research findings. If you would like additional information concerning this study before or after it is completed, please feel free to contact me by phone, by mail, or by e-mail.

Sincerely,

Carla Berg

Principal Investigator

Department of Psychology

Fraser Hall

University of Kansas

Lawrence, KS 66045

(785) 218-3277
C. R. Snyder, Ph.D.

Faculty Supervisor

Department of Psychology

340 Fraser Hall

University of Kansas

Lawrence, KS 66045

(785) 864-9855

Signature of subject agreeing to participate

Date

With my signature I affirm that I am at least 18 years of age and have received a copy of the consent form to keep. 


\section{Appendix J: Experimental Medical History Questionnaire \\ Experimental Medical History Questionnaire}

1. Please place a check mark next to any of the following conditions that you have been told you have:
a. arthritis
b. ___ circulatory problems (e.g. Raynaud's disease)
c. ___ any trauma to the non-dominant hand (hand you don't write with)
d. __ peripheral neuropathy
e. thyroid problems
f. diabetes
g. __ systemic lupus erythematosis
h. __ scleroderma
i.

2. Please list with dates any serious medical disorder that you have had, or currently have which is not mentioned above. 


\section{Appendix K: Introduction Script}

I'd like to start by telling you what is involved in this experiment. First, you will be asked to complete a questionnaire packet. After that, you will be asked to participate in the cold pressor task. This is a task in which you will be asked to immerse your hand in a bin of cold water up to the wrist. This stimulus will cause pain over time. You will be asked to keep your hand in the bin for as long as you can. At the point at which you can no longer tolerate the pain, you can remove your hand from the bin.

The point of this task is to see how you respond to the pain. This experiment is intended to help us understand how people deal with pain, like pain from surgeries or chronic conditions. By participating in this experiment, you are helping to inform research that will impact those who must experience pain. We want to know how to best help them, so please participate in this experiment to the best of your ability. 


\section{Appendix L: Hope Intervention Instruction Set}

Part A: Hope Imagery

I'd like you to relax in your chair, recline or lean back if you like, and close your eyes if you want to. First, I ask that you to pay attention to the instructions that follow, as they are important. I invite you to think about a time when you wanted to achieve something important to you... a time when you felt really motivated... a time when you had a plan...multiple plans for getting to your goal. Sometimes people find it helpful to close their eyes in order to see the images more clearly. Have you thought of a time like this? A time when you felt hopeful that you could achieve something important to you... something that motivated you...something that you had strategies to achieve. (Long pause.) You might notice how driven you felt...how empowered...you might remember times when you wanted to give up...but didn't...you kept going because of your commitment...your desire...instead, you might have worked harder...you may have tried a different strategy for dealing with the hard times...you might have broken your goal down into steps... with each step you achieved making you feel more energized...more empowered...more confident...you may have noticed how you focused on the goal...adjusting the goal based on what was happening... so that you knew that your goal was challenging...difficult...but achievable...knowing that once you achieved your goal...you would feel confident...motivated...proud of yourself...knowing that you have everything that it takes...the motivation...the ability to plan and create strategies...the ability to set challenging goals... and achieve them...everything that it takes to be successful with future goals...much like the goal of performing well on the cold pressor task. Take a moment to absorb all of these thoughts and then open your eyes (if eyes are closed). (VERY SLOW AND DELIBERATE.)

\section{Part B: Interactive Dialogue}

What situation did you think of?

Why was this goal so important to you?

How did you maintain your motivation when things got difficult?

How did you decide how you were going to go about getting to your goal?

How did achieving this goal make you feel?

How did these experiences help you to prepare for the future?

What did you learn from this experience that will help you on the task?

\section{Part C: Skills Enhancement}

I'd like to share with you some things that we have found through extensive research that enhance one's ability to reach goals. There are three main components necessary to reach your goals. One is your ability to set goals. Here are some strategies for setting goals:

- First, set goals that will be difficult but achievable. Be sure to set goals that are in line with your expectations, not the expectations of others.

- Second, be specific about your goals; define them objectively. 
- And third, take time in setting your goals, and allow yourself to adjust your goals once you have experiences to guide you. In the case of the cold pressor task, some people find it helpful to set a time they'd like to reach and to allow themselves to readjust their goals once they've started the task.

The second component is your ability to think of multiple strategies and alternative ways to reach your goals. Here are some ways to improve this skill:

- First, think about the steps involved in reaching your goal.

- Second, think about the different strategies that you have for reaching the goal. In the case of the cold pressor task, some people find it helpful to set time points along the way to their goal, while others chose to distract themselves or use another strategy in order to overcome it.

- And third, in your mind, rehearse what you will need to do during the pursuit of your goal to be successful in reaching it. Also, anticipate the problems you might have in reaching your goal and the alternatives you can use to overcome the problems.

The third component is the motivation to reach your goals. Here are some ways to increase motivation:

- First, think about the process of reaching your goal as a journey. In the case of the cold pressor task, don't consider it to be something scary; it's a challenge. Anticipating roadblocks that you might face may be helpful in reminding you that, when you start to feel discouraged, it is a signal that you must increase your motivation and work harder.

- Second, as you work toward your goal, remind yourself of how far you have come and think positively about your progress on the goal. Think about similar challenging situations where you were able to overcome the situation.

- And last, using positive self-talk like "I can do it," "Keep going," and "I am doing really well" tend to be helpful.

Which of these do you think you are particularly good at?

Which of these do you think you could stand improvement on?

Part D: Worksheet

Now, I'd like you to take about 10 minutes to complete this worksheet. Please read the instructions, take your time, and consider each question very thoroughly.

Adopted from: Snyder, C. R., Tran, T., Schroeder, L. L., Pulvers, K. M., Adams, V., \& Laub, L. (2000). Teaching the hope recipe: Setting goals, finding pathways to those goals, and getting motivated. Reaching Today's Youth, 4(4), 46-50.

Adopted from: Snyder, C. R. (1994b). The psychology of hope: You can get there from here. New York: Free Press. 


\section{Appendix M: Worksheet for Performing the Cold Pressor Task}

\section{Worksheet for Performing the Cold Pressor Task}

\section{Goal-Setting:}

- Set goals that will be difficult but not impossible.

- Be specific about your goals; define them objectively.

- Take time in setting your goals, and allow yourself to adjust your goals once you have experiences to guide you.

\section{Strategies:}

- Think about the steps involved in reaching your goal.

- Think about the different strategies that you have for reaching the goal.

- Rehearse in your mind what you will need to do during the pursuit of your goal in order to do well. Anticipate the problems you might have in reaching the goal and the alternatives you can use to overcome the problems.

\section{Motivation:}

- Think about the process of reaching the goal as a challenging journey with obstacles to be overcome. Anticipate the obstacles, and remind yourself that feeling discouraged is a signal that you must increase your motivation and work harder.

- As you go through the task, remind yourself of how far you have come and think positively about your progress on the task. Think about similar challenging situations where you were able to overcome the situation.

- Using positive self-talk like "I can do it," "Keep going," and "I am doing really well" tend to be helpful.

\section{ACTIVITIES:}

Please complete the worksheet below. You do not need to fill in all of the spaces, but please consider each question thoroughly.

Think about a time when you set a difficult but not unreachable goal and were successful at achieving the goal. Please write about this experience. Discuss how you decided that the goal was reasonable for you, even though you realized it would be difficult to achieve. Include strategies that you used while you were working toward this goal to keep yourself motivated. 
People find it helpful to talk to themselves when attempting to achieve a goal. Saying such things as "You are doing a good job," "You can do this," and "You have already come so far" are examples of statements that are called "positive self-talk statements." List some positive self-talk statements that you could use during a task such as the cold pressor task:

1.

2.

3.

4.

5.

6.

People find it helpful to list some possible strategies for overcoming obstacles in order to reach their goals. Think about the multiple strategies you can use during the cold pressor task to be as successful as possible. Which ones do you think you'll try first? Rank them in order of how well you think they'll work.

1 .

2.

3.

4.

5.

6.

I'd like you to take a few minutes to mentally rehearse the strategies you have while imagining that you are already performing the cold pressor task.

How long do you think you could, without a doubt, keep your hand in the bin of cold water?

How long would it take for you to feel like it is impossible to go on?

What do you think is a reasonable goal for you?

Adopted from: Snyder, C. R., Tran, T., Schroeder, L. L., Pulvers, K. M., Adams, V., \& Laub, L. (2000). Teaching the hope recipe: Setting goals, finding pathways to those goals, and getting motivated. Reaching Today's Youth, 4(4), 46-50.

Adopted from: Snyder, C. R. (1994b). The psychology of hope: You can get there from here. New York: Free Press. 


\section{Appendix N: Control Condition Instructions}

While you wait to perform the cold pressor task, I'd like to ask you to read this passage. I will return in a few minutes to take you to the cold pressor task. In order to control for your activity during the next few minutes, it is important that you do read during this time. Thank you, and I'll be back in about 10 minutes to get you. 


\section{Appendix O: Written Confirmation re Pain \\ Written Confirmation re Pain}

With my signature I confirm that I am no longer experiencing pain or discomfort as a result of this study.

Participant's Signature

Experimenter's Signature

Date

Date 


\section{Appendix P: Written Debriefing}

\section{Written Debriefing}

The purpose of this study is to determine how a person's previous thoughts and feelings about goal-related matters relate to his or her subsequent tolerance of pain. The hypothesis is that those individuals who have just recalled a previous successful as compared to unsuccessful goal-pursuit event should tolerate the pain longer and be less interfered by it. The results of this study will help determine if such goal motivation orientations are useful in understanding and managing pain. This information may be helpful for health professionals who conduct painful medical procedures or treat persons with pain.

Thank you for your cooperation. Please feel free to ask any questions at this time or in the future regarding the content of this study.

Carla Berg

Principal Investigator

Department of Psychology

Fraser Hall

University of Kansas

Lawrence, KS 66045

(785) 218-3277
C. R. Snyder, Ph.D.

Faculty Supervisor

Department of Psychology

340 Fraser Hall

University of Kansas

Lawrence, KS 66045

(785) 864-9855 


\section{Appendix Q: Power Analysis}

Power Analysis: 2 (Gender) x 2 (Condition) fixed factorial design; Alpha $=.05$

\begin{tabular}{|c|c|c|c|c|c|}
\hline \multirow[b]{2}{*}{$N$} & \multicolumn{5}{|c|}{ Effect Size } \\
\hline & 0.40 & 0.50 & 0.60 & 0.70 & 0.80 \\
\hline 10.00 & 0.45 & 0.64 & 0.81 & 0.91 & 0.97 \\
\hline 11.00 & 0.49 & 0.69 & 0.85 & 0.94 & 0.98 \\
\hline 12.00 & 0.53 & 0.74 & 0.88 & 0.96 & 0.99 \\
\hline 13.00 & 0.57 & 0.77 & 0.91 & 0.97 & 0.99 \\
\hline 14.00 & 0.61 & 0.81 & 0.93 & 0.98 & \\
\hline 15.00 & 0.64 & 0.84 & 0.95 & 0.99 & \\
\hline 16.00 & 0.67 & 0.86 & 0.96 & 0.99 & \\
\hline 17.00 & 0.70 & 0.89 & 0.97 & 0.99 & \\
\hline 18.00 & 0.73 & 0.90 & 0.98 & & \\
\hline 19.00 & 0.76 & 0.92 & 0.99 & & \\
\hline 20.00 & 0.78 & 0.93 & 0.99 & & \\
\hline 21.00 & 0.80 & 0.95 & 0.99 & & \\
\hline 22.00 & 0.82 & 0.96 & 0.99 & & \\
\hline 23.00 & 0.84 & 0.96 & & & \\
\hline 24.00 & 0.86 & 0.97 & & & \\
\hline 25.00 & 0.87 & 0.98 & & & \\
\hline 26.00 & 0.89 & 0.98 & & & \\
\hline 27.00 & 0.90 & 0.98 & & & \\
\hline 28.00 & 0.91 & 0.99 & & & \\
\hline 29.00 & 0.92 & 0.99 & & & \\
\hline 30.00 & 0.93 & 0.99 & & & \\
\hline 31.00 & 0.94 & 0.99 & & & \\
\hline 32.00 & 0.94 & 0.99 & & & \\
\hline 33.00 & 0.95 & & & & \\
\hline 34.00 & 0.96 & & & & \\
\hline 35.00 & 0.96 & & & & \\
\hline 36.00 & 0.97 & & & & \\
\hline 37.00 & 0.97 & & & & \\
\hline 38.00 & 0.97 & & & & \\
\hline 39.00 & 0.98 & & & & \\
\hline 40.00 & 0.98 & & & & \\
\hline 42.00 & 0.99 & & & & \\
\hline 44.00 & 0.99 & & & & \\
\hline 46.00 & 0.99 & & & & \\
\hline 48.00 & 0.99 & & & & \\
\hline 50.00 & 0.99 & & & & \\
\hline
\end{tabular}

Conclusion: In order to find a large effect size (conventionally .40) with a sufficient power (conventionally .80), 21 participants in each group are needed. 


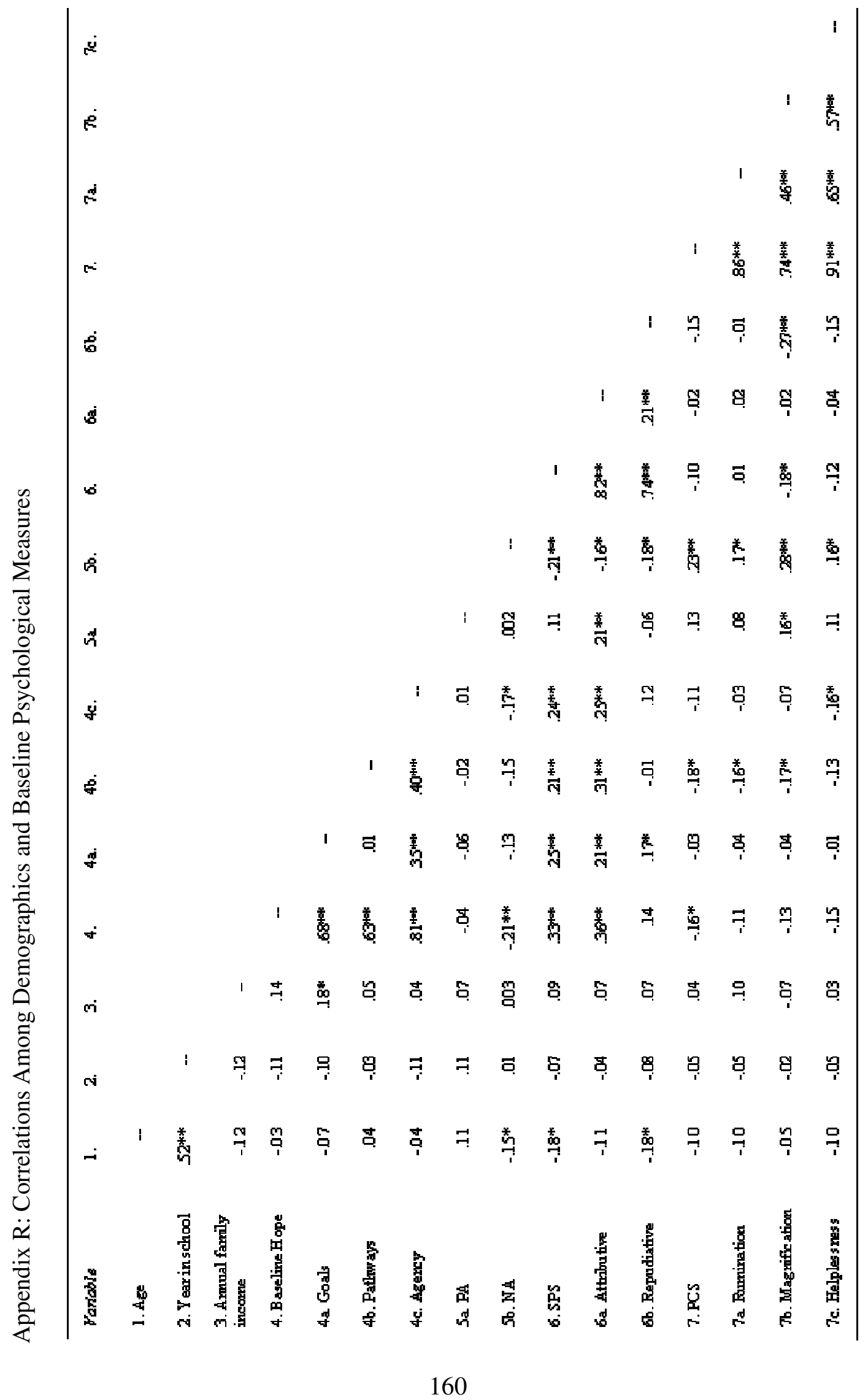




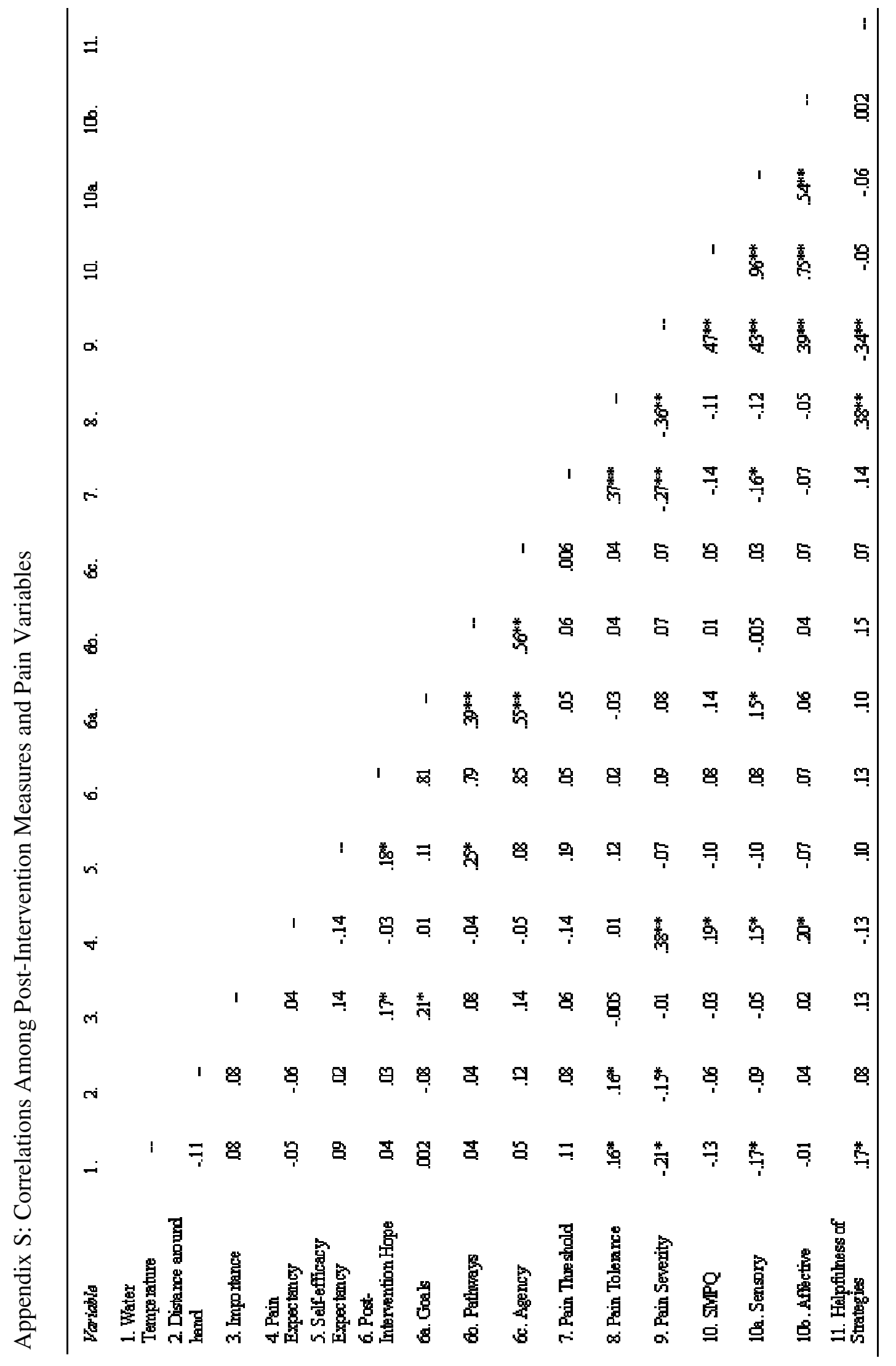




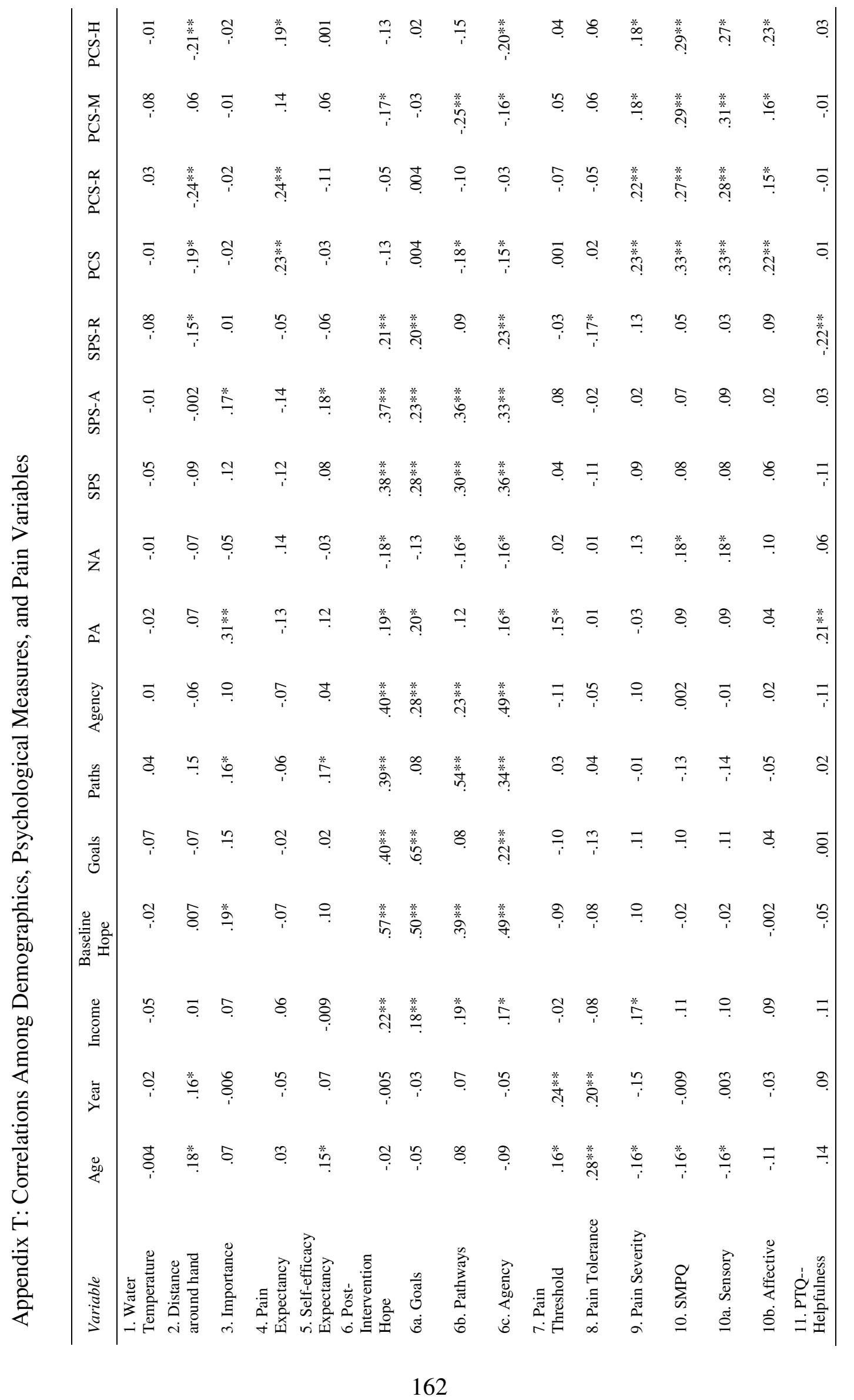

